\title{
Dietary habits and breast cancer : a case-control study in the Netherlands
}

Citation for published version (APA):

van 't Veer, P. (1990). Dietary habits and breast cancer : a case-control study in the Netherlands. [Doctoral Thesis, Maastricht University]. Rijksuniversiteit Limburg.

https://doi.org/10.26481/dis.19900518pv

Document status and date:

Published: 01/01/1990

DOI:

10.26481/dis.19900518pv

Document Version:

Publisher's PDF, also known as Version of record

\section{Please check the document version of this publication:}

- A submitted manuscript is the version of the article upon submission and before peer-review. There can be important differences between the submitted version and the official published version of record.

People interested in the research are advised to contact the author for the final version of the publication, or visit the DOI to the publisher's website.

- The final author version and the galley proof are versions of the publication after peer review.

- The final published version features the final layout of the paper including the volume, issue and page numbers.

Link to publication

\footnotetext{
General rights rights.

- You may freely distribute the URL identifying the publication in the public portal. please follow below link for the End User Agreement:

www.umlib.nl/taverne-license

Take down policy

If you believe that this document breaches copyright please contact us at:

repository@maastrichtuniversity.nl

providing details and we will investigate your claim.
}

Copyright and moral rights for the publications made accessible in the public portal are retained by the authors and/or other copyright owners and it is a condition of accessing publications that users recognise and abide by the legal requirements associated with these

- Users may download and print one copy of any publication from the public portal for the purpose of private study or research.

- You may not further distribute the material or use it for any profit-making activity or commercial gain

If the publication is distributed under the terms of Article $25 \mathrm{fa}$ of the Dutch Copyright Act, indicated by the "Taverne" license above, 


\section{Dietary Habits and Breast Cancer}

A Case-Control Study in the Netherlands 
Cover illustation: The delicate balance of nutrition, genes and environment is typified by the budding magnolia. 


\title{
Dietary Habits and Breast Cancer
}

\author{
A Case-Control Study in the Netherlands
}

\section{PROEFSCHRIFT}

ter verkrijging van de graad van doctor aan de

Rijksuniversiteit Limburg te Maastrichi, op gezag van de Rector Magnificus, Prof. Dr. F.I.M. Bonke,

volgens het besluit van het College van Dekanen, in het openbaar te verdedigen op vrijdag 18 mei 1990 om 14.00 uur

door

PIETER VAN' 'T VEER

geboren te Dokkum 
Promotores:

Co-promotor:

Beoordelingscommissie:
Prof. Dr. Ir. R.J.J. Hermus

Prof. Dr. F. Sturmans

Dr. Ir. F. J. Kok

Prof. Dr. F. Th. Bosman (voorzitter)

Prof. Dr. J.A. Knottnerus

Prof. Dr. R. Kroes

Prof. Dr. P. B. Soeters

Prof. Dr. F. de Waard

The study described in this thesis was financially supported by the Netherlands Cancer Foundation (grant no CIVO 84-4) and conducted at the TNO-CIVO Toxicology and Nutrition Institute, P.O. Box 360, 3700 AJ Zeist, the Netherlands. 
Aan mijn kinderen 

1. Introduction $\quad 13$

1.1. Scope 13

1.2. Ratiomale 14

1.3. Study objectives and outline of the thesis 15

2. Diet and the aetiology of breast cancer 19

2.1. Carcinogenesis 19

2.2. Risk factors of breast cancer 20

2.3. Dietary factors and breast cancer 21

2.3.1. Biological mechanisms 21

2.3.2. Epidemiological evidence 25

3. Design, conduct and analysis of the case-control study 43

3.1. Design 43

3.1.1. Subjects 43

3.1.2. Methods 46

3.2. Conduct 49

$3 \cdot 2 \cdot 1$. Cases 49

3.2 .2 . Controls 52

3.2.3. Response 52

3.2 .4 . Implications 53

3.3. Analysis 57

3.3.1. Strategy 58

3.3.2. Confounding 59

3.3.3. Effect modification 61

4. Dietary fat and the risk of breast cancer

International Journal of Epidemiology 1990 (in press) 69

5. Selenium in diet, blood and toenalls in relation to breast cancer: A case-control study

American Journal of Epidemiology $1990 ; 131$, no.6 (in press) B3

6. Consumption of fermented milk products and breast cancer: A case-contral study in the Netherlands

Cancer Research 1989;49:4020-4023 
7. Dietary fiber, beta-carotene and breast cancer: Results from a case-control study

International Journal of Cancer 1990 (in press)

8. Alcohol dose, frequency and age at first exposure in relation to the risk of breast cancer

International Journal of Epidemiology $1989 ; 18: 511-517$

9. Combination of dietary factors in relation to breast cancer (submitted)

10. General discussion

10.1. Methodological considerations

10.1.1. Selection bias and information bias 144

10.1 .2 . Bias towards the 'nu11" 146

10.2. Directions for research

148

10.2.1. Methodological improvements

148

10.2.2. Scope of case-control and cohort studies

10.3. Dietary recommendations 


\section{PREFACE}

The conduct of this case-control study and the witing of this thesis were challenging opportunities, handled in collaboration with many persons and a large number of institutions. I am indebted to many persons and institutions, who enabled me to complete the work described in this thesis.

Professor fudolph J.J. Hermus, you have enabled me to practice nutritional epidemiology during my studies; you have initiated epidemiological studies on the relation between diet and cancer at the TNO-CIVO Toxicology and Nutrition Institute, stresing the importance of both human and animal experiments in this field.

Professor Ferd sturmans, you have teached me the basics of epidemiology and have made me appreciate them, you have coached my education at the Harvard school of Public Health, and stimulated me to apply epldemiological methods to the study of associations between diet and cancer.

Dr Frans J. Kok, you have been a genuine tutor. Your experience in epidemiological research and the writing of scientific papers has greatly accelerated the successful completion of this study. Moreover, your stimulating criticism on the chapters in this thesis helped me to structure my knowledge, and to transfer the study results to the scientific community.

The Netherlands Cancer Foundation has funded this project, but also offered to me the opportunity to obtain my M.Sc. degree in Epidemiology at the Harvard School of Public Health, Boston, USA.

The many study subjects who have volunteered in the study have provided me with information on their diet and life style, and with biological matexials.

Surgeons and other medical specialists in the study areas have collected preoperative blood, recruited the subjects and given practical advice during the development of study procedures. Further useful advice was obtained from comprehensive cancer centres and representatives of women with breast cancer (Landelijk contactorgaan Begeleidingsgroepen Borstkankerpatiënten).

Municipal population registries in the study areas who are acknowledged for sampling the control subjects.

The TNO-CIVO Toxicology and Nutrition Institute have provided the know-how and technical equipment for the analysis of biological materials and the infrastructure required for this study. My colleagues in the Department of Human Nutrition have proved a pleasant team to cooperate with during all stages of the project. Dr Theo ockhuizen has supported the study at times project 
management mas at stake. Hanny Leezer-de Hoog has carefully prepared the manucripts for subnission. Dixk van der Heij has contributed useful editorial support.

Students at the Department of Human Nutrition and the Department of Environmental and Tropical Health, Agricultural University Wageningen, have contributed to the success of this study. Both Evert G. Schouten MD of the latter Department, and Dr Frans J. Kok have guided many of these students.

The Netherlands Energy Research Foundation $\mathbb{E C N}$ (Petten) have analysed selenium in various biomarkers. Dr Joost $R$.W. Woittiez gave useful advice on Instrumental Neutron Activation Analysis.

The TNo-crvo Institutes and the Dairy Foundation on Nutrition and Health" have sponsored the publication of this thesis.

My Eather and mother, you have made me learn that the scientific method is an instrument that must be tuned to the right key-notes. you have made me perceive nature as creation, worth of being studied. You have given me the opportunity to do so.

Matthea, you have supported me from the very start at wageningen, and shared my Bostonian experience. In spite of the consequences for your share in housekeeping and the education of our children, you have given me the opportunity to continue with my thesis and encouraged me to do so. Rene, Mirjam and Woutjan, you must have missed ry active involvement in family life, especially in the past year. Your youth, full of expectations, keeps me realize that life is challenging and wonderful. 


\section{ACKNOWLEDGEMENT}

Surgeons and medical specialists, laboratory and administrative staff at the hospitals in the study areas have contributed in a valuable way to the completion of this study. Since it would be impractible to mention them all, I will name in this formal acknowledgement just one person for each participating hospital. I am much indebted to the following surgeons, specialists and their coworkers:

H.P.J.M. Beerepoot (Diakonessenhuis, Arnhem), E.D.M. Bruggink (Canlsius Wilhelmina Ziekenhuis, Nijmegen), W.F. Eggink (Gemeente ziekenhuis, Arnhem), W. Eijlers (Hofpoort ziekenhuis, woerden), W.J.C. Geurts (Ziekenhuis Oudemrijn, utrecht), A. Hennipman (Academisch ziekennuis Utrecht, Utrecht), P.J.M. Keuning (Maasziekenhuis, Boxmeer), J.W. Koolman (Ziekenhuis Rivierenland, Tiel), K.A. Koop (Ziekenhuis Maarschalksbos, Baarn), P. Luning (St Anna Ziekenhuis, Oss), A.H.M. van der Maas (St Elisabeth Gasthujs, Armem), I. van Meerwijk (St Elisabeth ziekenhuis, Amersfoort). M.E" von Meyenfeldt (Academisch Ziekenhuis Maastricht, Maastricht), F.L. van Nlerop (Boerhaave Ziekenhuis, Harderwijk), M.M. Plomp-van Harmelen (ziekenhuis overvecht, utrecht), $c$. Rothengatter (Het ziekenhuis, Velp), R. Sybrandy (St Antonius Ziekenhuis, Nieuwegein), W. Veltheer (De Lichtenberg, Amersfoort), W.J. van der Ven (Zeister ziekenhuis, Zeist), S.H.M. Vrind (ziekenhuis Berg en Bosch, Bilthoven), Th. Wobbes (St Radboud Ziekenhuis, Nijmegen).

In addition, the following persons have kindly contributed to the organization and conduct of case recruitment in the study areas: J.M. Broekman (Academic Hospital, Mastricht), L.J. Schouten, (Department of Epidemiology, university of Limburg), A.L.M. Verbeek (Department of social Medicine, Catholic university, vijmegen), C. de Rover (TNO-CIVo Toxicology and wutrition Institute, zeist), H.J.A. Collette (Het preventicon, a breast cancex screening programme, Utrecht), J.M. Werre and M.J.A. Speijers-van Doremalen (Foundation of Collaborating Hospitals in the Arnhem Area). 



\section{INTRODUCTION}

\subsection{Scope}

The potential role of the diet in carcinogenesis is widely recognized. An association between diet and cancer seems biologically plausible, and might provide clues for cancer prevention. Despite this favourable starting-point for research, the identification of the major dietary factors determining cancer risk and the elucidation of the biological mechanisms is highly complicated. Diet is a time-related complex mix of exposures, simultaneously exerting protective and harmful effects on the biological organism. The development of cancer is closely intertwined with normal physiological processes, and the factors discriminating normal and malignant growth are only partially understood.

The objective of nutritional cancer research is to obtain additional knowledge on the presumed diet-cancer association by refinement or generalization of previous views, and corroboration or refutation of hypotheses. Although there is a vast amount of circumstantial evidence supporting the diet-cancer association, much essential information is still lacking both from laboratory and epidemiological research. Laboratory research may identify the necessary molecular and cellular causes of cancer initiation, with a high degree of generalizibility at this level of observation. Human and animal experimental research incorporates the functional complexities of the organism in vivo, albeit under narrowly defined, and sometimes artifucial conditions. Epidemiological research contributes to the identification of risk factors anong human individuals, within a wide range of highly complex conditions of normal daily life. This may help to quantify the relative importance of various presumed causes of cancer, to identify clues for further epidemiologic and laboratory research, and to evaluate the potential public health benefits of varjous strategies for cancer prevention.

In this thesis, the diet-cancer relationship is approached by the epidemiologic method of the case-control study, implying retrospective observation and subsequent comparison of human characteristics as the basic method to gain additional knowledge. Therefore, as compared to the scientific "golden standard", $\mathbb{1} . e .$, the experimental approach, the potential influence of systematic and random errors requires special attention. In the case-control design, systematic exrors may derive from selection of the study population, the gathering of the relevant information on exposure and disease, and confounding by extraneous factors. Random errors 
may resut from sampling variability and problems in standardization of the measurement of exposures and confounders, especially when the heterogeneity of exposure in the study population is limited. Compared to experimental cancer research (e.g. animal experiments, in vitro research, molecular blology), the epidemialogic approach lacks the potential for a direct biological explanation. on the other hand, however, epidemiology has the advantage of directly comparing rlsks experienced by human populations and, therefore, encounters less problems with regard to the direct relevance of study results.

Consistency of results from both research lines would provide the strongest basis for causal inference and preventive action. The scope of the research described in this thesis is to contribute data to the epidemiological evidence on the relation between diet and female breast cancer, and to discuss these in the light of the epidemiological literature.

\section{2 Rationale}

In the Netherlands, as in many other industrialized countries, about $25 \%$ of total mortality is caused by cancer. Breast cancer is the most common type of femalle cancer in most West European countries, North America and Australia. Breast cancer incidence rates in these countries may be four times the rates in countries like Japan, India, or China (1). Data on breast cancer incidence and mortality $(2,3)$ from the Netherlands and other countries suggest that it has increased in the past five decades. In the last decade about 6000 new cases have been diagnosed annualdy, and about 3000 women die of breast cancer in the Netherlands (4).

The international variation in breast cancer rates suggests that environmental and/or genetic factors may affect the disease. Bcological correlation studies (5), cancer risk in special populations (6), time trends in cancer occurrence (7), and studies in migrant populations (8-10) have suggested that environmental factors such as diet rather than genetics may play an important role in carcinogenesis. It has been suggested that one thixd to one half of cancer is avoidable by modification of dietary factors $(11,12)$. For cancer of the breast and colon, the most important malignancies among non-smokers in Western sacieties, Doll and Peto 'guestimated' that up to 50 and 90 per cent respectively might be avoidable (12). Although these figures should be interpreted with caution $(12,13)$, these types of cancer have gained most attention in research on diet and cancer (14). The modifications in dietary habits that would be required to abtain the maximum reduction in cancer rates may not be 
realistic for most countries, however, and it may take decades before they exert full effect (15). Therefore, papers refering to public health goals on a more limited term, tend to give less optimistic percentages $(16,17)$.

Ecological studies and animal experiments have suggested that the high breast cancer mortality in the Netherlands might be associated with a high per capita fat intake and a low selenium intake. Therefore, it was considered of interest to find out whether these associations could also be demonstrated at the individual level.

The potential role of fat and energy intake in carcinogenesis has already been recognized in animal experiments conducted in the 1940s. These studies have pointed out that ad libitum feeding (as compared to energy or food restriction and a high-fat diet might adversely affect cancer risk. In the early 1980s, several casecontrol studies have been conducted which indirectly tested the fat hypothesis by assessing the of consumption-frequency of foods with a high fat content, such as fried foods, meat and milk products. whe dietary methodology employed in these studies was generally not suited to measure fat intake adequately, and new studies need more advanced dietary assessment techniques to evaluate the fat-breast cancer bypothesis.

In the early 1980s, results from a number of animal experiments suggested that dietary selenium compounds might protect against cancer at several sites, including the mammary gland $(18,19)$. "These animal data were supported by ecological studies and preliminary epidemiological findings $(20,21$, chapter 3$)$. Furthermore, selenium intake among Dutch women (22) is considered to be on the lower end of the 'safe and adequate' intake range of 50-200 pg per day (23). Thus, the selenium status of Dutch wonten may be bordexline and this may enhance their risk of marmary cancer.

\subsection{Study objectives and outline of the thesis}

The primary ain of the study was to determine the relation of (type and amount of) fat consumed, dietary selenium, selenium status, and breast cancer in Dutch women. In addition to these main topics, the role of other dietary factors has been evaluated by assessment of the reproducibility of results from other studies. One of the additional hypotheses concerned the inverse association between fermented milk products and breast cancer, which has emerged from a case-control study in France. Furthermore, the possible protection 


\section{Introduction}

by (consituents of) vegetable products and the potential harmful cole of alcohol was studied.

In order to study the association between these dietary factors and breast cancer, the following leading questions were formulated:

- Is dietary fat intake in breast cancer cases higher than in controls, independent of total energy intake?

- Are dietary intake and biomarkers of selenium status lower in breast cancer cases than in controls?

- Is the consumption of fermented milk products lower in breast cancer cases than in controls?

- Is a diet rich in vegetable products inversely related to breast cancer? If so, to which food component can this association be attributed?

- Is the positive association between alcohol consumption and breast cancer also observed in the Netherlands? Is arinking alcohol at young age associated with breast cancer?

- To what extent is a combination of supposediy favourable and unfavourable dietary habits associated with breast cancer?

The scientific background of the above questions is summarized in Chapter 2. Because of the retrospective study design and limited accuracy of dietary recald from a distant past, the reference period for most food habits was limited to the relatively short period of one year before breast cancer diagnosis. In addition, the number of women that eventually entered the case-control study did not permit us to explore effect modification of the diet-breast cancer asocition by separate strata of menopausal status, as was initially intended. These and other aspects of study design, conduct and analysis are described in chapter 3. Results of the study with regard to dietary fat and selenium are presented in chapter 4 and 5 . The results concerning fermented milk products, vegetable products and acohol consumption are given in chapters 6 to 8 . After the separate evaluation of each of these dietary components, the question emerges whether a simple model can be formulated which summarizes the main findings of the study and relates the heterogeneity in dietary habits to breast cancer, assuming that the observed associations can be considered real. This is addressed in Chapter 9. 
Finally, in Chapter 10, the methodological issues pertaining to this study are discussed, suggestions for furthex research are provided and the study results are viewed in the light of current aletary guidelines.

\section{References}

1 Muir C, Waterhouse J, Mack "I" Powell J, Whelan s. Cancer Incidence in five continents. Vol $\mathrm{V}$. International Agency for Research on Cancer, Lyon, 1987.

2 Putten DJ, Habbema JDF, Dortmarssen GJ, van dex Maas PJ. Preliminaries for evaluation of breast cancer screening. Part I. An analysis of mortality from breast cancer in the Netherlands. Technical report. Erasmus Univ Rotterdam, 1981.

3 Centraal Bureau voor de statistiek. sterfte naar belangrijke doodsoorzaken 1950-1977. Staatuitgeverij, Den Haag, 1980.

4 Ministerie van Welzijn, Volksgezondheid en Cultuur. Jaarverslag 1988. Geneeskundige hoofdinspecteur van de volksgezondheid. Rijswijk, 1989 .

5 Knox EG. Foods and diseases. Br J Prev Soc Med 1977;31:77-80.

6 Lyon JL, Gardner JW, West DW. Cancer risk and life-style: Cancer among Mormons from 1967-1975. In: Cains J, Lyon LJ, Skolnick M (eds). Cancer incidence in defined populations. Banbury report no. 4. Cold Spring Harbor Laboratory, 1980, 3-30.

7 Boyle P, Leake R. Progress in understanding breast cancer: epidemiological and biological interactions. Breast Cancer Res Treatm 1988;11:91-112.

8 Haenszel W, Kurihara M. Studies of Japanese migrants. 1. Mortality from cancer and other diseases among Japanese in the United States. J Nat1 Cancer Inst 1968;40:43-68.

9 Buell P. Changing incidence of breast cancer in Japanese-American women. J Nat 1 Cancer Inst $1973 ; 51: 1479-83$.

10 Adelstein AM, Staszewski J, Muir CS. Cancer mortality in 19701972 among Polish-born migrants to England and Wales. Br J Cancer $1979 ; 40: 464-75$.

11 Wynder EL, Gori GB. Contribution of the environment to cancex incidence: An epidemiologic exercise. I Natl Cancex Inst $1977 ; 58: 825-32$.

12 Doll $R$, peto $R$. The causes of cancer, quantitative estimates of avoidable risks of cancer in the United states today. Oxford univ Press, oxford, 1981.

13 Peto $R$. The preventability of cancer. In: vessey MP, Gray $M$ (eds). Cancer risks and prevention. Oxford Univ press, Oxford, $1985,1-14$. 
14 Widett WC. The search for the causes of breast and colon cancer. Nature $1989 ; 338: 389-94$.

15 Stuurgroep Toekomsticenario's Gezondheidszorg. Kankex in Nederland. Scenario's over kanker 1985-2000. Bohn, Scheltema en Holkema, utrecht, 1987.

16. Greenwald P, Cullen JW, McKenna JW. Cancer prevention and control: From research to applications. J Natl Cancer Inst $1987 ; 79: 389-400$.

17 Lerman $C$, Rimex $B$, Engstrom PF. Reducing avoidable cancer mortality through prevention and early detection regimens. Cancer Re: $1989 ; 49: 4955-62$.

18. Ip C. Seleniun and experimental cancer. Ann Clin Res 1986;18: 22-9.

19 Vernie LN. Selenium in carcinogenesis. Biochim Biophys Acta 1984; $203-17$.

20 Shamberger RJ, Tytko $\$ A$, Wilis CE. Antioxidants and cancer. Part IV. Selenium and age-adjusted human cancer mortality. Arch Environ Health $1976 ; 31: 132-5$.

21 Schrauzer GN, White $D A$, schneider CJ. Cancer mortality correlation studies-III: Statistical associations with dietary selenium intakes. Bioinorg Chem $1977 ; 7: 23-34$.

22 Van 't Veer, Van Faassen A, Hermus RJJ, Ockhuizen $T$. De betekenis van selenium in de voeding. Ned Tijdschr Geneesk 1987;131:1036-9.

23 Committee on dietary allowances. Food and Nutrition Board. Recommended dietary allowances. 9th ed. National Acad of Sci, washington, 1980 . 


\section{DIET AND THE AETIOLOGY OF BREAST CANCER}

\section{1 Carcinogenes is}

Malignancy can be characterized by the capacity of cells to grow infinitely, to invade surrounding tissue and to metastasize to other tissues, and to express a large genetio heterogeneity (1). Depending on the tissue of origin of the tumour, these properties can be more or less clearly recognized. In the past decade, the discovery of oncogenes, controling cellular differentiation and proliferation, has provided a concept of carcinogenesis that may serve to largely integrate results from epidemiological, biological, chemical and radiological studies in this area $(2,3)$. In order to provide a framework to summarize the epidemiology of breast cancer, and to determine the potential role of diet, two fundamental issues in carcinogenesis need to be discussed first, i.e., the biological concept of stem cells, and the shape of the age-incidence curve observed for breast cancer.

First, the biological process of tissue turnover by a constant renewal of "old" tissue is essential to normal life as well as to carcinogenesis (4). The stem cells, which are the cellular source of tissue renewal, start to divide by the presence (or absence) of some endogenous factor, followed by the differentiation of daughter cells into a population of functionally adequate cells, integrated in the surrounding tussue $(5,6)$. The genetic code of the stem cells is held responsible for the proper differentiation and expression of the required cellular functions of the tissue. Alterations in key regulatory sites of the genetic code may lead to improper expression, resulting in cells escaping normal control of growth, which is characteristic of malignancy. For breast tissue, the state of differentiation reached by the stem cell descendants depends on sexual and hormonal factors and varies throughout Iffe $(7,8)$. These bilological concepts imply that the occurrence of breast cancer may be the result of decades of exposure of the stem cells, and that the role of diet in breast cancer aetiology may vary during different periods of life.

second, the relation between cancer incidence and age has been interpreted as evidence for the multistep nature of carcinogenesis, implying a total of about five distinct and independent ratelimiting steps in order to alter a normal (stem) cell into a completely transformed cell expressing its malignant properties (9-11). This general model has been modified to account for duration of exposure (e.g., smoking from an age of 20-40), rather than age, leading to the concept of early-and late-stage carcinogens (12). 
Diet and the aetiology of breast cancer

These theoretical models of carcinogenesis have been adapted to xplatn the characteristic cross-sectional age-incidence curve of breast cancer, which shows a steep increase up to an age of 50 and flattens after menopause (13). This characteristic curve has been observed in populations widely differing in breast cancer risk, once cohort effects on incidence are taken into account $(14,15)$. This typical curve has been interpreted in terms of a two-stage model (16), breast tissue 'age" (as related to hormonal and reproductive factors) (17), and of a two-disease model accounting for growth characteristics and hoxmonal exposure of breast tissue (18). There are many indications suggesting that factors operating during early life $(19,20)$ and hormonal factors may influence breast cancer $r i s k$ (21). Diet may affect breast cancer risk at young age, but also in the promotional stage, possibly mediated by hormonal interactions. Within the context of our case-control study, however, the dietary factors that are most $l i k e l y$ to be identified relate to breast cancex promotion, and the relevance of these factors at young age may be different.

\subsection{Risk factors af breast cancer}

As indicated in the previous section, genetic factors, tissue proliferation and differentiation, and hormonal factors play an important role in breast cancer aetiology. The increased breast cancer risk among women with a family history of breast cancer points at a role of hereditary factors (22-24). In case of familial cancer part of the genetic alterations required for complete cell transformation may be inherited, whereas the remaining steps are acquired during life $(2,25,26)$. Both inherited and acquired factors may be tumour-suppressing or cell-transforming genes, or may affect the differentiation and expression of growth-regulating cellular mechanisms (27).

Sexual and reproductive factors are well recognized as risk factors for breast cancer (13). Both are related to the development of breast tissue during pubexty and further differentiation during pregnancy, closely intertwined with hormonal factors. Early first full-term pregnancy protects against breast cancer, whereas risk increases as the first child is born at higher age. The number of children appears to have little additional protective effect, if any (13). Hormonal factors are involved as wel1, since a late age at menarche, and an early menopause (e.g., ovariectomy) reduce breast cancer risk (13). Furthermore, overweight may increase risk, especially after cessation of ovarian function in postmenopausal women, in whom adipose tissue is the main source of oestrogens (28). 
Finally, the presence or absence of oestrogen receptors in breast tumors is related to tumour doubling time (29), prognosis (30) and therapy (31).

Finally, other factors have been related to breast cancer, such as socio-economic status, level of education, and race (32)* The role of these factors will not be discussed here. In general, these factors are not believed to have a direct biological significance, but are considered to be indicators of life-style, including nutritional factors and use of health care facilities.

\subsection{Dietary factors and breast cancer}

\subsubsection{Biological mechanisms}

\section{General}

In the multistage model of carcinogenesis, any factor that affects the rate of transition of stem cells of the breast tissue from one stage to the next stage or that stimulates the proliferation of cells in an intermediate stage can be considered an aetiological factor. Foods and nutrients may affect the transition-probablility and growth-advantage of breast tissue in several ways, for example by providing (pre)carcinogens, by affecting metabolic activation (e.g. In the intestines or the liver), by affecting absorption and distribution of (pre)carcinogens and essential nutrients, by direct action on the target cells, or by indirect action mediated by hormonal factors (33). The biological mechanisms for the dietary factors under study are discussed in more detail below.

\section{Dietary fat}

With regard to fat intake and breast cancer, several mechandsms have been proposed. Because of the essential role of hormones in breat tissue development and function, hormone-mediated mechaniams are considered important. Other mechanisms, mediated by the type of fat or by factors specifically related to breast tissue, may offer ways of cancer prevention of more practical relevance. These mechanims are summarized below.

First, aigh intake of dietary fat, or a high energy intake (34, 35), may influence the risk factors of breast cancer, for example by an earlier menarche, a delayed menopause, and/or overweight, especially after menopause $(36-40)$. With respect to the biological mechanism, energy rather than dietary fat may be the relevant factor. Caloric restriction, associated with lowered body fat content, dramatically reduces carcinogenesis in various animal tumor 
models (41-45). Similar results have been reported for voluntary, but rot for forced exercise (46). The effect of caloric restriction may be mediated by hormonal (47) or hypothalamic factors (48). The lowexing of mamary cancer in rodents has been related to reduced organ cellularity and proliferation, but the precise role of these factors during different periods of life remains to be determined $(49,50)$

Second, dietary fat also erhances tumor development in ad libitum fed animas (51) and this may be of moxe direct relevance to human carcinogenesis in affluent societies. Dietary fat may affect hormonal exposure to breast tissue possibly mediated by the metabolism of the intestinal flora $(52-54)$, levels of circulating oestrogens and other hormones, or the development of hormone receptors (55). "These mechanisms may also be relevant to other hormone-dependent malignancies (56). The experimental evidence for the effect of fat on mamary carcinogenesis is not fully consistent, however, and several animal experiments have suggested that it is not meduated by hormonal factors $(57,58)$.

Third, the type of dietary fat may affect cancex risk by mechanisms unrelated to hormones, e.g. by altering the fatty acid composition of the cell membrane (35). These alterations are related to both the physico-chemical properties of fatty acids, such as membrane fluidity, and specific biological effects of fatty acids related to cell-to-celd comunication, immune responsiveness, and prostaglandin synthesis $(35,59-62)$. These factors, however, are not necessarily specific to cancer of the breast.

Finally, exogenous substances present in breast fat cells or ductal epithelium, may induce oxidation of fatty acids and cholesterol. High amounts of cholesterol, cholesterol oxidation products and lipid peroxides have been detected in breast fluid (63) cholesterolepoxides are known to have cytotoxic and mutagenic properties $(64,65)$. Furthermore, the concentration of cholesterol in breast fluid has been related to risk factors for breast cancer (66), and elevated levels of cholesterol oxidation products have been observed in women with benign breast diseases (67) considered to be precursor lesions for breast cancer $(68,69)$.

\section{Selenium}

The image of the trace element selenium has changed from a toxic and carcinogenic substance into an essential trace element with antioxidant and anticarcinogenic properties $(70)$. The range between deficiency and toxicity in animals is between $0.1-3.0 \mathrm{~kg} / \mathrm{g}$ (dry weight), which corresponds to an average daily intake of $50-1500 \mu \mathrm{g}$ 
Diet and the aetiology of breast cancer

for man $(71,72)$. In the USA and the Netherlamds these data have resulted in a 'safe and adequate' ramge of intake for adults of 50 $200 \mu \mathrm{g} / \mathrm{day}(72)$ and $50-150 \mu \mathrm{g} / \mathrm{day}$, respectively (73).

The mechanism by which selenium is related to carcinogenesis is still unknown. Selenium is an essential trace element, which can be incorporated in the selenium-dependent enzyme glutathione peroxidase (GSH-PX), which removes hydrogen and fatty acid peroxides from the cytosolic cell fraction. Selenium is also involved in the metabolism of DNA-peroxides, steroids, prostaglandins and antibodies $(70,74)$, and the search for essential roles of selenium is still uncompleted $(75,76)$.

Because antioxidants have been implicated in carcinogenesis, it seems attractive to attribute the favourable effects of selenium to its essential role in GSH-PX. Experimental evidence, however, is not in line with this hypothesis. First, animal experiments have indicated that the anti-tumour potential of selenium is observed most clearly when the supply of selenium (as selenite) is maintained at a high level $(77), 1 . e .$, above intake levels that influence GsH$\mathrm{Px}$ activity. Second, under marginal intake of selenium las selenite), the priority pathways of selenium distribution are those to the brain, the reproductive organs and the endocrine organs, and within these tissues to selenoproteins other than GSH-Px (78).

The elucidation of the mechanism of protection by selenium is further complicated by differences in metabolism among the various chemical forms of selenium (e.g., selenite, selenomethionine), their distribution over different metabolic pools and their association with protein metabolism. These chemical and biological characteristics of different selenium compounds may all contribute to a dilution of the alleged inverse association between an unknown but specific anticarcinogendic cellular function of selentum and the selenium intake of the organism (77).

\section{Fibre and micro-organisms}

Partially parallel with colonic carcinogenesis, the metabolic activity of the intestinal microflora, which is determined by dietary and host factors, has been related to breast cancex. In addition to intestinal secretion and cell turn-over, dietary factors provide the energy source of indigenous and ingested bacteria that managed to survive the passage through the upper gastro-intestinal tract. Both fibre, fat, and ingested micro-organisms (e.g., from fermented milk products may influence the metabolism of steroids excreted with the bile, the intestinal production of biologically active substances, and immologjcal. factors. 
Like other stexolds, oestrogens are excreted in the bile as glucuronide or sulphate conjugates. These may either be deconjugated by the bacterial enzymes $\beta$-glucuronidase and sulphatase, leaving free oestrogens available for reabsorbtion, or may remain conjugated and be excreted in the faeces. Modification of the microflora by antibiotics, a vegetarian diet or ingested viable micro-organisms may decrease the deconjugating activity of the flora, thus resulting in a decrease in urfiary $(79)$ and an increase in faecal oestrogen excretion, possibly associated with lower plasma levels $(80,81)$.

Furthermore, alteration of the bacterial flora may influence the intestinal production of oestrogens $(82,83)$, the formation of antioestrogenic lignans from fibre-rich products (84) and the metabolism of xenobiotics excreted in the bile or ingested with the diet.

In addition to alterations in the metabolic activity of the intestinal flora, (ingested bacteria may affect the host by stimulating the immue response, as has been shown for lactobacilli uged in cultured milk products $(85-87)$.

Most commonly, the low fat and the high fibre content of a vegetarian diet is held responsible for the metabolic and hormonal alterations observed. However, differences may also exist with regard to the use of milk products, lactobacilil, or other dietary components. Although it is extremely difficult to identify the crucial gastrointestinal factors, and to obtain quantitative assessment of these relations, the hypothesis seems attractive because it may identify dietary factors relevant to breast cancer promotion and progression.

\section{Antioxidants}

The concept of free radicals and reactive oxygen species provides a general framework for theories that contribute to an explanation of the occurrence of cancer and many other age-related diseases (88). ree radicals are generated in foods $(89)$, enzymatic (90) and nonenzymatic biological systems $(91)$, and may lead to biochemical damage to the cell and the organism. Both enzymatic and nonenzymatic systems are avallable to prevent such damage, e.g., the enzymes superoxide dismutase, catalase, glutathione reductase, and the selendum-dependent enzyme GSH-Px, and biological substances such as flavonoids, glutathione and uric acid. The net biological effect of these reactions depends on the balance between these processes in the various tissues and cell compartments.

There have been no specific attempts to relate this theory to breast cancer, but the antioxidant capacity of several dietary compounds, e.g., $\alpha$-tocopherol, $\beta$-carotene, other carotenoids and vitamin $c$, suggests that it might explain part of the association. With regard to breast cancex, this theory would gain in biological significance, 
Diet and the aetiology of breast cancer

if one of the antioxidants is specifically related to the endocine organs, to hormone metabolism or to protection of breast adipocytes or epithelium against oxidative damage.

\section{Alcohol}

In recent years, a positive association between alcohol intake and breast cancer has been reported several times. Blological mechanisms are largely unknown and mainly based on carcinogenesis of non hormone-related cancer sites in laboratory animals exposed to high doses of alcohol $(92,93)$. Mechanisms mediated by endocrine factors have received much less attention (94). Preliminary study results on serum and breast fluid oestrogens showed an inverse association between alcohol and serum oestrone, and a positive association between alcohol and breast fluid oestradiol in premenopausal but not in postmenopausal women (95). Results of a crossectional survey among postmenopausal women in the USA indicate that oestrone and oestradiol levels tend to decline with increasing alcohol. consumption (96). However, because of the potentially large risk enhancement at moderate drinking levels, more precise studies are needed.

\subsubsection{Epidemiological evidence}

\section{General}

In addition to ecological and time trend studies, and studies in migrant populations or populations with characteristic dietary habits, many epidemiological studies have investigated the potential role of dietary factors in breast carcinogenesis at the individual level. These studies have been reviewed extensively and it seems most useful to summarize the 'state of the art", rather than reviewing the same studies again $(97-101)$.

\section{Dietary fat}

In ecological studies, total fat-derived energy has been shown to be positively associated with breast cancer, but not with non-fat calories (102). This type of studies at the population level has been extensively reviewed, and they have generally been supportive of an association between the average diet in affluent societies and breast cancer (see also section $1.2 ; 98,99$ ). Because of their limited methodological strength (99), however, these and other studies on a population-level wil.1 not be discussed here in detail.

Many case-control studies have reported seemingly conflicting results. Several of these studies have reported associations with consumption of food groups rather than fat intake, probably because 
this was not allowed by the dietary assessment method employed. In a total of 14 case-control studies reviewed by Goodwin and Boyd (99), positive associations have been observed wh consumption frequency or daliy intake of high-fat food ltems such as butter in one study: at table), margarine, frying fats, fried potatoes, meat (pork, beef), visible eat on meat, cheese, whole milk, milk and dairy products combined. Fat intake was evaluated in eight of these 14 studies, but only one of these reported a statistically significant positive association. This result, however, might be attributable to the exclusion of subjects with fat-related diseases from the hospital controls. This particular study was not included in a recent review by Rohan and Bain (98) who mentioned only three casecontrol studies allowing the evaluation of total fat intake (103105), and considered the results presented by Howe (104) - which is essentially a reanalysis of Millers data (106) - weakly supportive of a positive association. The positive associations with fat-rich food items reported from other studies are given less weight since they are conslidered 'indirect measures of fat intake'. Based on three case-control studies (106-108), Prentice (109) derived an overall relative risk estimate of 1.2 (95 percent confidence interval 1.0 - 1.4) for subjects above versus below median fat intake.

Two recent case-control studies, from Italy (11.0) and canada (111) support a positive association between fat and breast cancer. The findings from Italy have been attributed to the (methodologically favourable) large heterogeneity in fat intake (112), but others have suggested that recall-bias might have played a role (113). In the Canadian study, mammographic features of the unaffected breast of cases were related to those of controls, showing a positive association with increased extent of nodular and homogeneous densities on the mammogram. Subsequently, it was shown in the controls that these mamographic features were positively associated with (energy-adjusted) intake of saturated fat (111).

In summary, mowt case-control studies can be viewed as consistent with a weak but positive association. The inconclusiveness of the overald wesults might be attributable to differences in study design (e.9., source of controls) and dietary methodology.

Prospective studies are less likely to produce biased results. Four of these have been reported. In Japan, Hirayama observed an elevated standardized mortality ratio among women who ate meat daily as compared to women wo ate meat rarely or were vegetarian. However, the number of breast cancer cases in the highest category of meat consumption frequency was very small and the dietary methodology was very simple as compared to current methods 114). In contrast, breast cancer mortality among Seventh-Day Adventists in California 
appeared not to be related to meat consumption (115). In addition to these studies, two other prospective studies have been conducted within a population that can be considered to consume a "western" diet. In the Nurses Health study, a total of 601 cases were identified from a cohort of 89,538 followed for four years (116). In this study, dietary fat intake was determined by means of a semiquantitative food frequency questionnaire, and the results refer to incidence rather than mortality. No association was observed with energy intake, fat intake, intake of saturated fatty acids, linoleic acid or cholesterol. Another prospective study included 99 breast cancer cases and 5,386 controls (117). In this study, nutrient intake was calculated from a 24-hour recall interview. The results showed an inverse relation with fat intake, which disappeared when energy was taken into account.

Thus, any overall conclusion on the relation between dietaxy fat and breast cancer strongly depends on the relative weights attributed to the results of the Nurses Health study as compared to the casecontrol studies. The apparent inconsistency of the results, however, does not provide a solid basis for conclusive inference (99), which may be attributed to limited heterogeneity within the populations studied, biases in case-control studies and problems in dietary assessment $(101,118,119)$. In fact, it has been shown that the associations observed in several case-control and cohort studies were in close agreenent with results from ecological studies, and that the apparent inconsistencies may simply arise by chance (109). In other words, there is a large problem with regard to statistical power in these studies, since even very large studies cannot rule out moderately increased risks, still considered relevant to public health (120).

To overcome several of these problems, a ten-year multi-centre cancer prevention trial among 32,000 American women aged 45 to 69, the women Health Irial, has been proposed and its feasibility explored (121). This study intended to test whether a low-fat diet (20\% of energy from fat) reduces breast cancer incidence in this age category of women $(101,121,122)$. Controversies as to the strength of the hypothesis, the statistical power and compliance to the diet, however, have resulted in the discontinuation of the full-scale implementation of the trial (121).

With regard to the type of fat, cross-cultural studies have not shown an association between vegetable fats and breast cancer (102). Case-control and cohort studies were generally not well suited to evaluate hypotheses on saturated, monounsaturated and polyunsaturated fatty acids separately. Their multicollinearity and the 
Iimited validity and reliablity of dietary methodology have pronibited detaled in-depth analysis of the potential effects of specific fatty acids.

In a small number of studies biochemical markers of diet have been included. Since high dietary fat and cholesterol intake are positively associated with serum cholesterol levels, the relation between serum cholesterol and breast cancer could provide another means to testing the fat-breast cancer hypothesis. Four of such stuclies are documented, but they fail to support the hypothesis, or even contradict it (98). In one study, the fatty acid composition of adipose tissue from breast cancer cases was compared to subjects with fibroadenona and other breast diseases, but the results did not show systematic differences between the (small) groups of subjects with regard to the quality of the fat or the polyunsaturated/saturated fatty acids ratio (123). Although it would have been interesting, there are no studies to our knowledge, that have considered fatty acid profile and antioxidant status simultaneously. In conclusion, there is essentially no reliable epidemiological evidence on breast cancer relating to specific types of fat, biomarkers of fatty acid composition, or fat-soluble antioxidants.

\section{Selenium}

The epidemiological evidence for an inverse relation between selenium and breast cancer is 1 imited. Ecological studies on trace elements and cancer have shown an inverse association between breast cancer mortality on the one hand and estimated per capita selenium intake and selenium in blood from donors on the other hand $(124$, 125). Additionally, in two case-control studies a lowered plasma selenium concentration was observed in breast cancer cases as compared to controls $(126,127)$.

since then, several analytical epidemiological studies have been conducted on selenium and total cancer risk. These are summarized in Table 1 (126-140). In general, selenium levels in cases were sightly lower than in controls, suggesting an inverse association. In studies reporting sex- or site-specific selenium levels, the differences tend to be smallex for female cancers or breast cancer. for breast cancer, however, the results are based on small numbers, and less compelling. Two studies supporting the inverse association $(127,137)$ were of limited size, used serum selenium as a biomarker, and recruitment and selection of cases and controls was not well described. In two $(135,136)$ of three $(128,135,136)$ other studies, long-term biomarkers of selenium were used (toenails, erythrocytes) and no inverse association was observed. In a nested case-control study (128) an inverse association was observed with gastrointestinal and prostatic cancers, but not with breast cancer. 
In conclusion, there is some epiamiological evidence for an inverse relation between selenium and cancex. Until recently, there was no substantial evidence on this relation regarding the most common female cancer in industrialized countries, i.e. breast cancer. preliminary results from the Nurses Health study, however, do not support the hypothesis (140).

Table 1. Analytical epidemiological studies on serum selenium and cancer.

\begin{tabular}{|c|c|c|c|c|c|c|c|}
\hline \multicolumn{2}{|c|}{ Study } & \multicolumn{4}{|c|}{ Study characteristics } & \multirow{2}{*}{\multicolumn{2}{|c|}{$\begin{array}{l}\text { Ratio of serum } \\
\text { selendum in } \\
\text { cases/controls }\end{array}$}} \\
\hline \multirow[b]{2}{*}{ Year } & \multirow[b]{2}{*}{ Author ${ }^{k}$} & \multirow[b]{2}{*}{$\begin{array}{l}\text { Duration } \\
\text { (yrs) }\end{array}$} & \multirow{2}{*}{$\begin{array}{l}\text { Number } \\
\text { Con- } \\
\text { trols }\end{array}$} & \multirow{2}{*}{\multicolumn{2}{|c|}{$\begin{array}{l}\text { of subjects } \\
\text { Cancer sites } \\
\text { All Breast }\end{array}$}} & & \\
\hline & & & & & & $\begin{array}{l}\text { Cancer } \\
\text { A.l. }\end{array}$ & $\begin{array}{l}\text { sites } \\
\text { pemale }\end{array}$ \\
\hline 1979 & Robinson & - & 113 & 80 & 6 & 0.84 & 0.84 \\
\hline 1980 & Mc Connell & - & 27 & - & 35 & - & $0.80^{\circ}$ \\
\hline 1983 & willett & 5 & 210 & 111 & 16 & $0.95^{\mathrm{b}}$ & $0.99^{\mathrm{C}}$ \\
\hline 1984 & Salonen & $5-6$ & 128 & 128 & $\leq 32$ & $0.93 \mathrm{~b}$ & $0.98^{\mathrm{d}}$ \\
\hline 1985 & Salonen & 4 & 51 & 51 & $\leq 21$ & $0.88^{\mathrm{D}}$ & $0.98^{\mathrm{e}}$ \\
\hline 1985 & Peleg & $2-12$ & 241 & 130 & 12 & $1.01_{h}$ & $0.98_{f}^{C}$ \\
\hline 1987 & Fex & 8 & 70 & 35 & - & $0.95^{\mathrm{b}}$ & -1 \\
\hline 1987 & Kok & $6-9$ & 69 & 69 & 6 & $0.96 \mathrm{~h}$ & $0.99^{9}$ \\
\hline 1987 & Akesson & 2 & 453 & 30 & - & $0.93^{\mathrm{D}}$ & $-\mathbb{I}$ \\
\hline 1987 & Van Noord & 2 & 290 & - & 61. & - & $0.96^{\mathrm{c}, \mathrm{h}}$ \\
\hline 1987 & Meyer & - & 116 & - & 38 & - & $1.01^{\mathrm{C}, \mathrm{I}}$ \\
\hline 1988 & Chaitchik & - & 36 & - & 32 & - & $0.64^{\mathrm{b}, \mathrm{c}}$ \\
\hline 1988 & Coates & 12 & 287 & 156 & 21 & 1.00 & $>1.00^{6}, \mathrm{~J}$ \\
\hline 1988 & Ringstad & 6 & 60 & 60 & 10 & 0.96 & $1.02_{\mathrm{b}}^{\mathrm{C}}$ \\
\hline 1989 & Hunter & 4 & 393 & - & 393 & - & $1.00^{\mathrm{n}}$ \\
\hline
\end{tabular}

a duration of follow-up in nested case-control study nested in cohort; '-' indicates case-control study.

p<0.05 for difference between cases and controls.

result for female breast cancer, other sites excluded.

ICD codes $170-174$.

e total female cancer.

forales only.

929 women in total, 12 with gastrointestinal tumors.

i selenium in toenalls.

j erythrocyte selenium.

j 39 controls for breast cancer cases.

references $126-140$ consecutively. 
Fibre and micro-organisms

Pibre and carbohydrates have not been studied extensively in epidemiological studies. The ecological studies reported, however, showed a positive association of breast cancer with refined caxbohydrates and an inverse association with starch. In a casecontrol study in Israel, the association between fibre and breast cancer was speclfically evaluated, suggesting an inverse association (141). A similar observation, though the association was not statistically significant, was reported from Australia (142). Further evidence for a possible association is majnly based on comparison of urinary and faecal homone excretion in women with contrasting dietary habits, in which not only fiber, but also meat and, possibly, milk consumption differed considerably (see 2.3.1).

Micro-organisms have not been studied specifically in relation to breast cancer. The inverse association between frequency of yogurt congumption and breast cancer (143) could be a chance finding. When dairy products are considered as a single food group, both positive and inverse associations with breast cancer have been reported. Few studies have reported separate results for cheese, milk and fermented milk products $(144,145)$. However, the Lower risk abserved in subjects consuming low-fat milk may be partially attributable to the presence of micro-organisms in fermented low-fat milk drinks.

In conclusion, the possible inverse relation between fibre and fermented rilk products on the one hand and breast cancer on the other hand has not received much attention. This may partially be due to the fact that food composition tables contain data on macronutrient content, rather than other metabolically interesting properties of foods as these are not well-defined chemically. studies in this area may need to rely on ingestion of foods rather than of its biologicaliy active components.

\section{Antioxidants}

Graham et al. (103) showed an inverse dose-response relation between a dietary ritamin $A$ index and breast cancer, but their rather crude assessment of dietary habits did not allow distinction between retinol and beta-carotene. Rohan et al. (142) recently reported results of a case-control study showing a statistically significant decrease of breast cancer risk with increasing intake of betacarotene. In a nested case-control study, willett found no differences in serum carotenold levels among 14 breast cancer cases and 31 matched controls (146).

Serum or plasma vitamin $\mathrm{E}$ levels have been studied in relation to breast cancer in several prospective epidemiological investigations 
$(130,146-148)$. In only one of these studies a significant hnverse association was observed between plasma vitamin $E^{n}$ level and subsequent risk of breast cancer (147). Wald (149) has suggested that decreased vitamin $E$ levels in the years preceding cancer could result from decreased cholesterol or lipoprotein levels " rather than being a cause of cancer.

So, epidemiological evidence for an association between Eat-soluble antioxidants and breast cancer is sparse, long-term biomarkers of exposure have not been used, and the results may be influenced by the presence of the disease. Further epidemiological evidence for the potential beneficial effects of antioxidants is required.

\section{Alcohol}

Alcohol consumption has been related to breast cancex in a number of studies published in the past five years. A meta-analysis demonstrated that both prospective and retrospective epidemiological studies are in line with a positive association (150). In the casecontrol data, the relative risk of drinking $24 \mathrm{~g}$ of alcohol daily as compared to non-drinkers was 1.4 (95 per cent confidence interval $1.0-1.8)$. In prospective studies, the relative risk found was 1.7 (1.4-2.2). Although this is supportive evidence for a positive association it does, of course, not prove causality. Alcohol might be an indicator of life-style, rather than just a high-energy food component. Furthermore, because of lack of accuracy in reported alcohol intake, the possible aetiological role of drinking alcohol at young age, and limited knowledge of potential mechanisms, it is difficult at present to discriminate between the real and spurious elements of this association.

\section{References}

1 Ponten J. Normal vs neoplastic tissue behavior: What differences are essential? In: Maskens $A P$, et al (eds). Concepts and theories in carcinogenesis, Elsevier, Ansterdam, 1987, 3-17.

2 Moolgavkar SH, Knudson AG. Mutation and cancer: A model for human carcinogenesis. I Natl Cancer Inst 1981;66:1037-52.

3 Bos JL. Ras oncogenes in human cancer: A review. Cancer Res $1989 ; 49: 4682-9$.

4 Pierce GB, Speers WC. Tumors as caricatures of the process of tissue renewal: prospects for thexapy by directing differentiation. Cancer Res $1988 ; 48: 1996-2004$.

5 Iversen $\mathrm{OH}$. What is new in endogenous growth stimulators and inhibitors (chalones). Path Res Pract 1985;180:77-80. 
6 Metcalf $D$. The roles of stem cell self-renewal and autacrine growth factor production in the biology of myeloid leukemia. Cancer Res 1989;49:2305-11.

7 Russo J, Russo IH. DNA labeling index and structure of the rat mamary gland as determinants of its susceptibility to carcinogenesis. J Natl Cancer Inst 1978;61:1451-9.

8 Russo J, Rusgo IH. Biological and molecular bas is of mammary carcinogenesis. Lab Invest $1987 ; 57: 112-37$.

9 Armitage $\mathbb{P}$, Dol $1, R$. The age distribution of cancer and a multistage theory of carcinogenesis. Br J Cancer 1954;8:1-12.

10 Armltage $P$, Doll $R$. A twa-stage theory of carcinogenesis in relation to the age-distribution of muan cancer. BI $J$ cancer $1957 ; 11: 161-9$.

11. Cook PJ, Doll R, Fellingham SA. A mathematical model for the age distribution of cancer in man. Int $J$ Cancer 1969;4:93-112.

12 Day ME, Brown CC. Multistage models and the primary prevention of cancer. I nat 1 Canc Inst 1980;64:977-89.

13 Macmahon B, Cole $\mathrm{P}$, Brown J. Etiology of human breast cancex: A review. I Nat1 Cancer Inst 1973;50:21-42.

14 Bjarnasson $O$, Day NE, Snaedal G, Tulinius H. The effect of year of birth on the breast cancer incidence curve in Iceland. Int J Cancer $1974 ; 13: 689-96$.

15 Putten DJ, Habbema JDF, Oortmarssen GJ van der Maas PJ. Preliminaries for evaluation of breast cancer screening. Part I. An analysis of mortality from breast cancer in The Netherlands. Technical report. Erasmus univ Rotterdam, 1981.

16 De ward F. Premenopausal and postmenopausal breast cancer: one disease or two? I Natl Cancer Inst 1979;63:549-52.

17 Pike MC, Krailo MD, Henderson BE, Casagrande JT, Hoel DG. 'Hormonal. risk factors, 'breast tissue age' and the ageLincidence of breast cancer. Nature $1983 ; 303: 767-70$.

18 Moolgavkar $\mathrm{SH}$, Day $\mathrm{NE}_{\text {, }}$ stevens RG. Two-stage model for carcinogenesis: Epidemiology of breast cancer in females. J Nat 1 Cancer Inst 1980;65:559-69.

19 Stmpson HW, Candlish W, Pauson AW, McArdle CS, Griffiths $\mathrm{K}$, Small RG. Genesis of breast cancer is in the premenopause. Lancet $1988 ; 2: 74 ;-6$.

20 De waard $F$, Trichopoulos D. A unifying concept of the aetiology of breast cancer. Int $J$ Cancer $1988 ; 41: 666-9$.

21 Kelsey JL. A review of the epidemiology of human breast cancer. Epidemial Rev 1979;1:74-109.

22 Petrakis. NL. Genetic factors in the etiology of breast cancer. Cancer $1977,39: 2709-15$.

23 Anderson DE. Genetic study of breast cancer: Identification of a high risk group. Cancer $1974 ; 34: 1090-7$. 
24 Wynder EL, Maccornack RA, stellman SD. The epidemiology of breast cancer in 785 United states caucasian women. Cancer $1978 ; 42: 737-69$.

$25 \mathrm{King} M C$, Go RC, Elston $\mathrm{RC}$, Lynch HT, Petrakis NL. Allelle increasing susceptibility to human breast cancer may be linked to the glutamate-pyruvate transaminase locus. Science 1980;208: 406-8.

26 Ponder B. Gene losses in human tumours. Nature 1988;335:400-2.

27 Hansen MF, Cavenee WK. Genetics of cancer predisposition. Cancex Res $1987 ; 47: 5518-27$.

28 De waard F. Body size and breast cancer risk. In: pike MC, Sititeri FK, Welsch CW (ed). Hormones and breast cancer. Banbury Report 8. Cold Spring Harbor Laboratory, 1981, 21-30.

29 Fournier DV, Schiller U, Junkermann H, Legler U, Bauer $M$. Matural growth rate in 300 primary breast carcinomas and correlation to homone factors. In: Angeli A, Bradow HL, Dogliotti L. Endocrinology of the breast: basic and clinical aspects. New York Academy of Scilences, New York, 1986, 563-5.

30 Campbell FC, Blamey RW, Elston CW, Morris AH, Nicholson RT, Griffiths $K$, Haybittle $J L$. Quantitative oestradiol receptor values in primary breast cancer and response of metastases to endocrine therapy. Lancet $1981 ; 2: 1317-9$.

31 Harmsen $\mathrm{HJ}$, Porsius AJ. Endocrine therapy of breast cancer. Eur J Cancer Clin oncol 1988;24:1099-116.

32 Van 't Veer $P$, De Vet HCW, Van Gilse HA. Voeding en borstkanker. Dee1. 1. Epidemiologie. Voeding $1984 ; 45: 39-45$.

33 Doll $R$, Peto $R$. The causes of cancer. Quantitative estirates of avoidable risks of cancer in the united states today. oxford, 1981 .

34 Carroll KK, Gammal EB, Plunkett ER. Dietary fat and mammary Cancer. Canad Med Assoc J 1968;98:590-4.

35 Welsch $\mathrm{CW}$. Enhancement of mammary tumorigenesis by dietary fat: review of potential mechamisms. Am J Clin Nutr 1987;45:192-202.

36 Frisch RE, McArthur JW. Menstrual cycles: fatnes as a determinant of the minimum weight for height necessary for their maintenance or onset. Science 1974;185:949-51.

37 Frigch RE. Body fat, menarche, fitness and fertility. Human reproduction $1987 ; 2: 521-33$.

38 Daniell HW. Smoking, obesity and the menopause (letter). Lancet $1978 ; 2: 373$.

39 Rose DP. Dietary factors and breast cancer. Cancer Surveys $1986 ; 5: 671-88$.

40 Tretli s. Height and weight in relation to breast cancer morbidity and mortality. A prospective study of 570,000 women in Morway. Int J Cancer 1989;44:23-30. 
41 Ross MH, Bras $G_{*}$ Lasting influence of early caloric restriction on prevalence of neoplasms in the rat. I Nat1 cancer Inst 1971; $47: 1095-113$.

42 Krtchevky 1 , weber MM, Klurfeld DM. Dietary fat versus caloric content in initiation and promotion of 7,12-dimethylbenz(a)anthracene-induced mammary tumorigenesis in rats. Cancer Res $1984 ; 44: 317.4-7$.

43 Klurfeld DM, Kritchevsky D. Update on dietary fat and cancer. Proc Soc Exp Biol Med 1986;183:287-92.

44 Beth M, Bergex MR, Aksoy M, Schmall D. Comparison between the effects of dietary fat level and of calorie intake on methylnitrosourea-induced mammary carcinogenesis in female SD rats. Int $J$ Cancer $1987 ; 39: 737-44$.

45 Boissoneault GA, Elson CE, Pariza MW. Net energy effects of dietary fat on chemically-induced mammary carcinogenesis in E344 rats. J wat 1 Cancer Inst $1986 ; 76: 335-8$.

46 Cohen LA, choi $k$, wang $C X$. Influence of dietary fat, caloric restriction, and voluntary exercise on $N$-nitrosomethylureainducea mamary tumorigenesis in rats. Cancer Res 1988;48:427683.

47 Sylvester Pw, Aylsworth CF, Meites J. Rellationship of hormones to inhibition of mammary tumox development by underfeeding during the 'critical period" after carcinogen administration. Cancer Res 1981;41:1384-8.

48 Martin $\mathbb{R} J$. Dietary restriction and hypothalamic metabolism: $A$ model of aging and food intake control. In: snijder DL (ed). Dietary restriction and aging. Alan $\mathrm{R}$ Liss Inc, New York, 1989, $201-9$.

49 Albanes D, Winick M. Are cell number and celd proliferation risk factors for cancer? J Nat1 Cancer Inst 1988;80:772-5.

50 Lok $E_{\text {, Nera }} \mathrm{EA}$, Iverson $F$, scott $\mathbb{F}$, so $\mathrm{Y}$, Clayson DB. Dietary restriction, cell proliferation and carcinogenesis: a preliminary study. Cancer Letters $1988 ; 38: 249-55$.

51 Rogers $\mathbb{A E}_{\text {, Lee }} \mathrm{SY}$. Chemically-induced mamary gland tumors in rats: Modulution by dietary fat. In: Ip C, Birt DE, Rogers AE, Mettin $\mathrm{C}$ (eds). Dietary fat and cancer. Alan $\mathrm{F}$ Liss Inc, New York, $1986,255-82$.

$52 \mathrm{Hi1} \mathrm{MJ}$. Microbes and human carcinogenesis. Cancex of the breast and endometrium. Edward Arnold, London, 1986, 117-27.

53 Adlercreatz $M$, Fotsis $T$, Hejkkinen $R$, et al. Excretion of the lignans enterolactone and enterodiol and of equol in omnivorous and vegetarian women and in women with breast cancer. Lancet $1982 ; 2: 1295-8$.

54 Gorbach SL. Estrogens, breast cancer, and intestinal flora. Rev Infect Dis $1984 ; 6$ (suppl) : $85-90$. 


\section{Diet and the aetiology of breast cancer}

55 welsch cW. Interrelationship between dietary fat and endocrine processes in mammary gland tumorigenesis. In Ip C, Birt DF, Rogers AE, Mettin C (eds). Dietary fat and cancer. Alan $R$ Liss Inc, New York, 1986, 623-54.

56 Henderson BE, ROSS RK, Pike MC, Casagramde JT. Endogenous hormones as a major factor in human cancer. Cancer Res 1982:42: $3232-9$.

57 Sylvester PW, Russe11 M, Ip MM, IP C. Comparative effects of different animal and vegetable fats fed before and during carcinogen administration on mamary tumorigenesis, sexual maturation, and endocrine function in rats. Cancer Res 1986:46:757-62.

58 Bunnik GSJ. Diet, hormones and NMU-induced rat mammary cancer. Thesis. Kxips Repro, Meppel, the Netherlands, 1988.

59 Rolland $\mathbb{P H}$, Mattin PM, Jacquemler J, Rolland AM, Toga M: Prostaglandin in human breast cancer: Evidence suggesting that an elevated prostaglandin production is a marker of metastatic potential for neoplastic cells. J Natl Canc Inst 1980;64:106170 .

60 Karmali RA, welt $S$, Thaler HT, Lefevre $\mathbb{H}$. Prostaglandins in breast cancer: relation to disease stage and homone status. Bx J Cancer $1983 ; 48: 689-96$.

61 Laekenan GM, Vergote IB, Keersmakers GM, et al. Prostacyolin and thomboxane in benign and malignant breast tumors. Br I Cancer $1986 ; 54: 431-7$.

62 kort WJ, Weijma IM, Bijma AM, Van schallkwijk WP, Vergroesen AJ, Westbraek DL. Omega-3 fatty acids inhibiting the growth of transplantable rat mammary adenocarcinoma. I Natl Cancer Inst $1987 ; 79: 593-9$.

63 Petrakis NL. Physiologic, biochemical and cytologic aspects of nipple aspirate fluid. Breast Cancer Res Treatm 1986;8:7-19.

64 Sevanian A, Peterson AR. Cholesterol epoxide is a direct-acting mutager. Proc Natl ACad Sci 1984;81:4198-202.

65 Sevanian $A$, Peterson AR. The cytotoxic and mutagenic properties of cholesterol oxidation products, Fd Chem Toxic 1986;24:1103 10 .

66 Gruenke LD, Wrensch MR, petrakis NL, Milke R, Ernster vL, Craiq JC. Breast fluid cholesterol and cholesterol epoxides: relationship to breast cancer risk factors and other characteristics. Cancer Res $1987 ; 47: 5483-7$.

67 Wrensch MR, Petrakis NL, Gruenke LD et al. Breast fluid choles-terol and cholesterol $\beta$-epoxide concentrations in women with benign breast disease. Cancer Res 1989;49:2168-74.

68 Dupont WD, Page DL. Risk factors for breast cancer in women with proliferative disease. N Engl J Med 1985;312:146-51.

69 Carter CL, Corle DK, Micozzi MS, schatzkin A, Taylor PR. A prospective study of the development of breast cancer in 16,692 
Diet and the aetiology of breast cancer

women with benign breast disease. Am J Epidemiol 1988;128:46777.

70 Vernie LN. Selenium in carcinogenesis. Biochim Biophys Acta $1984 ; 738: 203-17$.

71 Underwood EJ. Trace elements in human and animal nutrition (4th ed) Acadenic Eress, New York, 1977, 302-46.

72 Comittee on dietary allowances. Food and Mutrition Board. Recomimended dietary allowances. 9th ed. National Academy of Sciences, Washington, 1980 .

73 Voedingsraed. Nederlandse voedingsnormen 1989. Advies opgesteld door de Commissie Voedingsnormen. Voorlichtingsburo voor de voedingt, Den Haag, 1989.

74 Nohl H. Blochemische grundlagen vitamin-E und selen-mangelbedingter exkrankungen. Wien Tieraerzt Monatschr 1984;71:217-23.

75 LeBoewf RA, Hoekstra WG. Changes in cellular glutatione levels: possible rellation to selenium-mediated anticarcinogenesis. Fed Proo $1985 ; 44: 2563-7$.

76 Morrison DG, Berdom RC, pauly DF, Turnex DS, Oborn CJ, Medina D. Selenium distribution in mamary epithelial cells reveals its possible mechanism of intibition of cell growth. Anticancer Res $1988 ; 8: 51-64$.

$77 \mathrm{Ip} C$. Is seleniummetabalism necessary for its anticarcinogenic activity? In: Wendel $A$ (ed). Selenium in biology and medicine. Springer-verlag, Berlin, 1988, 305-12.

78 Behne D. Hilmert $H$, Scheid S, Gessner H, Kyriakopoulos A, Elger W. Studies on new selenoproteins and specific selenium target tissues. In: Wendel A (ed). Selenium in biology and medicine. Springer-Verlag, Berlin, 1988, 14-20.

79 Armstrong BK, Brown JB, Clarke HT, et al. Diet and reproductive hormones: study of vegetarian and nonvegetarian postmenopausal. women. I Nat1. Cancer Inst 1981;67:761-7.

80 Henegan $\mathfrak{I B}$. Alimentary tract physiology: Interactions between the host and its microbial flora. In: Rowland IR (ed). Role of the gut flora in toxicity and cancer, Academic Press, London, $1988,39-78$.

81 Goldin BR. The metabolism of the intestinal microflora and its relationship to dietary fat, colon and breast cancer. In: Ip C, Birt DE, Rogers AE, Mettlin C (eds). Dietary fat and cancer. Alan R Liss Inc, New York, 1986, 655-86.

$82 \mathrm{HiJl}$ MJ, Goddard P, Williams REO. Gut bacteria and aetiology of cancer of the breast. Lancet $1971 ; 2: 472-3$.

83 Goddard $P$, Hill MJ. The in vivo metabolism of cholesterol by gut bacteria in the rat and guinea pig. I Steroid Biochem 1974;5: $569-72$.

84 Setchell KDR, Adlercreutz. Mammalian lignans and phytooestrogens. Recent studies on their formation, metabolism and 
biological role in health and disease. In: Rowland IR (ed). Role of the gut flora in toxicity and cancer, Academic Press, London, $1988,15-45$.

85 Rao DR, Pulusani SR, Chawan CB. Natural inhibitors of carcinogenesis: Fermented milkproducts. In: Reddy BS, cohen LA (eds), Diet, nutrition and cancer: critical evaluation, vol 2, Boca Raton, $1986,63-75$.

86 De simone C. Microflora, yogurt and the immune system. Int J Immunotherapy 1986 ; Suppl II:19-23.

87 Perdigon $G$, Nader de Macias $M E_{*}^{*}$ Alvarez $S$, oliver $G$, Pesce de, Ruiz Holgado A de. Enhancement of immune response in mice fed with streptococcus thermophilus and Lactobacillus acidophilus. J Dairy Sci $1987 ; 70: 919-26$.

88 pryor WA. Free radical biology: Xenobiotics, cancer and aging. New York Academy of Sciences, 1982:1-21.

89 Eriksson CE. Oxidation of lipids in food systems. In: Chan HWS (ed). Autoxidation of unsaturated lipids. Academic Press Inc Ltd, London, 1987, 207-31.

90 Harman D. Role of free radicals in aging and disease. In: Johnson HA (ed). Relations between normal aging and disease. Raven Press, New York, 1985, 45-85.

91 Gey KF. On the antioxidant hypothesis with regard to arteriosclerosis. In: Somogyi JC (ed). Scientific evidence for dietary targets in Europe. Biblthca Nutr Dieta 37. Karger, Base1, 1986, 53-91.

92 Lieber CS, Seitz HK, Garro AJ, worner TM. Alcohol-related diseases and carcinogenesis. Cancer Res 1979;39:2863-86.

93 Seitz HM, Simanowski UA. Alcohol and carcinogenesis. Ann Rev Nutr $1988 ; 8: 99-119$.

94 Massiha FS, Pasi A. Alcohol and endocrine interaction. Res Comm in Substances of Abuse 1987;8:97-107.

95 Ernster VL, Wrensch MR, Petrakis NL, et a d. Benign and madugnant breast disease: Initial results of serum and breast fluid analyses of endogenous estrogens. I Natl Cancer Inst 1987;79: 949-60.

96 Cauley JA, Gutai JP, Kuller LH, LeDonne D, Powell JG. The epidemiology of serum sex hormones in postmenopausal women. Am J Epidemiol $1989 ; 129: 1120-31$.

97 Kelsey JL. E review of the epidemiology of human breast cancer. Epidemiol Rev $1979 ; 1: 74-109$.

98 Rohan TE, Bain CJ. Diet in the etiology of breast cancer. Epidemiol Rev $1987 ; 9: 120-45$.

99 Goodwin PJ, Boyd NF. Critical appraisal of the evidence that dietary fat intake is related to breast cancer $r$ isk in humans. J Nat I Canc Inst $1987 ; 79: 473-85$. 
Diet and the aetiology of breast cancer

100 Boyle P, Leake R. Progress in understanding breast cancex: epldemiological and biologicaj. inceractions. Breast canc Res Treatirit 1988; 11:91-112.

101 prentice $\mathbb{R L}$, Kakar $F$, Hursting S, Sheppard L, Klein R, Kushi LH. Aspects of the rationale for the women"s health trial. I Natl Canc Inst 1988;80:802-14.

102 carroll $\mathrm{KK}$. Dietary factors in hormome-dependent cancers. In: Winiok M (ed). Nutrition and Cancer. Wiley, New York, 1977, $25-40$.

103 Graham S. Diet in the epideniology of breast cancex. Am. J Epidemiol $1982 ; 116: 68-75$.

104 Howe GR. The Use of polytomous dual response date to increase power in case-control studies; an application to the association between dietary fat and breast cancer. J Chron Dis 1985;38:66370 .

105 Hirohata T", Shigematsu, Nomura AM, et a l. Occurrence of breast cancer in relation to diet and reproductive history: a casecontrol study in Fukuoka, Japan. Natl Cancer Inst Monogr 1985; $67: 187-90$.

106 Miller AB, Kelly A, Choi NW, et al. A study of diet and breast cancer. Am J Epidemiol 1978;107:499-509.

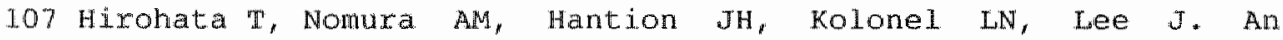
epideniological study of the association between diet and breast cancer. J Wat l Cancer Inst 1987;78:595-600.

108 Rohen TE, MCMichael AJ. Baghurst PA. A population-based casecontrol study of diet and breast cancer in Australia. Am J Epidemiol $1988 ; 128: 478-89$.

109 Prentice RT, Pepe $M$, Self SG. Dietary fat and breast cancer: A quantitative assessment of the epidemiological literature and a discussion of methodological issues. Cancer Res 1989;49:3147-56.

110 Toriolo P, Riboli E, Protta F, Charrel M, Cappa APM. Caloxieprowiding nutrients ard risk of breast cancer. I Nat 1 cancer Inst $1989,81: 278-86$.

111 Brisson $J$, Verreault R, Morrison AS, Tennina S, Meyer F. Diet, mammographic features breast tissue, and breast cancer $r i s k$. Am J Epidemiol. $1989 ; 130: 14-24$.

112 Tonjolo $\mathrm{P}$. et ad. Dietary fat intake and breast cancer risk (reply). J Natl Cancer Inst 1989;81:1423-4.

113 Willet WC, stampfer M. Dietary fat intake and breast cancer risk. J Natl Cancer Inst 1989;81:1422 (letter).

1.1.4 Hirayama T. Epidemiology of breast cancer with special reference to the role of diet. Prev Med $1978 ; 7: 173-95$.

1.5 Mils PK, Annegers JF, Phillips RL. Animal product consumption and subsequent fatal breast cancer risk among seventh-day Adventists. Am J spidemiol 1988;127:440-53. 
Diet and the aetiology of breast cancer

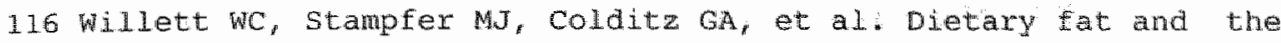
risk of breast cancer. New Engl J Med 1987:316:22-8.

117 Jones $Y D$, Schatzkin A, Green SB, et al. Dietary fit and breast cancer in National Health and Nutrition Examination survey I. Epidemiologic follow-up study. I Natl Cancer Inst 1987;79:46571.

118 Zaridze DG, Muir CS, MCMichael AJ. Diet and cancer: Value of different types of epidemiological studies. Nutr Canc 1985;7: $155-66$.

119 Bazarre TL, Myers MP. The collection of food intake data in cancer epidemiology studies. Nutr Cancer 1978;1:22-45.

120 Day NE. Statistical considerations. In: Wald NJ, Doll $\mathbb{R}$ (eds). Interpretation of negative epidemiological evidence for carcinogenecity. IARC Scientific Publications No 65, Lyon 1985, $13-27$.

121 Greenwald, P. Issues raised by the Women's Health Trial. J Nat 1 Cancer Inst $1988 ; 80: 788-90$.

122 Sun $M$. Debate rages over breast cancer study. Science 1988;239: $17-8$.

123 Eid A, Berg EM. The relationship between dietary fat, adjpose tissue composition, and neoplasms of the breast. Nutr cancer $1988: 11: 173-7$.

124 Shamberger RJ, Tytko SA, Willis CE. Antioxidants and cancer. part $I V$. Selenium and age-adjusted human cancer mortality. Arch Environ Health $1976 ; 31: 132-5$.

125 Schrauzer GN, white DA, Schneider CJ. Cancer mortality correlation studies- III: Statistical associations with dietary selenium intakes. Bioinorg chem $1977 ; 7: 23-34$.

126 Robinson MF, Godfrey PJ, Thomson CD, et al. Blood selenium and glutathione peroxidase activity in normal subjects and in surgical patients with and without cancer in New Zealand. Al J clin Nutr $1979 ; 32: 1477-85$.

127 Mcconnel1 KP, Jagex RM, Bland KI, Blotcky AJ. The relationship of dietary selenium and breast cancer. I Surg oncol 1980;15:6770 .

128 Willet WC, Polk BF, Morris JS et al. Prediagnostic serum selenium and risk of cancer. Lancet $1983 ; 2: 130-4$.

129 Salonen JT, Alfthan G, Huttunen JK, Puska P. Association between serum selenium and the risk of cancer. Am J Epidemiol 1984: ${ }^{2} 20$ : $342-9$

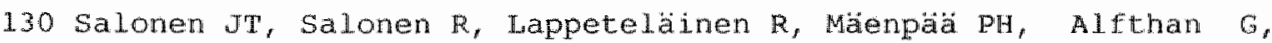
Puska $\mathrm{P}$. Risk of cancer in relation to serum concentrations of selenium and vitamins $A$ and $E$ : matched case-control analys $1 \mathrm{~s}$ of prospective data. Br Med J 1985;290:417-20.

131 Pelleg I, Morris S, Hames CG. Is serum selenium a risk factor for cancer? Med oncol and Tumox Pharmacother 1985:2:157-63. 
132 Fex G, pettexson B, Mkesson B. Low plasma selenium as a risk factor for cancer death in middle-aged men. Nutr cancer 1987; $10: 221-9$ *

133 Kok $\mathrm{F}$, De Bruijn AM, Hofman A, Vermeeren R, Valkenburg HA. Is serum seleniun a risk factor for cancer in men only? Am J Epidemio1 1987;125:12-6.

134 Akesson $\mathbb{B}$, steen B. Plasma selenium and glutathione peroxidase in relation to cancer, angina pectoris and short-term mortality in 68-year-old men. Comp Gerontol A $1987 ; 1: 61-4$.

135 Var Noord PAH, Collette HJA, Maas MJ, De waard F. Selenium levels in neils of premenopausal breast cancer patients assessed prediagnostically in a cohort-nested case-referent study among women screened in the DoM project. Int I Epideraiol 1987;16 (suppl): $: 318-22$.

136 Meyer $F$, Verreaul $R$. Erythrocyte selenium and breast cancer risk. Am J Epideniol 1987;125:917-9.

137 Chaitchik S, Shenberg $c$, Nir-el $\mathrm{X}$, Mantel M. The distribution of selenium in human blood samples of Israeli population Comparison between normal and breast cancer cases. Biol Trace Elem Res 1988;15:205-12.

138 Coates RJ, Weiss NS, Daling JR, Morris JS, Labbe RF. Serum levels of selenium and retinol and the subsequent risk of cancer. Am J Epidemiol 1988;128:515-23.

139 Ringstad $J$, Jacobsen BK, Tret1i $S$, Thomassen $Y$. Serum selenium concentration associated with risk of cancer. J Clin Pathol $1988 ; 41: 454-7$.

140 Hunter DJ, Morris IS, stampfer MJ, Colditz GA, Speizex FE, Willett WC. Selenium intake and risk of breast cancer among women. Am J Epiderniol 1989;130:810-1 (abstract).

141 Lubin F, Wax $Y$, Modan B. Role of Eat, animal protein and dietary fiber in breast cancer etiology: a case-control study. I Natl. Cancer Inst 1986;77:605-12.

142 Rohan TE, MCMichael. AJ, Baghurst PA. A population-based casecontrol. study of diet and breast cancer in Australia. Am J Epidemiol $1988 ; 128: 478-89$.

143 LE MG, Moulton LH, Hill $\mathrm{C}$, et al. Consumption of dairy produce and alcohol in a case-control study of breast cancer. I Nat 1 Cancer Inst $1986 ; 77: 633-6$.

144 Van "t Veer P. Milk products, microorganisms and breast cancer. In: Fermented Milk and Health. Proceedings of a Workshop held on septenber 25 and 26, 1989 at Arnhem, the Netherlands. NIZO, Ede $1989,93-103$.

145 Katsouyanni $K$, "Trichopoulos $D$, Boyle $p$, et al. Diet and breast cancer: a case-control study in Greece. Int J cancer 1986;38: 815-20. 
146 Willett WC, Polk $F_{s}$ Underwood BA, Stampfer Mi, Pressel S, Rosner $B$, et $A$. Relation of serum vitamin $A$ and $E$ and carotenoids to the risk of cancer. N Engl J Med 1984;310:430-4.

147 Wald $N J$, Boreham $J$, Hayward $J L$, et al. Plasma retinol, betacarotene and vitamin $\mathrm{E}$ levels in relation to future risk of breast cancer. Br J Cancer $1984 ; 49: 321-4$.

148 knekt $P$. Serum vitamin $\mathrm{E}$ level and risk of female cancers. Int $J$ Epldemiol 1988; 17:281-8.

149 Wald NJ, Thompson SG, Densem JW, Boreham J, Bailey A. Seruin vitamin $E$ and subsequent risk of cancer. Br J Cancer 1987;56:6972 .

150 Longnecker MP, Berlin JA, Orza MJ, Chalmers TC. A meta-analysis of alcohol consumption in relation to $r i s k$ of breast cancer. I Am Med Assoc 1988;260:652-6. 



\section{DESIGN, CONDUCT AND ANALYSIS \\ OF THE CASE-CONTROL STUDY}

The case-control study is a major tool in epidemiological research. It provides an efficient means of studying the aetiology of both rare and common diseases (e.g. breast cancer), provided that certain reguirements for internal and external validity are fulfilled $(1,2)$. In practice, however, there are many pitfalls which may obscure the diet-breast cancer association in this type of study.

This thesis describes the first case-control study on dietary habits and cancer conducted in the Netherlands. This chapter presents considerations on the design of this study, describes the actual conduct of the study, and discusses implications for the interpretation of the study results (and the conduct of future studies). Finally, the general strategy followed for data analysis is presented, with specific refexence to issues relevant to the study of the association between diet and cancer.

Because the chapters $4-9$ describe the study results in a publication format, parts of those chapters contain elements similax to those included in chapter 3 , albeit in a condensed form.

\subsection{Design}

\subsubsection{Subjects}

\section{Cases}

In our case-control study on diet and breast cancer, cases are defined as newly diagnosed women with breast cancer (ICD 174). Women with a history of breast cancer or with ipsidateral benign breast disease in the past five years were not eligible, because they were considered to be prevalent cases. Furthermore, cases should have the Dutch nationality and have lived in the Netherlands for at least ten years. So, recently immigrated women who had not adopted Dutch eating habits and who might differ largely with respect to Iffestyle and breast cancer risk, were excluded.

cases had been recruited with the help of surgical units. In the areas of Utrecht, Arnhem, and Nijmegen, cases had also been recruited with the help of regional cancer regigtries. Surgeons and cancer registries in these areas have contributed considerably to the succes of this study (Figure 1 ).

\section{Controls}

Population controls are defined as those women who would have been enrolled in the study if they had developed breast cancer (3). In 
practice, this means that controls were chosen through agestratified sampling anong unhabitants of the study areas (Figure 1), and that the same eligibility criteria were applied to controls as cases. For efficiency reasons, the age distribution of controls was sinilar to the expected age distribution of cases. The controls were sampled from municipal population registries in the study areas.

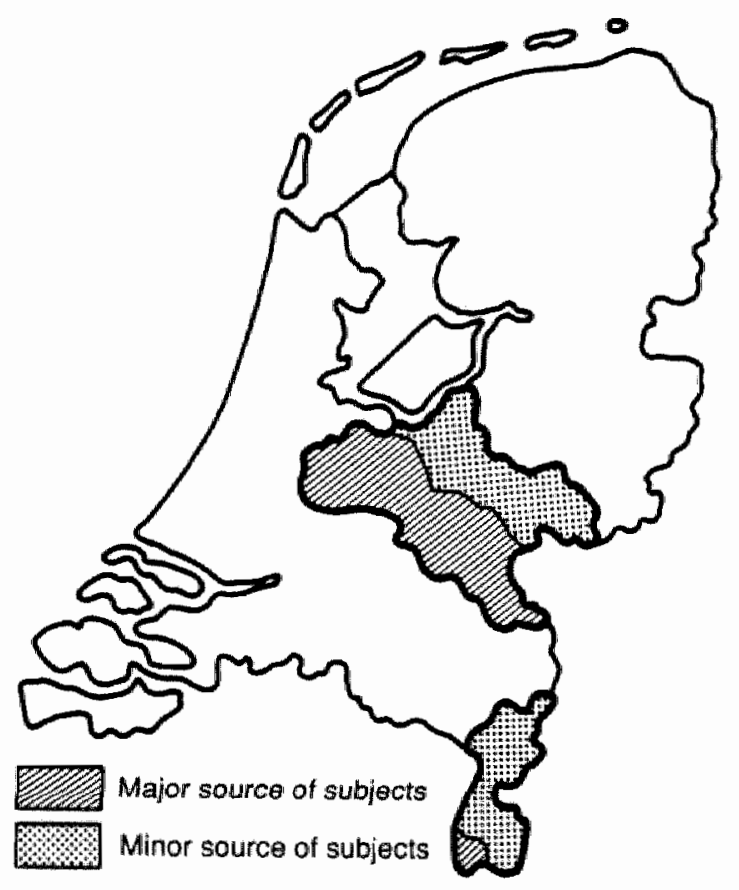

Figure 1. Wocation of study areas in the Netherlands.

\section{Age range}

The primary aim of the study was to investigate the potential role of dietary fat and selenium in breast cancer aetiology. Because the role of body composition might be different for pre- and postmenopausal women, eligibility was restricted to women aged 25-44 and 55-64 years, each group of approximately equal size. The perimenopausal age group was excluded from the study for costefficiency reasons. Inclusion of these women, who gradually enter 
Design, conduct and analysis

menopause, might have reduced the strength of effect modification by menopausal status because of misclassidication of 'menopausal status". Because of the modest number of women that eventually entered the study, however, it was difficult to study this hypothesis with sufficient statistical power.

study areas and sample size

The intended study areas from which cases and controls were recruited are shown in Figure 1. Based on population size (data provided by the Central Bureau of Statistics, CBS) and breast cancer incidence figures $(4,5)$, a total of 530 breast cancer cases was expected annually in these areas.

The sample size required to detect an association considered relevant (with given type I and II errors) may be assessed before the conduct of the study. In retrospect, based on the actual number of cases $(n=133)$ and controls $(n=289)$ in the study, it is appropriate to consider the strength of the associations that can be detected with given type I error (5\%, one-sided) and type II error (10\%, i.e. statistical power of 90\%). This has been calculated considering a dichotomous as well as a continuous exposure.

Assuming a dichotomous exposure, the study power was computed for several values of the odds ratio (after In transformation) and the corresponding standard error for the above values of type I and II errors. When the distribution of controls is split round the median, an odds ratio of 1.9 can be detected with $90 \%$ power. Similarly, for a comparison of extremes of the exposure distribution of controls (each extreme with 60 controls), the corresponding odds ratio is about 3.0 .

For continuous nomally distributed exposures, there is a direct relation between the odds ratio and the mean case-control difference divided by the pooled standard deviation of the exposure in cases. and controls (16). For such exposures, there is a linear doseresponse relation between exposure and the odds in favour of disease (after In transfomation). Given that the coefficient of variation for dietary intake data usually ranges from 20 to $30 \%$, a mean exposure difference between cases $(n=133)$ and controls $(n=289)$ of about 6 to 99 can be detected with 908 power (type I error, onesided 5\%). This corresponds to an odds ratio of 1.4 for an exposure contrast of one standard deviation (of the exposure variable).

of course, the above figures must be considered approximations, because they do not take into account the necessity of controlling for confounding factors. Furthermore, they depend on assumptions both with respect to statistical characteristics, as well as the exposure variables. In general, however, they indicate that strong associations (odds ratio $>5.0$ ) will not be missed by this study, 
Design, conduct and analys is

that moderate asgoditions lodas ratio $2.0-5.0$ ) are likely to be detected, and that meak associations (odds ratio $1.4-2.0$ ) may still be detected when the dose-response relation is (log)linear and exposures are normaly distributed.

\subsubsection{Methods}

In ordex to assess exposure to the relevant dietary factors and potential confounders, data collection included an interview on food habits and confounders, a blood sample and toenail clippings to assess selenium status). The choice of dietary methods and biomarkers of selenium aimed at reducing the potential for information bias in the study results, requiring standardized methods for assessment of prediagnostic exposures, minimally influenced by disease status. In addition, assessment of exposure aimed at control of within subject variability by using long-term indicators of exposure, thereby reducing the attenuation of measures of association and, consequently, false-negative study results.

\section{Data collection}

Blood of cases was collected prior to surgery in the hospital, so that influences of treatment modalities were excluded. Since breast tumours are generally detected when they are relatively small, it was considered unlikely that their presence would have seriously altered selenium metabolism and the measured status parameter. After discharge from the hospital, cases were interviewed on food habits and potential confounders. To minimize recall bias by physical or mental stress or by possibly altered post-diagnostic food habits, the interview was conducted at home, when cases were feeling relatively well (i.e. not auring chemotherapy), three to six months after discharge from the hospital, and referred to food habits in the year preceding diagnosis. At the end of the interview, weight." height and skinfolds were measured, followed by a request for toenail collection (to be returned by mail). The interview took about one and a half to two hours.

Controls were interviewed on food habits in the year preceding the interview, followed by the assessment of potential confounders and indicators of body composition. Toenails were requested as well. The blood sample was drawn one to four months after the interview.

\section{Dietary interview}

Dietary habits were assessed by a structured dietary history interview, conducted by well-trained registered dieticians, each of whom interviewed both cases and controls. After an introduction, the interview was directed at dietary habits, assessed from a total of 
Design, conduct and analysis

236 itens. These items were selected on the basig of the study hypotheses (at the nutrient level), nutrient content of the foods and expected heterogeneity of the population (7). For each item, frequency, amount (number of standard portions), seasonal variation (important for vegetables) and differences between weekdays and the weekend were coded.

To facilitate the recall of dietary habits, a hierarchical structure of the items was applied $(8,9)$. First, the meal pattern was asked about, then the major constituent food groups, and finally specific items or foods. Extra items could be added to maintain flexibility of the questionnaire and to take individual peculiarities into account. This structure allows the dietician to check the consistency of reported consumption frequencies, and to trace and adjust inconsistent answers, if necessary. In order to quantify the amounts of foods consumed, standard portions were assumed for many items. These data were supplemented with data on serving size, obtained by measurement of relevant household utensils (spoons, cups and glasses, at the end of the visit.

The dietary interview started with the dinner, thereby diverging from the 'traditional' dietary history, which usually assesses food habits in their daily order (e.g*, breakfast, lunch, dinner, evening) $(10,11)$. This was done because results of a pilot study showed that the usual order of meals leaves the most difficult part, i.e. the dinner (including food preparation), to the end of the interview, when subjects tended to loose interest or to get tired. This was considered far from optimal, since the dinner generally contributes largely to the intake of many nutrients, including dietary fat and selenium $(12,13)$. Moreover, questions on breakfast and lunch could often be integrated and were generally considered easier to answer, partially because the estimation of portion sizes tended to be less complicated. After these meals, a number of snacks were asked about, followed by drinks (including alcohol). Drinking hablts at young age $(25 \mathrm{Yr})$ were added to the questionnaire at a later stage.

\section{Biomarkers of selenium}

Exposure to selenium can be determined in various ways $(14-16)$ : in blood plasma, erythrocytes and toenails, or by determining the activity of the selenium dependent enzyme glutathione pexoxidase.

Plasma or serum have been used most frequently to determine exposure to selenium, especially in prospective studies (see chapter 2). Ihis biomarkex reflects both recently absorbed dietary selenium and selenium incorporated in plasma proteins and amino acids. Therefore, day-to-day variability in selenium intake may unfavourably affect within-subject variability in plasma selenium $(17,18)$. To allow 
Design, conduct and analysis

comparison with previous case-control studies, however, this bionarkex was incorporated in the study. Moreover, it may help to determine whether different biomarkers of selenium, possibly reflecting its different chemical forms (19) lead to a similar association with breast cancer.

Selenium in erythrocytes and toenail clippings is considered to reflect the selenium status over a longer period of time, with less disturbances due to short-term vaxiability in selenium intake $(17,18,20)$. Erythrocytes have been formed during a period of several months prior to blood collection. Sinjlarly, selenium incorporation in toenails integrates available plasma selenium over an extended period of time. Even nails of the big toe, collected up to several months after surgery, will reflect selenium incorporation prior to clinical diagnosis (18). Although erythrocytes and toenails may reflect chemicaldy distinct forms of selenium $(18,19)$, the absence of an inverse relation with breast cancer in both of them weakens the study hypothesis.

The activity of glutathione peroxidase can be determined in plasma as well as erythrocytes (21). Because this enzyme may be an Indicator of the availability of selenium to a specific biochemical function, incorporation of this functional biomarker was explored. owing to difficulties with respect to stability of the enzyme during transport (from the hospital to the TNO Institute), and with respect to quality control of biochemical determination of the enzyme activity, however, this biomarker was not included in the study.

\section{Risk factors and confounders}

To Alow for potential confounders of the association between diet and breast cancer, risk factors of breast cancer as well as ind lcators of $\mathbb{l}$ ife-gtyle were assessed during the interview.

The interview began with general life-style factors related to eating habits, such as accupation, visits and parties, number of people usually at home during the meals, use of food from a vegetable garden, meal pattern, dieting (including duration), and specific food habits (vegetarianism). These introductory questions were followed by the structured dietary history interview described above. Subsequently, use of vitamin supplements and stability of food habits were assessed.

The interview part on life-style factors began with smoking habits (current and past). To facilitate recald, the questionnaire was largely structured in the chronological ordex of events during lifetime, starting with general information on place of birth and marital status, followed by family structure (brothers, sisters). For the women aged 55-64, nutritional factors during the period 
Design, conduct and analysis

1930-1945 were given special attention. Then, hormonal and reproductive events were assessed, including use of oral contraceptiwes and presence of breast diseases in the past. This was followed by questions on familial history of breast cancer (grandmother, mother, aunts, sisters). Part of the questionnaire was directed at physioal activity, but reliable answers were found hard to obtain.

The questionnaire concluded with the assessment of educational level and questions on current weight, and recent and past weight changes. This was followed by anthropometry (height, weight, skinfolds, waist and hip circumference).

Finally, the content of household utensils was measured in the kitchen) and instructions were given for toenail clipping and sending of the collected material (by mail).

\subsection{Conduct}

Although the case-control study is a major tool in epidemiological research, this design had not been employed before for the study of diet and cancer in the Netherlands. When the study started (1984), Comprehensive Cancer Centres were just beginning to implement their Cancer Registries (22). Thereiore, they merely provided the infrastructure to introduce the study into the medical circles and gave valuable advice. Their usefulness for case recruitment was limited because the study design included collection of preoperative blood, requiring close collaboration with medical specialists. Therefore, the conduct of the study started with the development of procedures for case recruitment, along with the implementation of these procedures in cooperating hospitals. Most feasibility problems were encountered in the recruitment of cases, whereas procedures for control recruitment were smoothly developed and inplemented.

\section{2 .1 Cases}

\section{Development of procedures}

The collection of pre-operative blood required that procedures for case recruitment were developed in close cooperation with participating surgeons. Furthermore, the procedures proposed were discussed with representatives of the $\mathrm{LCBB}$ (Landelijk Contactorgaan Begeleidingsgroepen Borstkankerpatienten), a national board for the guidance of women with breast cancer. The major issues to be agreed upon were related to collection of blood for non-curative purposes, prowision of patient names and addresses to a non-medical institution (TNO-CIVO) and freedon of choice with regard to participation. 
ro cope with these delicate questions, an independent health adrinistrator cordinated the study in each of the three study axeas, invited the cases on behalf of the "pwo-cIvo Institutes, and prowided names and addresses only of those women who were willing to participate.

Procedures for case recrutment are summarized in Table 1 . When an aigible case entered the surgical unit of a participating hospital, a blood sample was drawn before surgery (in hospital routine) by means of matexials supplied by wO-CIVO. Blood samples were given unique codes (without names), and immediately sent to TNomcrvo.

buring their hospital-stay or after hospital-discharge (exceptionally) cases were informed about the study by their surgeon. If permitted by the patient, the health administrator was notified and supplied nore detailed information on the ain and procedures of the study by mail. When the case subsequently decided to participate, the lealth adninistrator provided her name and address to the CIVO-TNO dieticians who made an appointment for the interview at home. In the Utrecht, Arnhem and Nijmegen areas, cases missed by the surgeons were also traced through regular contacts with regional Cancer Registries. Although the pre-operative blood sample was lacking for these cases, they provided interview data and toenail clippïngs.

Table 1. Procedures of case recruitment.

1. Patient enrolled in the surgical unit of a cooperating hospital.

2. Pre-operative blood sample, sent to the TNo-cIvo Institutes.

3. H. Health administrator notified of (confirmation of) diagnosis. b. Cases missed by surgeons, traced in Cancer Registry.

4. Cases invited by health administrator; names and addresses of volunteer"s spplied to "INO-CTVO Institutes.

5. House vitit scheduled and conducted by TNO-CIVo dietician.

\section{Participation of hospitals}

In order to obtain cooperation of the 35 surgical units in the study areas, surgeons were informed on the study proposal in 1984 and early in 1985. This briefing usually included an oral presentation of the study hypotheses and design, presented at a meeting organized by the comprehensive cancer centre. Interested and motivated surgeons helped to implement and, if necessary, adapt the procedures. 
The study areas comprised 35 staffed with one to four surgical units were willing

surgical units, each of which was surgeons. A total of 23 of these 35 to participate in the study. Data obtained from the National Health care Information center (SIG) indicated that these covered 67\% of hospital admissions in the study areas. Two of these hospitals, geagraphically isolated from the other participating hospitals, were excluded. Four other hospitals were willing to participate, but did not actually contribute to case recruitment. Thus, cases were actually recruited from 17 surgical units. Hospital statistics and SIG-data revealed that $55 \%$ of hospital admissions for breast cancex in the study areas could be covered by these hospitals. Most of the 23 hospitals ready to participate, however, were located in the central part of the study areas, with a coverage of 83 of all first hospital admissions for breast cancer.

\section{Case recruitment}

According to hospital statistics (SIG), 294 cases were expected annually in the 21 participating hospitals in the central part of the study area. A total of 168 eligible breast cancer cases were actually recruited during the 18 -month study period. Taking into account that:

- only 17 hospitals did actually contribute to case reoruitment,

- SIG data on first hospital admissions for breast cancer may actually overestimate the real number of cases,

- some breast cancer patients initially did not enter the surgical unit of the hospital,

- several cases mentioned in hospital statistics may be not eligible (e.g. they lived outside the study area),

- not all eligible cases permitted that their name and address were supplied to the health administrator,

it may be inferred that 40-50\% of eligible cases were actually enrolled in the study by the participating surgioal units. In the areas of utrecht and of Nijmegen, $i . e$. the areas where breast cancer screening projects were conducted, coverage of case recruitment was considerably above average.

\section{Concluding remarks}

In this case-control study, case recruitment was a major concern, predominantly because of limited cooperation among surgical units, and because of failure to collect blood from cases by participating surgeons.

Non-cooperation among surgical units was related to privacy issues, feasibility of study procedures, and constraints of time and personnel. It seems unlikely that these factors are related to dietary factors in the study population residing in the hospitals' 
catchment areas. Moreover, SIG data indicated that the coverage of case recruttent was independent of age and degree of uxbanization of residence of the cases, and the cases area of residence was taken into account in data analysis to account for potentilal imbalance in recruitment of cases and controls.

In paxticipating hospitals a substantial number of cases were missed by the surgeons, many of which were traced afterwards by two of the regional cancex registries. Section 3.2 .4 addresses the question whethex this is related to case characteristics relevant to the study.

\section{2 .2 Controls}

To select control subjects, an age-stratified sample was drawn from the female population residing in the study areas. First, the number of women residing in the 189 municipalities in the study areas was obtained classified in 5-year age categories (data provided by CBS). Breast cancer incidence figures $(4,5)$ were used to calculate the expected annual number of breast cancer cases for each ivive-year age category. Subsequently, the number of controls to be sampled from each age category was determined. For each age category, a random sample was arawn from the municipalities in the study area. This resulted in a listing of the number of women to be sampled from each municipality by age.

Once the number of women to be sampled from each municipality was determined, cooperation was sought from the municipal registries. All 189 municipal registries agreed to cooperate. Each morth 10 to 15 municipalities were asked to supply names and addresses of the required number of controls. For each municipality, the number of names was doubled to compensate for non-response. When it became clear that no coperation of surgical units could be obtained in a part of the study area, sampling of controls from those areas was stopped. Evertually, a total of 548 women were sampled from the municipal registries.

\section{2 .3 Response}

cases and controls were formally invited by letter, explaining the general scope and design of the study. They were allowed to respond by indicating their choice and motivation on a form to be returned in a stamped addressed envelope, or by asking more detailed information by telephone. 
Design, conduct and analysis

A total of 168 eligible cases were identified during the study period, 134 of whom (80\%) were willing to be interviewed at home. As expected, it appeared that response was higher among cases with less advanced disease at diagnosis. Sone cases, who were willing, but unable, to participate completed a short questionnare on food habits and risk factors of breast cancer (see below). Moreover, 10 cases were willing to supply a blood sample for the study, but were not willing/able to be interviewed at hone. Thus, data could be obtained from a total of 146 of 168 (87\%) of the cases, indicating their high readiness to cooperate.

If the controls asked for additional information, when the motivation for a negative reply indicated that the purpose of the study was not understood, or if no answer was obtained within 2 weeks, the women were called (up to three times if there was no reply) or visited at home (once, controls only). Of the 548 controls invited, eight women appeared to be not eligible and 11 could not be reached. Of the remaining 529 women, $223(42 \%)$ immediately agreed to cooperate, and 66 (128) agreed upon a telephone call. To characterize the non-responders, the controls who refused to be interviewed at home $(\mathrm{m}=240 ; 45 \%)$ were asked to complete a short malled questionnaire, upon which 89 (17\%) of them agreed. This questionnaire was also completed by the cooperating controls, before they were interwiewed at home. Section 3.2.4 presents a comparison of data obtained from the 289 intensively interviewed women with data from these 89 partial responders, together representing 71 of the initial sample of 529 women.

The response rates among cases and controls, according to age, is shown in Figure 2. The response among controls (55\%) was lower than among cases, especially in the older age group. When the women who completed the short questionnaire are included in the response rate, the differences in response rate decrease, but the genexal pattern remains similar. The response rate was independent of degree of urbanization, both in cases and in controls.

\subsubsection{Implications}

As a result of the requirement of collection of blood before surgery, and the absence of fully implemented Cancer Registries in the whole study area, the recruitment of cases was confronted with many logistic problems. Once these were overcome, the response of cases was quite satisfying. For controls, the reverse situation was encountered. The sampling procedures were simple, efficient and successful, but the response rate was moderate. Thus, it may be that 


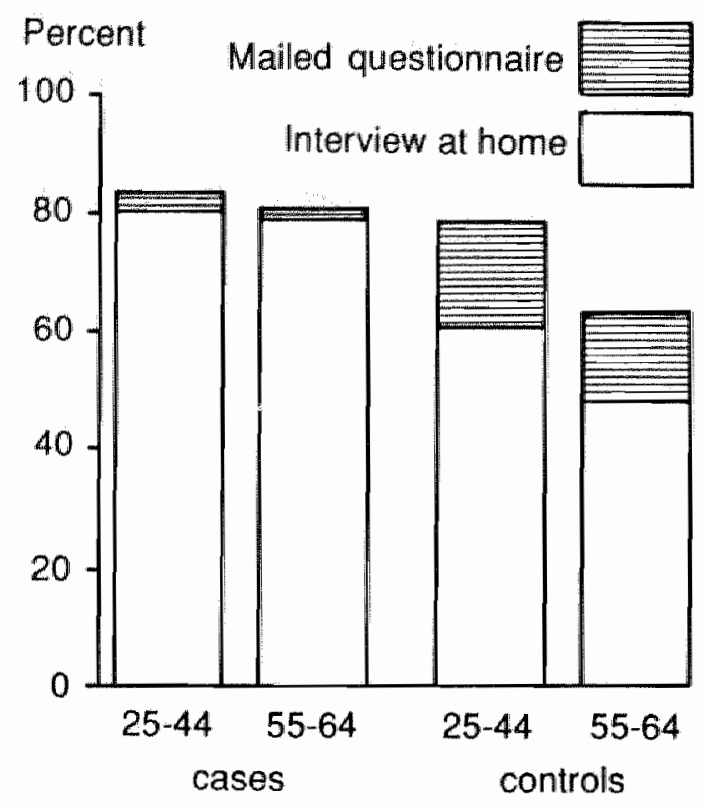

Figure 2. Response of cases and controls, according to age (yr).

the frorts made in collecting detalled exposure data have been counterpraductive with regard to cooperation of surgeons with cespect to case recruitment, and of controls with respect to response.

The following sections present some data addressing the potential implications for the interpretation of study results and discuss some issues to be considered in future case-control studies.

\section{Selection of cases by surgeons}

Cases were identified by the surgeons at diagnosis " or by the local Cancer Registries afterwards. If there would be an obviously dietrelated selection of cases by any of these sources, the characteristics of both groups would differ according to the mode of recruititent.

The most obvious characteristic that may have encouraged the surgeons to enroll a patient could be overweight. The body mass index, however, was very similar for both groups (Table 2). "Thus, 
Table 2. Body size indices and dietary pattern of breast cancer cases by mode of recruitment via surgeons of cancer registries.

\begin{tabular}{|c|c|c|}
\hline \multirow{2}{*}{$\begin{array}{l}\text { Dietary factor } \\
\text { (mean } \pm \text { SD) }\end{array}$} & \multicolumn{2}{|c|}{ Mode of case-recruitment } \\
\hline & $\begin{array}{l}\text { Surgeons } \\
\text { (84 cases) }\end{array}$ & $\begin{array}{c}\text { Cancer Registry } \\
\text { (49 cases) }\end{array}$ \\
\hline \multicolumn{3}{|l|}{ Body size indices } \\
\hline Height $(\mathrm{cm})$ & $164 \pm 6$ & $165 \pm 7$ \\
\hline Weight $(\mathrm{kg})$ & $68.0 \pm 11.8$ & $70.0 \pm 10.8$ \\
\hline Body mass index $\left(\mathrm{kg} / \mathrm{m}^{2}\right)$ & $25.4 \pm 4.6$ & $25.7 \pm 4.1$ \\
\hline Energy (koal) & $2088 \pm 575$ & $2207 \pm 533$ \\
\hline protein $\left(\frac{1}{b}\right)^{1}$ & $14.6 \pm 2.0$ & $13.9 \pm 2.2$ \\
\hline Fat $(8)$ & $41.7 \pm 6.4$ & $41.5 \pm 7.0$ \\
\hline Carbohydrates (\%) & $43.8 \pm 6.8$ & $44.6 \pm 6.2$ \\
\hline
\end{tabular}

a contribution to total energy intake excluaing alcohol.

there is no evidence in these data, that obese women have been selected by the surgical units. In addition, Table 2 shows the intake of energy and several nutrients, without substantial differences between the groups. Results were also similar when both age groups were considered separately. Furthermore, it is difficult to imagine by what mechanism selection of cases according to nutrient intake might occur, especially for a relatively unknown component like selenium. Thus, these main diet-related characteristics are independent of mode of recruitment, which does not support serious bias in exposure distribution.

\section{Selection of controls}

Before the interview at home, controls were asked to complete a short mailed questionnaire, which was also completed by 89 of the controls who were not interviewed at home. In luable 3 , risk factors for breast cancer and dietary factors included in the questionnaire are presented for both groups, showing only minor differences. The variables on type of food items used with bread, fat content of milk products, and type of bread were included to assess possible differences between full responders and partial responders with regard to intake of fat and fibre. The calculated aifferences in nutrient intake from these products do not suggest that there are relevant differences in these dietary factors. Therefore, the observed values of risk factors and dietary habits anong the interviewed controls are considered to be essentially similar to 
Design, conduct and analysis

values that would have been obtained if partial responders and nonresponders had been included in the intensively interviewed control group.

\section{suggestions for improvement in conduct}

This case-control study aimed at data collection by an extensive interview and biomarkers of exposure. Major problems in the conduct of the study were related to case recruitment, collection of preoperative blood, and response of contrals. Some general suggestions for improving the conduct of future case-control studies on diet and cancer are given below.

First, when a population-based case-control study is considered (without biomarkers), the following issues need attention with respect to data collection:

- cancer Registries may now play an important role in case recruitment, by providing the infrastructure, and data on diagnosis and number of cases.

- Exposure data from cases should be collected as soon as possible after diagnosis, e.g. by means of a short questionnaire provided by cooperating hospltals which can be returned by mail. More extended data can be obtained at a later stage, during an interview in the hospital or at home.

- Each contact with controls should aim at collecting data to explain non-response, for example by adding a short questionnaire to the invitation letter, by telephone interview, ar both.

Second, when biomarkers or (tumour) tissue are included in data collection, close cooperation with medical specialists, hospital and pathological laboratories is necessary. Studies of that type are usually confined to a relatively small geographical area. In addition to the above, the following issues are of importance in the conduct of such studies:

- Collection of biological material has the best chance of being successful in laboratory routine in large hospitals.

- Complete case recruitment is generally not possible. Therefore, data fom eligible though not included cases may be required (Carcer Registries).

- The source population of the cases is difficult to define. Therefore, (matched) hospital controls shouid be considered. Furthermore, cooperation with hospitals may facilitate sampling of controls via the same general practitioner who also referred the case. This will probably also increase response. 
Design, conduct and analysis

Table 3. Comparison of risk factors of breast cancer and food habits in responding and non-responding controls.

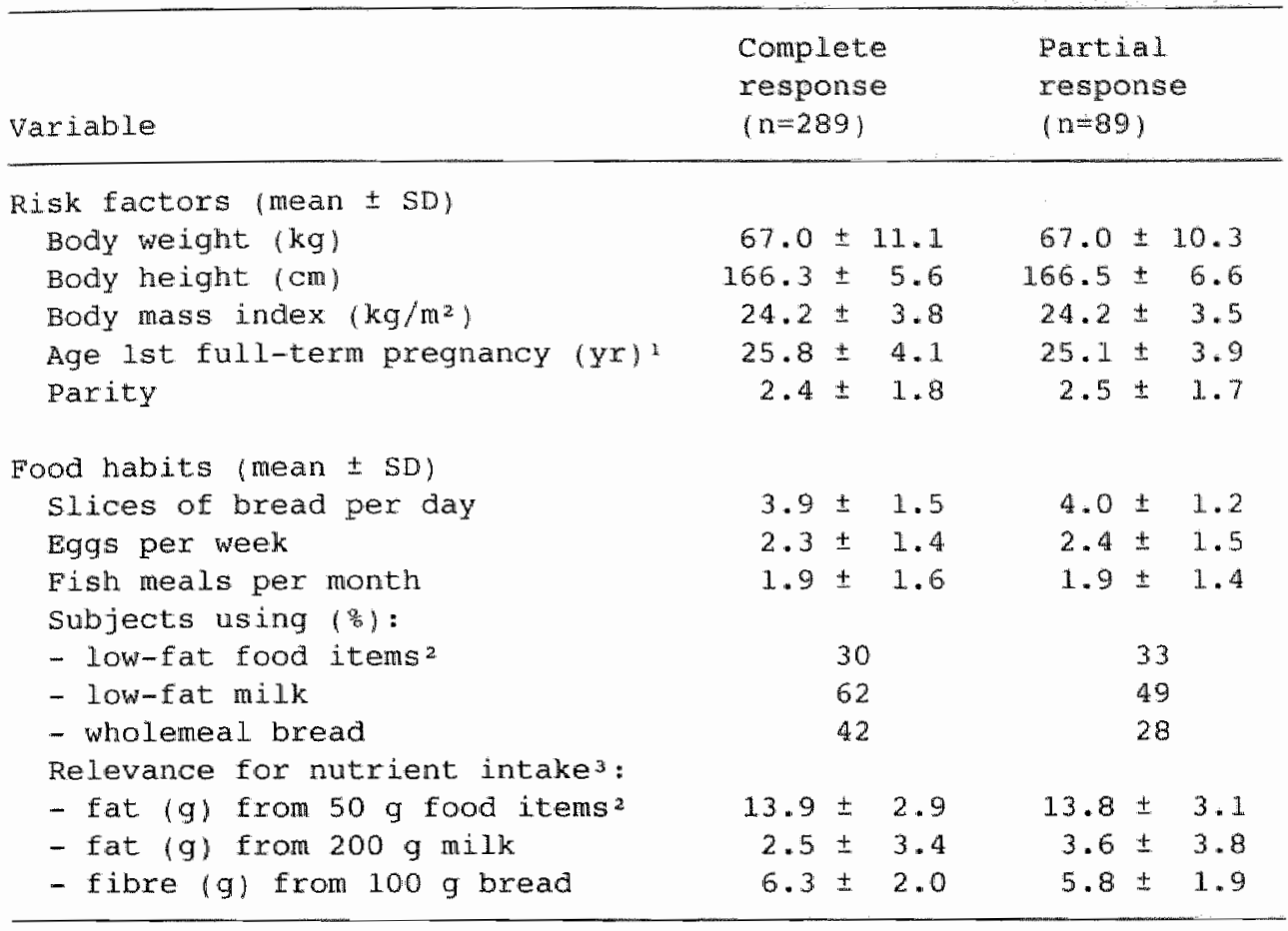

1 Mothers only.

2 Used with bread.

3 Calculated from data from fuld responders and partial responders and the nutrient content of foods.

\subsection{Analysig}

Before discussing the general strategy for data analysis and issues of particular importance for the diet-cancer association, some general issues concerning the interpretation and analysis of casecontrol studies are discussed.

The basic idea of the case-control design is that a factor with high (or low) prevalence (p) among cases, as compared to controls, might have contributed to the clinical accurrence of the disease. The resulting higher exposure odds $(p / 1-p)$ among cases, divided by the exposure odds arrong controls, yields the exposure odds ratio (23). This measure of association has several favourable characteristics, both from the epidemiological and the statistical point of view 
$(23,24)$. Using Bayes" formula, it can be shown that the exposure odds ratio (in cases as compared to controls) equals the disease odds ratio (in exposed as compared to non-exposed subjects) $(1,25)$. This identity provides a link to the rate ratio of alsease among exposed subjects as compared to non-exposed subjects, as can be estinated from a prospective cohort study $(1,3)$.

These conceptual developments have evolved along with biostatistics. Methods of data analysis range from simple comparison of proportions $(2,24)$, trend in proportions (2), adjustment for confounders by the Mantel-Haensze l. estimator (26), log-1inear (24) and logistic moded.l. ing (1). The logistic model essentially explains the disease odds by a linear function which includes the exposure of interest and potentially confounding covariables as explanatory variables. In practice, the method of data analysis depends on type and quality of the data collected, the object of the analysis, the assumptions to be made and study size. In the data analysis of this study, logistic regression analys is has been used extensively. This type of model is generally considered to be well suited for aetiological cancer research $(1,27)$.

\subsection{1 strategy}

First, descriptive data on the exposure of interest were provided, using means and standard deviations. This was done separately for exposure among cases and among controls, in both the younger (25-44 yr) and the older (55-64 yr) group. Exposure differences between cases and controls from these groups were generally similar, and age-adjusted differences were calculated by multiple regression analysis. Although this approach does not address the shape of the relation between exposure and disease, it yields a reasonable overall test for association.

Second, stratified analyses were conducted. In these analyses, odds ratios of breast cancer were calculated for categories of exposure of similar aize fquartiles or quintiles, based on data from controls), or for "logical" categories (e.9., glasses of alcohol or milk). Subsequently, these analyses were repeated for strata of age and potential confounders, including tests for statistical interaction.

Finally, logistic regression analysis was used to obtain estimates of multivariate adjusted odds ratios and their corresponding confidence limits. Since the odds ratios for the successive exposure categories are not independent of each other and based on small numbers, they tend to have wide confidence intervals. Therefore, a 
Design, conduct and aralyis

test for trend and/or an analysis using the original continuous exposure variable was generally conducted as well.

\section{3 .2 Confounding}

The control of confounding is one of the typical concerns in observational research. Confounding occurs when the observed relation between exposure and disease is influenced (i.e. biased) by one or more risk factors of disease associated with the exposure. Conditions under which confounding may occur, and methods to adjust for the resulting bias, are given in many epidemiological textbooks $(1-3,23,28,29)$. Conceptualiy, confounding originates from the absence of randomization of study subjects over categories of exposure (3), which is a fundamental difference with experimental research.

The simultaneous presence of energy as weld as nutrients in the foods ingested often leads to high associations between dietary variables. Therefore, when several dietary factors are potentially related to disease, it may be difficult to estimate their independent associations, or to identify the truly responsible factor. In contrast to this, other risk factors of breast cancer are less likely to be strongly associated with dietary habits, thereby a priori reducing the belief in their potential impact on the associations of interest.

\section{Confounding by energy intake}

In observational research, energy requirements and energy intake cannot be controlled in the design. Since energy intake may be related to breast cancer, this has several important implicationg for the analysis of the diet-breast cancer association. These relate to the balance between energy intake and requirementw, as well as to the generally positive association of energy intake with the intake of other nutrients. In the paragraphs below, these topics are discussed and the relevance to our study is indicated. Furthermore, the conceptual issues of analytical methods for energy adjustment are discussed.

First, a smal. but persistent positive net energy balance will lead to overweight, which may be related to breast cancer. Under this hypothesis, a slightly higher energy intake of cases might be expected (all other things being equal.), but small differences in energy intake are not likely to be detected by dietary methods referring to a recent and restricted period of time. In order to account for a long-term imbalance in energy intake and expenditure, adjustments for indicators of body composition can be made in data 
Design, conduct and analysis

analysig. In most of our analyses body mass index was taken into account but it appeared not to be essential to the results, sirce indicators of overweight were only weakly associated with breast cancer (Table 4 ).

Second, variation in energy intake between subjects depends on energy requirements as determined by body size (metabolic rate). physical activity, metabolic efficiency (e.g." nutrient absorption), and energy balance. In observational research, when subjects are, on average, in energy balance, vaxiations in physical activity are largely responsible for variation in energy intake (30). Therefore, energy requirement and intake must be considered fixed (unless subjects are to alter substantially their physical activity or weight), and the primary interest is not in energy intake itself, but rather in vaxiation in nutrient intake at a given level of energy intake. Therefore, energy-adjusted nutrient intake is considered more jnformative for making decisions about changes in the composition of the diet (31). Thus, in the analysis of our data, we adjusted either for energy intake or for fat intake (which was highly associated with energy intakel. The latter may even be the method of preference in the light of the fat-breast cancer hypothesis.

In the procedures for energy adjustment, the conceptual issues and analytical methods, though related, need to be distinguished.

Conceptually, when the interest is in dietary fat at a given intake of energy, variability in fat intake should be interpreted in terms of equicaloric substitution of fat by other energy sources (e.g., carbohydrates). Therefore, the fat-disease association should be interpreted in terms of fat as compared to other energy sources. For other dietary exposures, e.g., selenium or vitamins, the interpretation of energy-adjusted associations is more straightforward, since these exposures themselves do not contribute to energy intake. For instance, such factors could easily be added to the diet without necessarily interfering with energy intake.

In data analysis, energy intake can be taken into account by mutiple regression, or by expressing nutxient intake relative to energy intake (density method). Although the density method is widely used in experimental nutrition research (where energy intake is usually well controlled, it is not necessarily the method of preference in epidemiological research. This method may lead to spurious associations, especially for nutrients (or other substances) that are only weakly associated with energy intake. For instance, suppose that high energy intake is positively related to disease and that fibre intake is not. Then, when fibre density is used in the analysis, a spurious inverse relation may appear between this newly defined exposure and disease (32). Moreover, nutrient 
Design, conduct and analysis

densities may be still associated with total energy intake, which results in insufficient control for confounding.

In conclusion the above illustrates that the difficulties in interpreting the role of energy intake arise partially from its role as potential confounder, and partially from the concept of dietary composition (rather than total amount). Adjustment for energy intake by multiple regression analysis takes both issues into account, while the density method merely addresses the last issue.

\section{Confounding by risk factors of breast cancer}

Familial, reproductive and hormonal risk factors of breast cancer were considered as potential confounders. First, their association with breast cancer was studied by cross-tabulation, followed by agestratified analysis and estimation of odds ratios and standard errors by logistic regression analysis.

second, the dietary variables were screened for association with breast cancer risk factors by analysis of vaxiance, taking into account age as a covariate. No strong associations were found. Finally, the risk factors of breast cancer were added to the logistic regression model, already containing terms for the exposure of interest, age, (and energy, if applicable). In general, their separate addition did not substantially affect the odds ratios, but in some instances their simultaneous presence in the model revealed higher or lower odds ratios. The moderate effect of these confounders can be explained by their weak association both with breast cancer and with the dietary variables.

\subsubsection{Effect modification}

Effect modification is an important element in atelological research, either observational or experimental. Effect modification occurs when the measure of association (e.g. odus ratio, or rate difference) is not uniform in various strata of some other factor (effect modifier). In data analysis, effect modification (sometimes called biological interaction) is evaluated in terms of statistical interaction. In these statistical models, absence of interaction (the null hypothesis) depends on the type of model used, i.e. additive or multiplicative. Based on the sufficient cause/component cause model, Rothman (28) strongly favours additive models, whether or not biological interaction is considered. In cancer epidemiology. however, multiplicative models are widely used, both for empirical and logical reasons. For instance, these models provide an adequate description of both the temporal and geographical variation in agespecific cancer incidence, as well as the effects of cancer risk as 
a Eunction of time elapsed since exposure (e.g. to radiation) or duration of exposure (e.g. to smoking) (1). Moreover, in multiplicative models, strong associations are unikely to be explained by confounders, and provide information on the specificity of the association with a particulax disease entity (1), i.e. a particular sufficient cause (28). Binally, the multiplicative model relates directly to the biological ideas underlying the multistage model of carcinogenesis (see chapter 2). Thus, as Rothman (28) provides a conceptual franework for considering the nature of causality leading to additive models of disease occurrence, Breslow and Day $(1,27)$ provide data supporting the usefulness of multiplicative models when studying cancer aetiology. Despite these differences in modelling (and the underlying philosophy), both agree that the absolute magnitude of incidence rates are of inportance in assessing public health consequences, and that biological mechanisms should be considered when studying effect modification.

In the following, effect modification by dietary factors is approached from a biological point of wiew and subsequently related to the analyses conducted. Furthermore, the problems related to the limited study size and, probably equally important, lack of specific hypotheses on effect modification of dietary factors by other risk factors, are $\mathbf{1}$ lustrated in the final part of this chapter.

\section{Effect modification involving dietary factors}

The concept of effect modification can be approached both from the side of the disease process, and from the side of dietary habits.

Because of the reference period of the dietary interview in the present case-control study, the observed associations between diet and breast cancer are most likely to reflect biological mechanisms relevant to the later stages of carcinogenesis (promotion). In the context of the multistage model of carcinogenesis, additivity of the effects of two risk factors may be more likely to occur if they independently affect the same stage of the process, and multiplicativity may be more likely if two distinct stages are affected (27). It cannot be known a priori, however, whether two distinct dietary factors affect the same or different stages of the disease, or even the growth of already completely transformed stem celis. Without an a priori hypothesis, nowever, consideration of all possible combinations of dietary factors is likely to result in uninterpretable results and chance findings. Therefore, in data analygis, interaction assessment was limited to dietary factors that are likely to be involved in a similar biological mechanism. This is especially relevant to the summary analysis presented in chapter 9. 
Design, conduct and analysis

The assessment of effect modification can also be approached from the side of dietary habits. Conceptually, physiological effects of nutrients may depend on their simultaneous presence in foods or in. the gastrointestinal tract, affecting nutrient avalability and bacterial metabolism. Therefore, the biological consequences of the consumption of foods and meals may differ from the effects expected when the nutrients are ingested separately. Furthermore, it is not necessarily the average daily intake (i.e., frequency times dose) that is biologically important: frequency and amount of food may have different physiological effects. Thus, although calculation of nutrient intake (if available in the food composition tables) is important for the evaluation of specific hypotheses (e.g. energy, fat), it may fail to elicit important elements of the diet-cancer association, and it is not automatically the method of preference for further research in this area. These considerations provide the conceptual background of the analyses with respect to fermented millk products (Chapter 6), vegetable products (Chapter 7) and alcohol. consumption (Chapter 8 ).

\section{Effect modification involving risk factors of breast cancer}

When the study was designed, a comparison of odds ratios of breast cancer was intended for pre- and postmenopausal women, in particular. for measures of body composition. Because of the problems encountexed in the recruitment of study subjects, however, separate analysis of the pre- and postmenopausal age stratum would be hampered by lack of statistical power. Furthermore, comparison of various measures of body composition in the younger $(25-44 \mathrm{yr})$ and older (55-64 yr) age group did not suggest any important difference between both age categories (Table 4 ). Therefore this association has not been amalysed in detail.

In addition to body composition, age (or menopausal status) may be al modifier of the diet-breast cancer association. This possibility has been evaluated for the fat hypothesis (Table 5). Although point estimates of the odds ratio differ between both age categories, it appears that this can easily be due to sampling variability. Again, this illustrates the limited study power with respect to effect modification.

In theory, the association between diet and breast cancer may hold only for women who also have certain other characteristics, for example with respect to familial history, benign breast disease, or reproductive factors. Because of the limited study size and because many combinations of variables can be imagined, a priori selection of meaningful candidate effect modifiers is indicated. For instance, potential modification of the fat-breast cancer association by other 
Design, conduct and analysis

Table 4. Measures of body size and body composition of breast cancer cases and population controls, according to age category (group means).

\begin{tabular}{|c|c|c|c|c|}
\hline \multirow[b]{2}{*}{ Body size indicators } & \multicolumn{2}{|c|}{ women aged $25-44 \mathrm{yr}$} & \multicolumn{2}{|c|}{ Women aged $55-64 \mathrm{yx}$} \\
\hline & $\begin{array}{l}\text { Cases } \\
n=54\end{array}$ & $\begin{array}{l}\text { Conterols } \\
n=150\end{array}$ & $\begin{array}{l}\text { Cases } \\
n=79\end{array}$ & $\begin{array}{l}\text { Controls } \\
n=139\end{array}$ \\
\hline \multicolumn{5}{|l|}{ Measured characteristics } \\
\hline Weight (kg) & 66.7 & 65.5 & 69.7 & 70.3 \\
\hline Height (cm) & 167.1 & 166.2 & 162.2 & 163.6 \\
\hline Body mass index $\left(\mathrm{kg} / \mathrm{m}^{2}\right)$ & 24.0 & 23.7 & 26.5 & 25.2 \\
\hline Blceps skinfold (mm) & 15.2 & 14.7 & 17.1 & 17.0 \\
\hline Triceps skinfold (mm) & $25 \cdot 3$ & 25.5 & 27.6 & 27.6 \\
\hline Walst circumference (cm) & 80.3 & 80.3 & 89.2 & 88.2 \\
\hline Hip circumference (cm) & 99.2 & 98.11 & 100.8 & 101.1 \\
\hline Waist-hip ratio $(* 100)$ & 81.2 & 81.8 & 88.9 & 87.2 \\
\hline \multicolumn{5}{|c|}{$\begin{array}{l}\text { Self-reported characteristics } \\
\text { Prediagnostic or }\end{array}$} \\
\hline current weight (kg) & 65.9 & 64.4 & 68.7 & 69.9 \\
\hline \multicolumn{5}{|l|}{ Weight change $(\mathrm{kg})$} \\
\hline since diagnosis (kg) & 0.2 & - & -0.5 & - \\
\hline previous year $(\mathrm{kg})$ & $-1 \cdot 3$ & 0.1 & -0.2 & -0.3 \\
\hline \multicolumn{5}{|l|}{ Clothing size (Dutch units) } \\
\hline blouses & 40.8 & 40.4 & 43.3 & 43.2 \\
\hline skirts & 41.2 & 40.6 & 43.6 & 43.4 \\
\hline
\end{tabular}

risk tactors of breast cancer was investigated by simple stratified analyses, followed by logistic regression analysis (Table 5). The results indicate that potentially relevant differences in the odds ratio for fat ie.g. 1.7 and 1.2 for positive and negative history of benign breast disease respectively), can be ascribed to chance. Therefore, such detailed analyses of effect modification in this limited data set must be considered explorative data analysis, secondary to the main study objectives. Because of this, effect modification by other risk factors of breast cancer has not been studied for the other dietary factors of interest. 
Design, conduct and analysis

Table 5. Association between fat intake and breast cancer for different levels of selected risk factors.

\begin{tabular}{|c|c|c|c|c|}
\hline \multirow[b]{2}{*}{ Risk factor } & \multicolumn{2}{|c|}{ Age adjusted } & \multicolumn{2}{|c|}{ Multivariate } \\
\hline & $\begin{array}{l}\text { Odds } \\
\text { Ratio }\end{array}$ & $\begin{array}{l}L^{2} \\
(\mathrm{P}-\mathrm{value})\end{array}$ & $\begin{array}{l}\text { Odds } \\
\text { Ratio }\end{array}$ & $\begin{array}{l}\text { LR } \\
(p-v a l u e)\end{array}$ \\
\hline \multicolumn{5}{|l|}{ Menopausal status } \\
\hline Premenopausal & 1.19 & 0.34 & 1.14 & 2.10 \\
\hline Postmenopausal & 1.30 & $(0.56)$ & 1.47 & $(0.15)$ \\
\hline \multicolumn{5}{|l|}{ Familial history } \\
\hline Negative & 1.22 & 0.01 & 1.30 & 0.01 \\
\hline Positive & 1.24 & $(0.94)$ & 1.28 & $(0.93)$ \\
\hline \multirow{2}{*}{\multicolumn{5}{|c|}{$\begin{array}{l}\text { History of Benign } \\
\text { Breast Disease }\end{array}$}} \\
\hline & & & & \\
\hline Negative & 1.19 & 1.36 & 1.21 & 2.64 \\
\hline Positive & 1.47 & $(0.24)$ & 1.74 & $(0.10)$ \\
\hline \multicolumn{5}{|c|}{ Age at menarche (yr) } \\
\hline$\leq 12$ & 1.28 & & 1.29 & \\
\hline $13-14$ & 1.29 & 0.00 & 1.32 & 0.03 \\
\hline$\geq 15$ & 1.27 & $(1.00)$ & 1.27 & $(0.99)$ \\
\hline \multicolumn{5}{|c|}{$\begin{array}{l}\text { Age at first full- } \\
\text { term pregnancy }(\mathrm{yr})\end{array}$} \\
\hline Nu1liparous & 1.74 & & 1.86 & \\
\hline $18-23$ & 1.02 & & 1.03 & \\
\hline $24-26$ & 1.36 & & 1.42 & \\
\hline $27-28$ & 1.08 & 6.20 & 1.02 & 9.99 \\
\hline$\geq 29$ & 1.55 & $(0.18)$ & 1.97 & $(0.04)$ \\
\hline \multicolumn{5}{|l|}{ Parity } \\
\hline Nulliparous & 1.83 & & 2.01 & \\
\hline 1 & 1.23 & & 1.23 & \\
\hline 2 & 1.40 & 7.32 & 1.41 & 6.06 \\
\hline$\geq 3$ & 0.92 & $(0.06)$ & 1.00 & $(0.11)$ \\
\hline \multicolumn{5}{|c|}{ Body mass index $\left(\mathrm{kg} / \mathrm{m}^{2}\right)$} \\
\hline$\leq 22$ & 1.49 & & 1.46 & \\
\hline $23-24$ & 1.25 & 1.70 & 1.23 & 0.68 \\
\hline$\geq 25$ & 1.16 & $(0.43)$ & 1.25 & $(0.71)$ \\
\hline
\end{tabular}

1 Adjusted for (first- and second-degree) familial history, history of benign breast disease, educational level, employment status, age at menarche, age at first full-term pregnancy, parity, ever use of oral contraceptives, smoking habits, body mass index, current alcohol intake.

2 Likelihood Ratio statistic, testing absence of statistical interaction in logistic model.

3 Odds ratio per $24 \mathrm{~g}$ of fat $(=10$ percent of energy). 
Design, conduct and analysis

References

1 Breslow WE, Day NE. Statistical methods in cancer research. vol 1. The analysis of case-control studies. TARC Sci Publ no 32. IARC, Lyon, 1980 .

2 Schlesselman JJ. Case-control studies. Design, conduct, analysis. oxford unit press, Oxford, 1982.

3 Miettinen os. Theoretical epidemiology. Principles of occurrence research in medicine. John Willey G Sons, New York, 1985.

4 Cancer Incidence in the Netherlands. South eastern part 19781982. Comprehensive Cancer centre south, sooz-cancer registration. Eindhoven, 1985.

5. Muir C, Waterhouse J, Mack $\mathbb{T}$, Powell J, Whelan $S$. Cancer incidence in five continents. Vol $V$. International Agency for Research on Cancer, Lyon, 1987.

6. Wu ML, whittemore AS, Jung DL. Errors in reported dietary intakes I. Short-term recall. Ann J Epidemiol 1986;124:826-35.

7 Bausch-Goldbohm RA, Van den Brandt $P A$, Van 't Veer $P$, Sturmans $F$, Hermus RJJ. Results of the methodological study for the design of a simplified, self-administered questionnaire. In: Riboli E, Saracci R (eds). Diet, homones and cancer: methodological issues for prospective studies. IARC Technical Report 4, IARC, Lyon, $1988,201-14$.

8 Mauritz $B J$, Van 't Veer P. [Selenium, fat and breast cancer in pre- and postmenopausal women: a case-control study with emphasis on dietary factors (in Dutch) l. Progress report no 5, part 1: Development of questionnaires. CIVO-TNO report no V85.279A, Zeist, 1985 .

9 Mauritz BJ, van 't Veer. [Selenium, fat and breast cancer in preand postmenopausal women: a case-control study with emphasis on nutritional factors. progress report no. 5 , part 2: questionnaire on dietary habits and life-style. (in Dutch)] TNO-cIvo report no. v85.279k, zeist, 1985 .

10 Burke BS. The dietary history as a tool in research. I Am Diet Assoc $1947 ; 23: 1041-6$.

11. Cameron ME, Van staveren WA. Manual on methodology for food consumption studies. Oxford Univ Press, Oxford, 1988.

12 Hulshof KFAM. Spoorzoeken in voedingsmiddelen. Voeding 1985;46: $227-32$.

13 Ministerie van Welzijn, volkgezondheid en Cultuur, Ministerie van Landbow en visserij. Wat eet Nederland. Resultaten van de voedselconsumptiepeiling 1987-1988. Rijswijk, 1988 .

14 Robinson MF, Thomson $C D$. The role of selenium in the diet. Nutr Abstr Rev Clin-Series A $1983 ; 53: 3-26$.

15 Riboli E, Rönnholm H, Saracci R. Biological maxkers of diet. Cancer surveys $1987 ; 6: 685-718$. 
Design, conduct and analysis

16 Hebert JR, Miller DR. Methodologic considerations for investigating the diet-Cancer link. An J Clin Nutr 1988;47:1068-77.

17 Levander $O A$. Considerations on the assessment of seleniun status. Fed Proc 1985;44:2579-83.

18 Willett WC. Nutritional epidemiology: Issues and challenges. Int J Epidemiol $1987 ; 16: 312-7$.

19 Burke RF. Selenium and cancer: Meaning of serum selenium levels. J Nutr $1986 ; 116: 1584-6$.

20 Morris Js, stampfer MJ, Willett WC. Dietary selenium in humans. Toenails as an indicator. Biol Trace Elem Res 1983;5:529-37.

21 Paglia DE, Valentine WN. Studies on the quantitative and qualitative characterization of erythrocyte glutathione peroxidase. I Lab Clin Med 1967;70:158-69.

22 Haffmans TPF, Frijters DHM (eds). Verslag opbouw Landelijk Kanker Registratie 1986. LoK, Landelijk overlegorgaan Kankexcentra, Leiderdorp, 1989 .

23 Kleinbaum DG, Kupper LL, Morgenstern H. Epidemiologic Research. principles and quantitative methods. Lifetime Learning public, Belmont CA, 1982 .

24 Fienberg SE. The analysis of cross-classified categorical data. MIT Press, Cambridge, 1981.

25 Weinstein MC, Fineberg HV. Clinical decision analysis. WB Saunders Company, Philadelphia, 1980.

26 Mantel N, Haenszel W. Statistical aspects of the analysis of data from retrospective studies of disease. I Matl Cancer Inst $1959 ; 22: 719-48$.

27 Breslow NE, Day NE. Statistical methods in cancer research. Val II. The design and analysis of cohort studies. IARC Sci Publ no 82. IARC, Lyon, 1987.

28 Rothman KJ. Modern epidemiology. Little, Brown and co, Boston, 1986.

29 Hennekens $\mathrm{CH}$, Buring JE, Mayrent sL. Epidemiology in medicine. Little, Brown and Co., Boston, 1987.

30 Willett WC. Implications of total energy intake for epidemiologio studies of breast and large-bowel cancer. Am J Clin Nutr 1987 ; $45: 354-60$.

31 Willett WC. The search for the causes of breast and colon cancer. Nature $1989 ; 338: 389-94$.

32 Willett WC, Stampfer MJ. Total energy intake implications for epidemiologic analysis. Am J Epidemiol 1986;124:17-27. 

DIETARY EAT AND THE RISK OF BREAST CANCER'

Pieter van "t Veer, Frans J Kok, Henny AM Brants, Theo Ockhuizen, Ferd Sturmans, Rudolph JI Hermus.

\section{Abstract}

Age-adjusted dietary fat intake of 133 incident Dutch breast cancer cases was significantly $(p<0.01)$ higher than in 289 apparently healthy controls (mean and standard deviation: $102 \pm 36 \mathrm{~g}$ and $92 \pm 30 \mathrm{~g}$, respectively). The age-adjusted relative odds of breast cancer showed a positive trend $(p<0.05)$ with increasing fat intake. The multivariate adjusted relative odds was 3.5 $(95 \%$ confidence interval $=1.6-7.6)$ for subjects in the highest quintile of fat intake (above $113 \mathrm{~g}$ ) compared to those in the lowest quintile (below $65 \mathrm{gl}$; this corresponds to a 30 increased $\mathrm{risk}$ per $10 \%$ of energy derived from fat. The association could not be attributed energy intake, nor to the degree of saturation of the fat nor to any specific dietary source of fat.

\section{Introduction}

The impact of diet on breast cancer prevention may be of great importance (1), especially in Western countries, where the incidence is high and stage-specific survival does not improve $(2)$. Crosssectional data (3) and anlimal experiments point at either energy or fat intake as risk factors (4-6). The role of energy intake also hampers the interpretation of epidemiological studies $(7-9)$. Casecontral and cohort studies generally have falled to contribute convincing evidence with regard to the fat hypothesis, because their interpretation was hindered by methodological problems in dietary assessment or selection of the control group (10). In the Netherlands, known for both a high breast cancer indidence (11) and mortality, as well as a high per capita fat intake (12), we conducted a case-control study on dietary fat intake and breast cancer and applied an extensively standardized and reproducible dietary history technique for the assessment of usual fat intake.

I International Journal of Epidemiology 1990 (in press). 
Subjects and methods

\section{Study population}

The study was conducted in 1985-1987 among Dutch Caucasian women aged 25-44 and 55-64 years, residing in a defined region of the Netherlands. A total of 168 newly diagnosed breast cancer cases from 17 hospitals in the study region were enrolled in the study, either by cooperating surgeons or by regional cancer registries. The diagnosis was histologically confirmed in $96 \%$ of the cases. 134 (808) eligible cases agreed to participate in the study. An agestratified sample of controls (548 women) was obtained from the municipal population registry in the same area as the hospitals; After exclusion of 19 subjects who did not fulfil the eligibility oriteria $(n=8)$, or who covld not be traced $(n=11)$, a total of 289 155\% eligible control subjects participated, with age distribution and period of investigation similar to the case series. In order to evaluate representativeness of the control group, the entire control sample was asked to complete a condensed postal questionnaire. This questionnaire was returned by virtually all responders and by 89 (37\%) of the non-responding controls. No major differences were detected between responders and non-responders with regard to age, age at first ful1-term pregnancy, parity, weight, height and body mass index. With respect to food consumption, no differences were observed between responders and non-responders in daily intake of fat containing foods (fat-content of milk products; meat products and cheese vis sweet food items on bread), bread, eggs, and fish. Responders, however, tended to use whole-meal bxead more frequently than non-responders.

\section{Data collection}

Cases were interviewed within one year after diagnosis $191 \%$ within 6 months\}, but not during periods of chemotherapy. The data obtained in the interview referred to the year preceding diagnosis (for cases) or interview date (controls). The interviews were carried out by two well-trained, registered dietitians in a twa-hour home visit. The questionnaire inquired after dietary, drinking and smoking habits; sability of food habits; demographic and socio-economic characteristics; reproductive history and prior breast diseases; oral contraceptive and other hormone use; (prediagnostic) weight. Finally, anthropometrical measurements were obtained; in order to address additional hypotheses, toenail clippings were collected and a blood sample was drawn (for cases before surgery). To assess the reproducibility of the answers, the interview was repeated in a 
subsample of 39 control subjects, one year after the first interview.

\section{Dietary questionnaire}

To obtain data on average daily food and nutrient intake, a dietary history interview was conducted covering the complete dietary pattern in the twelve-month period prior to diagnosis or interview date. To minimize effects of between-interviewer variability and to maintain comparability of information from cases and controls, the dietary history was highly structured. The questionaice comprised 236 separate food items, covering the (traditional) hot meal, its preparation, breakfast and lunch, fats used, snacks and drinks, and supplements. Another 32 items were added to take account of apecial foods used. In order to ensure internal consistency of the reported pattern, and to take account of exceptions to this pattern, checks were included in the questionnaire. For each food item in the questionnaire, frequency (number of times per week) and amount were quantified. The content of the most frequently used household utensils (spoons, cups, glasses, dishes) was measured to obtain a more accurate quantification of the portion sizes.

Average daily energy and nutrient intake was calculated using the standardized Dutch Uniform Encoding System (13) and the 1984 release of the computerized Dutch Nutrient Data Bank (14). Fat intake from the following five food groups was calculated separately: meat and meat products; milk and dairy products; oils and fats; cake, biscuits and snacks; miscellaneous. Because items on the use of sugar in coffee, tea and desserts, and soft drinks were included a few months after the start of the study, fat intake as a percentage of energy could not be calculated for 51 control subjects. For one case, the dietary history interview was judged unreliable and data were excluded from the analysis.

\section{Validity and reproducibility of the questionnaire}

Although validation of the structured dietary history by means of independent assessment of dietary intake or biochemical parameters was not carried out, the following three essential components of validity were evaluated: completeness of assessment of fat intake, reproducibility of the method and stability of food habits.

In a previously gathered data set comprising 73 women aged 55-69 years, interviewed using an extensive dietary history containing over 950 food items, average daily fat intake was calculated for all subjects (15). A number of 236 food items were selected for inclusion in the structured dietary history used in this case-control 
study. Intake of energy, total dietary fat, saturated, monounsaturated and polyunsaturated fatty acids for these 236 items differed legs than $2 \%$ from the intake of these nutrients calculated by using the total number of items. Furthermore, the Pearson correlation coefficient exceeded 0.95 for energy and total fat well as for saturated, monounsaturated and polyunsaturated fatty acids. These data suggest that the items in our structured dietary history covex individual fat intake adequately.

Reproducibility of the questionnaire was assessed by repeated measurement one year after the first interview. In a subsample of 39 controls, average daily intake of fats differed by less than 28 between these subsequent years of reference. The Pearson correlation coefficient, affected by both measurement error and true changes in food habits, was 0.71 for energy intake, 0.64 for daily fat intake, and $0.65,0.64$ and 0.55 for saturated, monounsaturated and polyunsaturated fatty acids, respectively.

To investigate whether food habits of cases and controls remained constant during the past five years, changes in the use of fat from seven food groups were assessed: table fats; other fats and oils; meat; meat products; cheese; other dairy products; fish. For these food groups, the majority of the subjects (75\% for most food groups) reported no change in the amount consumed, whereas almost the total group (95:) reported no change towards products with a higher or lower fat content.

\section{Data analysis}

Using loglinear analysis (16) crude and age-adjusted relative adds of breast cancer were calculated for levels of (potential) risk factors; likelihood ratio statistics resulting from these models were used for statistical testing (Table 1). Average daily intake of energy and fat (total, and saturated, monounsaturated and polyunsaturated fatty acids) was compared between cases and controls, separately for those aged 25-44 years (98: being premenopausal) and for those aged 55-64 yxs (97\% being postmenopausal): the casecontrol differences were similax in both age groups. To adjust fat intake for age, regression analyses were carried out for cases and controls separately. The age-adjusted case-control difference in fat intake was estimated from a regression analysis including both cases and controls. In this analysis age was specified in four groups (25$39,40-44,55-59$ and 60-64 years old) using three dummy variables (Table 2). Similar analyses were carried out for fat intake from five major food groups. Because of several skewed distributions, these analyses were repeated with log transformations, which yielded essentially similar results. In the logistic regression models fat intake was included either as a continuous variable or in quintiles. 
Dietary fat

Table 1. Age-adjusted odds ratio (OR) of breast cancer for major risk factors in a case-control study in the Netherlands, $1985-1987$.

\begin{tabular}{|c|c|c|c|c|c|}
\hline \multirow[b]{2}{*}{ Risk factor } & \multirow[b]{2}{*}{ Level } & \multicolumn{2}{|c|}{ Number of } & \multicolumn{2}{|c|}{ Age-adjusted } \\
\hline & & Cases & controls & OR & P-value \\
\hline \multirow{2}{*}{$\begin{array}{l}\text { First degree } \\
\text { familial history }\end{array}$} & Negative & 117 & 269 & 1.0 & \\
\hline & Positive & 16 & 20 & 1.6 & 0.17 \\
\hline \multirow{2}{*}{$\begin{array}{l}\text { Second degree } \\
\text { famillal history }\end{array}$} & Negative & 105 & 252 & 1.0 & \\
\hline & Positive & 28 & 37 & 1.7 & 0.05 \\
\hline \multirow{3}{*}{$\begin{array}{l}\text { Age at } \\
\text { menarche }(y x)\end{array}$} & $<12$ & 44 & 75 & 1.0 & \\
\hline & $13-14$ & 63 & 145 & 0.8 & \\
\hline & $\geq 15$ & 22 & 60 & 0.6 & 0.27 \\
\hline \multirow{5}{*}{$\begin{array}{l}\text { Age at first full- } \\
\text { term pregnancy (yr) }\end{array}$} & Nu11iparous & 19 & 43 & 1.0 & \\
\hline & $18-23$ & 36 & 85 & 1.0 & \\
\hline & $24-26$ & 33 & 72 & 1.1 & \\
\hline & $27-28$ & 23 & 44 & 1.1 & \\
\hline & $\geq 29$ & 22 & 45 & 1.0 & 1.00 \\
\hline \multirow[t]{4}{*}{ Number of births } & 0 & 19 & 43 & 1.0 & \\
\hline & 1 & 21 & 32 & 1.5 & \\
\hline & 2 & 57 & 104 & 1.4 & \\
\hline & $\geq 3$ & 36 & 110 & 0.6 & 0.01 \\
\hline \multirow{3}{*}{$\begin{array}{l}\text { Current smoking } \\
\text { (cigarettes/day) }\end{array}$} & No & 87 & 196 & 1.0 & \\
\hline & $1-11$ & 18 & 39 & 1.1 & \\
\hline & $\geq 12$ & 28 & 53 & 1.4 & 0.44 \\
\hline \multirow[t]{3}{*}{ Level of education } & Low & 72 & 160 & 1.0 & \\
\hline & Medium & 47 & 93 & 1.2 & \\
\hline & High & 14 & 35 & 1.0 & 0.67 \\
\hline \multirow[t]{2}{*}{ Employment status } & Unemployed & 95 & 182 & 1.0 & \\
\hline & Employed & 38 & 107 & 0.8 & 0.32 \\
\hline \multirow{2}{*}{$\begin{array}{l}\text { Use of oral contra- } \\
\text { ceptives }\end{array}$} & Never & 70 & 138 & 1.0 & \\
\hline & Ever & 63 & 151 & 1.1 & 0.81 \\
\hline \multirow{2}{*}{$\begin{array}{l}\text { History of benign } \\
\text { breast disease }\end{array}$} & Negative & 106 & 232 & 1.0 & \\
\hline & Positive & 27 & 56 & 1.1 & $0.66^{\circ}$ \\
\hline Body mass index & $<22$ & 38 & 100 & 1.0 & \\
\hline \multirow[t]{2}{*}{$\left(\mathrm{kg} / \mathrm{m}^{2}\right)$} & $23-24$ & 29 & 62 & 1.2 & \\
\hline & $\geq 25$ & 65 & 1.27 & 1.2 & 0.77 \\
\hline
\end{tabular}




\section{Ditetary fat}

Confounding was evaluated by means of logistic regression analyses, in which fat intake was specified as a continuovs variable. The potential confounding effect of the following factors was considered: history of benign breast disease, first-and seconddegree familal history, smoking habits, educational level, employment status, history of use of oxal contraceptives, age at menarche, age at first full-term pregnancy, parity, body mass index, intake of alcohol. None of these factors substantially influenced the estimate of the relative odds by more than $5 \%$ when they were introduced in the model either separately or simultaneously. Adjustment for energy intake was carried out in three different ways: by specification of fat intake as a percentage of energy; by logistic regresion analysis including terms for both energy and fat; and by the residual method recently proposed by willett and stampfer (17). In these analyses, 51 control subjects with incomplete data on energy intake were excluded. Effect modification of the fat-breast cancer association by majox risk factors was addressed by introducing interaction terms in the age-adjusted model with fat specified as a continous variable. Taking into account the size of the study and the number of associations considered, no relevant effect modifiers were identified. Assuming that the association between fat and breast cancer for women aged 45-54 years would be similax to the association for younger (25-44 years) and older (55-64 years) women, we used the logistic regression model to estimate the potential public health impact of a reduction of fat intake by $25 \%$ (e.g., from 92 to $69 \mathrm{~g} \mathrm{daily,} \mathrm{or} 10 \%$ of energy).

\section{Results}

The age-adjusted relative odds of breast cancer for several $x i s k$ factors is shown in Table 1. An increased relative odds was observed among women with first-and second-degree familial history of breast cancer. A late age at menarche was associated with reduced risk. Age at first full-term pregnancy was not related to disease, but, among parous women, number of children was associated with decreased risk. The other risk factors showed only weak associations with breast cancer risk.

Average age-adjusted daily intake of energy, fat, type of fat and source of fat are presented in Table 2 . The age-adjusted casecontrol difference in average daily fat intake ( $10 \mathrm{~g}$ ) was reflected in each of the three types of fatty acids (saturated 49 , monounsaturated $4 \mathrm{~g}$ and polyunsaturated $1 \mathrm{~g})$. These case-control differences resulted from fat from meat and meat products (3 g), from table fats, cooking fats and oils $(3 \mathrm{~g})$, as well as from fat from cakes, biscuits and snacks ( $3 \mathrm{~g})$. 
Table 2. Age-adjusted daily energy and fat intake of breast cancer cases and their population controls in a case-control study in the Netherlands, 1985-1987.

\begin{tabular}{|c|c|c|c|c|c|}
\hline \multirow{3}{*}{$\begin{array}{l}\text { Daily intake of } \\
\text { (mean } \pm \text { standard } \\
\text { deviation }) \\
\text { Energy }(\mathrm{kcal})^{2}\end{array}$} & Cases & Controls & \multicolumn{3}{|c|}{$\begin{array}{l}\text { Age-adjusted } \\
\text { difference }\end{array}$} \\
\hline & $(n=133)$ & $(n=289)$ & Mean & $95 \%$ & $\mathrm{CII}$ \\
\hline & $2225 \pm 587$ & $2102 \pm 499$ & 126 & 13 & 240) \\
\hline Total fat $(9)$ & $1.02 \pm 36$ & $92 \pm 30$ & 10 & 13 & 16) \\
\hline \multicolumn{6}{|l|}{ Type of fatty acids (g) } \\
\hline saturated & $45 \pm 16$ & $41 \pm 14$ & 4 & 11 & 7) \\
\hline mono unsatuxated & $39 \pm 14$ & $35 \pm 11$ & 4 & 1 & 7) \\
\hline poly unsaturated. & $16 \pm 8$ & $15 \pm 7$ & 1 & 10 & 3) \\
\hline \multicolumn{6}{|l|}{ Source of fat (g) } \\
\hline meat and meat products & $21 \pm 12$ & $18 \pm 9$ & 3 & $(1$, & 5) \\
\hline $\begin{array}{l}\text { milk products and cheese } \\
\text { cooking oil and fats, }\end{array}$ & $22 \pm 12$ & $22 \pm 11$ & 0 & $1-2$ & 3) \\
\hline shortening, butter etc. & $31 \pm 21$ & $28 \pm 17$ & 3 & 10 & 7) \\
\hline cakes, biscuits, snacks & $13 \pm 9$ & $10 \pm 8$ & 3 & 1 & 5) \\
\hline miscellaneous & $14 \pm$ & $14 \pm$ & 0 & $(-1$, & 1.) \\
\hline
\end{tabular}

$195 \%$ confidence interval.

2238 controls had complete data on energy intake.

The crude relative odds of breast cancer for subjects in the highest quintile of fat intake $(\geq 114 \mathrm{~g} ; 45 \%$ of energy intake) as compared to the lowest quintile ( 5649 ; 328 of energy intake) was 2.67 and increased - albeit irregularly - from the lowest to the highest quintile. Adjustment for age, followed by multivariate analysis, increased the strength of the dose-response relation. The relative odds increased to 3.54 after adjustment for age and other major ris.k. factors of breast cancer. When fat intake was entered as a continuous variable in the multivariate model, the relative adds expressed per $24 \mathrm{~g}$ fat (10\% of energy intake) was 1.30 195\% confidence interval $C I=1.10-1.54)$. When an interaction-term between fat and menopausal status was considered in the logistic model, the age-adjusted relative odds per $24 \mathrm{~g}$ fat was essentially similar in premenopausal women (relative odds $=1.2$ ) and postmenopausal women (relative odds $=1.3$ ); in the multivariate model the corresponding figures were 1.1 and 1.5 respectively. These relative odds, however, were not significantly different, neither in the ageadjusted model $(p=0.56)$, nor in the multivariate model $(p=0.15)$. 
since total fat intake is highly associated with energy intake (Pearson coefficlent of correlation $=0.89$ in controls), the observed association could be confounded by energy intake. The relative odds of breast cancer, adjusted for energy intake and age was 1.54 per $24 \mathrm{~g}$ fat $(95 \mathrm{~g} \mathrm{CI}=1.06-2.22)$, irrespective of whether adjustment for energy intake was carried out by logistic regression analysis or by the residual method. When adjustment for energy intake was carried out by dividing fat energy by total energy (density method), however, the relative odds pex 10\% of energy from fat was lightly higher $(1.62 ; 95$ \% $C I=1.14-2.30)$; it decreased to 1.50 when energy was also included in the analysis, which points at residual confounding by energy when the density method is used. These results remained essentially similar when the other risk factors were also included in the model.

Table 3. Crude and adjusted relative odds of breast cancer for quintiles of fat intake in a case-control study in the Netherlands, 1985-1987.

\begin{tabular}{|c|c|c|c|c|c|c|}
\hline \multirow{2}{*}{$\begin{array}{l}\text { Quintile } \\
\text { (g fat) } \\
564^{2}\end{array}$} & \multicolumn{2}{|c|}{$\begin{array}{c}\text { Number of } \\
\text { cases controls }\end{array}$} & \multicolumn{4}{|c|}{$\begin{array}{l}\text { Relative odds of breast cancer } \\
\text { crude age- } \\
\text { adjusted } \\
(95 \% \mathrm{CI})^{2}\end{array}$} \\
\hline & 15 & 57 & 1.00 & 1.00 & 1.00 & \\
\hline $65-81$ & 31 & 57 & 2.07 & 1.52 & 2.00 & $(0.91-4.38)$ \\
\hline $182-97$ & 26 & 59 & 1.67 & 1.60 & 2.32 & $(1.05-5.16)$ \\
\hline $98-113$ & 21 & 59 & 1.35 & 1.32 & 2.29 & $(1.00-5.29)$ \\
\hline$\geqq 114$ & 40 & 57 & 2.67 & 2.60 & 3.54 & $(1.64-7.64)$ \\
\hline total & 133 & 289 & & & & \\
\hline OR per 24 & 9 tota & 1 fat $^{3}$ & 1.25 & 1.25 & 1.30 & $(1.10-1.54)$ \\
\hline$x^{2}$ for $t x$ & end * & & 3.22 & 5.65 & 9.53 & \\
\hline$(p-v a)$ & & & $(0.07)$ & $(0.02)$ & $(<0.01)$ & \\
\hline
\end{tabular}

1 Adjusted for first-and second-degree familial history, history of benign breast disease, educational level, employment status, age at menarche, age at first ful1-term pregnancy, parity, ever use of oral contraceptives, smoking habits, body mass index, current alcohol intake (CI $=95 \%$ confidence interval ).

2 Reference category for quintile analysis.

3 odds ratio (OR) corresponding to $10 \%$ of energy intake.

* Based on likelihoodratio statistic, quintiles scored 1-5. 
Total fat intake was strongly associated with the intake of each of the types of fat. In the highest and lowest quintlle of average daily fat consumption the intake of saturated fatty acids was 61 and $24 \mathrm{~g}$ respectively; the intake of monounsaturated and polyunsaturated fatty acids in these quintiles was 52 and 20 , and 22 and 89 , respectively. As a consequence, each type of fat was positively associated with breast cancer as well. In order to remove the association between total fat and type of fat, the latter was expressed as a percentage of tatal fat: this also removed the association between each of the types of fat and breast cancer. Thus, substitution of a particular type of fat by the other types did not affect the relative odds of breast cancer.

When fat intake from each of the five food groups distinguished in Table 2 was entered into the age-adjusted logistic model (all five groups simultaneously), fat from meat and meat products (relative odds per $24 \mathrm{~g}$ fat $=1.76 ; 95 \% \mathrm{CI}=1.04-2.96$ ) and fat from cakes, biscuits and snacks (relative odds per $24 \mathrm{~g}$ fat $=2.48$; $95 \%$ $C I=1.34-4.59$ ) appeared to be strongest associated with breast cancer risk. However, comparison of this model with a simple age-adjusted model including total fat intake as a single variable (adds ratio per $24 \mathrm{~g}$ fat $=1.25$; see $\mathrm{Table} 3$ ), indicated that the different point-estimates of the relative odds for these particular food groups may result from chance variation around the overall fatbreast cancer association (likelihood ratio statistic $\chi_{4}^{2}=8.79$; $\mathrm{p}=0.07)$.

\section{Discussion}

We abserved a positive association between average daily fat intake and the risk of breast cancer. This association was due to total fat intake, rather than to energy intake, or to any specific type or source of fat. Previous case-control and cohort studies have not convincingly demonstrated a fat-breast cancer association. In most of these studies, standardized, short-cut methods of food consumption were applied, not allowing calculation of total average dajly fat intake. Miller et al. (18) applied several interviewing techniques, provided some evidence of their validity (19), and observed a slightly positive, but non-significant association. willett et al. (20) applied a short-cut, validated (21), written food frequency questionnaire, and observed no association between fat intake and breast cancer incidence in a study of 601 breast cancer cases in a cohort of 89,538 us nurses. If fat intake is truly associated with breast cancer risk, this negative finding may be attributed to random misclassification of fat intake, resulting from both imperfect measurement at the start of the study and changes in 
food habit during the follow-up period. We provided data suggesting that our method covers fat intake adequately, in a time-integrated and reproducible manner. Moreover, as compared to a classical Burke"s dietary history ith cross-check (22), our structured method standardizes the interviewing of cases and controls and may therefore leave less room for between-interviewer bias. Furthermore, it is not vexy likely that a general overreporting of food consumption by cases can explain the observed association, because adjustment for energy did not remove the association. Because there was no indication that the relative odds of breast cancer increased or decreased with increasing time-lag between diagnosis and interview date, recall bias is unlikely to explain the results. Elnally, we do not expect that serious biases have resulted from subject selection: the relative odds did not vary significantly with degree of cooperation of surgeons in geographical regions, and among control subjects no substantial differences were observed between responders and non-responders with regard to indicators of nutritional status or dietary habits.

Although statistical variability and unknown biases may partially account for the apparent inconsistencies between observational. studies, explanations may also be found in population characteristics and differences in potential dietary confounders. Meat consumption, used as an indicator of total fat intake, was positively associated with breast cancer risk in case-contral studies $(23,24)$ as well as in a prospective study in Japan (25), although no clear association was observed among seventh Day Adventists $(26,27)$. In our data, fat from meat and meat products was positively associated with both total fat intake and $x$ isk of breast cancer. With regard to the frequency of use of dairy products, a positive association with breast cancer risk was reported in an Italian population (28), but not in Seventh Day Adventists (26,27); cheese was positively associated in a French (29) "but not in a Canadian (23) case-control study; dairy products (except milk) were positively associated with breast cancer risk in a case-control study (26), but not in a prospective study (27) among seventh Day Adventists; for yogurt, on the other hand, a protective effect was suggested (29). In the Netherlands, per capita consumption of dairy products is high as compared to most other countries (30), while there is substantial heterogeneity in type and amount of dairy products used. Although dairy constituents or their possible effects on faecal flora may influence breast cancer risk (31), our results suggest that this is probably not related to their contribution to fat intake. The positive association between breast cancer risk and fat from cakes, biscuits and snacks seems to be an isolated finding in our data. Although the literature would not be inconsistent with 
regard to a special role of meat and meat products in breast cancer etiology, the evidence in our data is weak, and we prefer to attribute our results to total fat intake rather than to fat from any food group in particular.

We did not observe an association between breast cancer and type of dietary fat i.e., saturated, monounsaturated and polyunsaturated fatty acids (expressed as a percentage of total fatty acids). Thus, however, does not exclude the possibility of an association with fatty acids with specific biological effects, such as $n-3$ fatty acids (32). To evaluate such hypotheses, however, it may be insufficient to rely on dietary intake data; biochemical parameters, such as fatty acid composition of subcutaneous fat (33) or of plasma phospholipids, may be biologically more relevant indicators of exposure.

We adjusted the fat-breast cancer association for energy intake using three different methods. Logistic regression analysis and the residual approach proposed by willett and stampfer (17) yielded identical results. When we adjusted for energy by dividing fat energy by total energy (fat 6 ), confounding by energy intake was not completely removed. For all three methods, however, the degree of association substantially increased. In contrast to logistic regression analysis, however, the residual method clearly indicates that the energy-adjusted heterogeneity of fat intake in the study population is not very large istandard deviation $13 \mathrm{~g}$ instead of $30 \mathrm{~g})$. Thus, in our population, reduction of fat intake by $24 \mathrm{~g}$ may be a goal that can only be achieved with great societal and individual efforts.

In conclusion, our results suggest a dosemresponge relationship between average daily fat intake and breast cancer risk. This association could not be explained by energy intake, any particular type of fat or source of fat, although meat and meat products may account for a large part of the association. Furthermore, it is not very likely that biases in the study design or dietary methodology may account for our results. It remains to be shown, however, whether other characteristics of the dietary pattern in the Netherlands can explain these findings. So far, however, the results suggest that in a country with a high fat consumption, reduction of dietary fat intake, for instance from 40 to $30 \%$ of energy intake, may lower breast cancer incidence by ten to thirty per cent. 
References

1 Doll $R$, Peto $R$. The causes of cancer. Quantitive estimates of avoidable risks of cancer in the united states today. oxford Univexsity press. Oxford, 1981.

2 Haybittle IL. Results of treatment of female breast cancer in the Cambridge axea 1960-71. Br J Cancer 1979;40:56-61.

3. Knox EG. Food and disease. Br J Prev Soc Med 1977;31:71-80.

$4 \mathrm{Kritchevsky} \mathrm{D,} \mathrm{weber} \mathrm{MM,} \mathrm{Klurfeld} \mathrm{DM.} \mathrm{Dietary} \mathrm{fat} \mathrm{versus} \mathrm{caloric}$ content in inftiation and promotion of 7,12-dimethylbenz (a) anthracene-induced mamary tumorigenesis in rats. Cancer Res $1984 ; 44: 3174-7$.

5 Beth M, Berger MR, Aksoy M, Schmahl D. Comparison between the effects of dietary fat level and of calorie intake on methylnitrosurea-induced mamary carcinogenesis in female SD rats. Int J Cancer $1987 ; 39: 737-44$.

6 Welsch $\mathrm{CW}$. Enhancement of mammary tumorigenesis by dietary fat: review of potential mechanisms. Am J clin Nutr 1987;45:192-202.

7 Graham S. Hypotheses regaraing caloric intake in cancer development. Cancer $1986 ; 58: 1814-7$.

8 Klurfeld DM, Kritchevsky D. Update on dietary fat and cancer. Proc Soc Exp Biol Med $1986 ; 183: 287-92$.

9 Willett WC. Implications of total energy intake for epidemiologic studies of breast and large-bowel cancer. Am J CLin Nutr 1987; $45: 354-60$.

10 Goodwin PJ, Boyd NF. Critical appraisal of the evidence that dietary fat intake is related to breast cancer risk in humans. J Natl Canc Inst $1987 ; 79: 473-85$.

11 Muir $C$, Waterhouse J, Mack $T$, Powe11 J, whelan $S$ (eds). Cancer incidence in five continents. Volume $v$. IARC scientific publication no. 88. IARC, LYon, 1987.

12 Wynder FL, Chan PC, Cohen LA, MacCormack F, Hill P. Etiology and

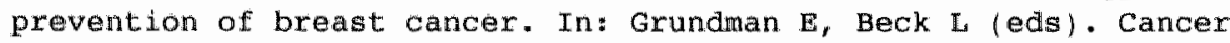
campaign, early diagnosis of breast cancer. Vol 1, 1-28. Gustav Fisher Verlag, New York, 1976.

13 Hautvast JGAJ. Comissie uniforme codering voedingsmiddelen: ontwikkeling van een systeem om gegevens van voedingsenquetes met behulp van de computer te verwerken. Voeding $1975 ; 36: 356-60$.

14 Uitgebreide Voedingsmiddelentabel. Kommissie ucv, Voorlichtingsbureau voor de Voeding, The Hague, 1984.

15 Bausch-Goldbolm RA, Van den Brandt PA, Van 't Veer P, sturmans $F$, Hermus RJJ. Results of the methodological study for the design of a simplified, self-administered questionnaire. In: Riboli $E_{\text {, }}$ Saracci $\mathbb{R}$ (ed). Diet, hormones and cancer: Methodological issues for prospective studies. IARC Technical Report no.4. Iyon, IARC, $1988,79-89$. 


\section{Dietary fat}

16 Fienberg SE. The analysis of cross-classified categorlal data. MIT Press, Cambridge MA, USA, 1981.

17 Willett $W C$, Stampfer MJ. Total energy intake: implications for epidemiologic analyses. Am J Epidemiol 1986;124:17-27.

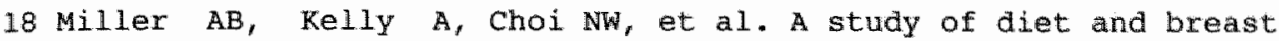
cancer. Am J Epidemiol 1978;107:499-509.

19 Morgan $R W$, Jain $M$, Miller $A B$, et al. A comparison of dietary methods in epidemiologic studies. Am J Epidemiol 1978; 107:488-98.

20 willett WC, stampfer MJ, colditz GA, et a1. Dietary fat and the risk of breast cancer. N Engl J Med 1987:316:22-8.

21 Willett WC, Sampson $L$, stampfer MJ, et al. Reproducibility and validity of a semiquantitative food frequency questionnaire. Am J Epidemiol $1985 ; 122: 51-65$.

22 Burke BS. The dietary ristory as a tool in research. I Am Diet Assoc $1947 ; 23: 1041-6$.

23 Lubin JH, Burns $\mathbb{P E}$, Blot WJ, et al. Dietary factors and breast cancer risk. Int J Cancer $1981 ; 28: 685-9$.

24 Lubin F, Wax $Y$, Modan B. Role af fat, animal protein, and dietary fiber in breast cancer etiology: A case-control study. I NatI Canc Inst $1986 ; 77: 605-12$.

25 Hixayama T. A large scale cohort study on cancer risks by dietwith special reference to the risk reducing effects of greenyellow vegetable consumption. In: Hayashi $Y$ et al. (eds): Diet, nutrition and cancer. Japan Sci Soc Press, Tokyo, 1986, 41-53.

26 Phillips RL. Role of life-style and dietary habits in risk of cancer among Seventh-Day Adventists. Cancer Res 1975:35:3513-22.

27 Mills PK, Annegers JF, Phillips RL. Animal product consumption and subsequent fatal breast cancer risk among seventh-day adventists. Am J Epidemiol 1988;127:440-53.

28 Talamini. R, La Vecchia $C$, Decarli A, et al. Social factor, diet and breast cancer in a northern Itallan population. Br J cancex $1981 ; 49: 723-9$.

29 Lê MG, Moulton LH, Hill C, Kramar A. Consumption of dairy produce and alcohol in a case-contral study of breast cancer. I Nati Canc Inst $1986 ; 77: 633-6$.

30 Food and Agriculture Organisation of the United Nations. Food balance sheets and per caput food supplies. Rome, 1980.

31 Gaskill SP, McGuire WL, osborne CK, Stern MP. Breast cancer mortality and diet in the united states. Cancex Res 1979;39:362837 .

32 Karmali RA, Marsch J, Fuchs C. Effect of omega-3 fatty acids on growth of a rat mammary tumor. J Nat 1 Canc Inst 1984;73:451-61.

33 Van Staveren WA, Deurenberg P, Katan MB. Burema I, De Groot LCPGM, Hoffmans MDAF. Validity of the fatty acid composition of subcutaneous fat tissue microbiopsies as an estimate of the 


\section{Dietary fat}

long-term average fatty acia composition of the diet of separate individuals. Fm J Epidemiol 1986;123:455-63. 
SELENIUM IN DIET, BLOOD AND TOENAILS IN RELATION

TO BREAST CANCER: A CASE-CONTROL STUDY 1

Pieter van 't Veer, Reggy PJ van der Wielen, Frans $J$ Kok,
Rudolph JJ Hermus, Ferd Sturmans.

Abstract

The association between breast cancer and selenium, measured in the diet, plasma, erythrocytes and toenails, was investigated in a casecontrol study in the Netherlands during 1985-1987. Dietary selenium intake was assessed by a structured dietary history technique among 133 breast cancer cases and 238 population controls. Absolute and energy-adjusted selenium intake and selenium concentrations in plasma, exythrocytes and toenails were similar in cases and controls. The multivariate adjusted odds ratios of breast cancer for subjects in the lowest compared to the highest quartile were 1.6 $(\mathrm{CI}=0.8-3.4)$ for dietary selenium, $2.0 \quad(\mathrm{CI}=0.9-4.4)$ for plasma selenium, $0.9(\mathrm{CI}=0.4-1.9)$ for exythrocyte selenium, and $1.1(C I=0.6-2.1)$ for toenail selenium. No statistically significant trend was observed in the odds ratios for any of the four indicators of selenium. These results do not suggest a substantial association between selenium and breast cancer for both short- and long-term markers of selenium status.

\section{Introduction}

An inverse association between selenium and cancer is stili the subject of debate (1). In a majority of past prospective epidemiologic studies, blood sellenium levels were found to be inversely associated with the risk of total cancer $(2-10)$, though not always statistically significant (7-10). In general, however, the number of subjects was not sufficient to allow site-specific analyses, leaving results for breast cancer inconclusive $(2,8-10)$. Case-control studies have shown that serum selenium, a short-term biologic marker of selenium intake, was lower in breast cancer cases compared to controls $(11,12)$, but selenium in long-term markers, such as erythrocytes (13) or toenails (14), was not. The use of prevalent cases, small numbers, or different markers of selenium hampers imtexpretation of these findings. Simultaneous measurement of both short- and long-term markers of selenium (15), and

\footnotetext{
1 Anerican Journal of Epidemiology $1990 ; 131$, no.6 (in press).
} 
consistency in their association with breast cancer will contribute to the understanding of the role of selenium in breast cancer pathogenesis.

In the Netherlands selenium intake is moderate (16) and blood selenium levels (17) are intermediate between those reported from Wew zealand and the united states (18i). Breast cancer incidence is one of the highest in western countries (19). Therefore, we conducted a came-control study on selenium and breast cancer in which we measured comprehensively selenium in the diet, plasma, erythrocytes and toenails $(20)$.

\section{Materials and methods}

Recruitment of subjects

Dutch white women 25-44 or 55-64 years of age, who resided in the central and southern Netherlands, and who were without a history of breast cancer were eligible. The perimenopausal age group was excluded to enhance an efficient comparison of risk indicators in pre- and postmenopausal women with regard to other study hypotheses. Data collection included interviews in person (food habits and lifestyle) and biologic specimens (blood and toenail clippings).

Cases were recruited by collaboration with surgeons, hospital laboratories and regional cancer registries in the study area. Cooperation of surgeons was obtained from 17 out of 35 hospitals covering 55 percent of hospital admissions, and non-cooperation was largely determined by privacy regulations and feasibility of study procedures. A total of 168 eligible cases were recruited, with 66 and 102 women in the age categories $25-44$ and 55-64 respectively, and diagnosis was histologically confirmed in 96 percent. From 103 cases a preoperative blood sample was obtained by the hospital laboratories before surgery, radiation or chemotherapy was started. A totall of 134 cases $(80$ percent) were interviewed on prediagnostic food habits in the 12-months before diagnosis, on life-style factors and on potential confounders. Response of cases was lower in advanced breast cancer and independent of age and degree of urbanization of residence. Most interviews were conducted within three to four months after diagnosis, 91 within six months. Following the interview, toenail clippings were collected from 128 cases. The dietary interview from one case was considered unreliable and excluded from data analysis.

A total of 548 controls, with age-distribution similar to the cases, was sampled randomly from the municipal registries in the study area. Subjects who were ineligible $(n=8)$ or could not be reached $(n=11)$ were excluded. Of the remaining 529 controls, 289 women 
( 55 percent) were interviewed, 89 partial responders (17 percent) completed a short written questionnaire, and 151 subjects (29 percent) refused any form of participation. Response of controls was lower for the older age group and independent of degree of urbanization of residence. From the 529 controls, 311 provided toenail clippings (including 55 partial responders) and from 255 (of the interviewed, women blaod was collected, one to two months after the interview. A total of 250 samples of toenails and 160 blood samples from controls were randomly selected for analysis.

Data were collected from $1985-1987$ and all seasons of the year were covered. In order to obtain a seasonal distribution of data collection comparable to the cases, interviewing of the controls started simultaneously with case-recruitment and referred to the twelve-month period before diagnosis. Because blood from cases had to be collected preoperatively, this objective could not be achieved for the biologic specimen. Furthermore, data on selenium intake from 51 controls had to be excluded from data analysis regarding energy intake, because sugar intake was not completely covered by the questionnaire when the interviewing started.

\section{Dietary selenium intake}

Average daily food consumption was assessed by two well-trained, registered dietitians using a structured dietary history interview in which frequency and amount of 236 food items were recorded. portion sizes of cups, glasses, dishes and spoons were measured to obtain accurate estimates. Average daily energy intake was calculated using the standardized Dutch Uniform Encoding system (21) and the 1984 release of the computerized Dutch Nutrient Data Bank (22). Use of selenium containing supplements was included in the questionnaire, but not taken into account in calculation of average daily selenium intake.

Selenium intake was calculated from a table of selenium contents, developed for this study. This table was mainly based on extensive analyses of cereals, meat and milk products (23). For minor selenium sources, such as fishery products (24), fruits, vegetables and mixed dishes, the selenium content was estimated on the basis of data from surrounding countries, additional analyses and ingredients. The validity of the table was evaluated by comparison of the calculated average daily intake of selenium with the chemical analysis of ten identically composed market baskets of an average-day meal (25). The mean difference between calculated and analyzed total selenium intake was less than 4 percent (Table 1), suggesting validity of our table with respect to estimation of the selenium intake from foods: Reproducibility of the dietary questionnaire was assessed in 39 control subjects, re-interviewed ane year after the first interview. 
Average dally intake of selenium differed by 1.1 percent only; the pearson coeficient of correlation was $r=0.73$ for selenium intake.

Table 1. Comparison of selenium intake determined by chemical analyses and calculated using table of selenium contents.

\begin{tabular}{lrcc}
\hline Food groups & $\begin{array}{c}\text { Chemical } \\
\text { analysis }(\mu g)^{1}\end{array}$ & $\begin{array}{c}\text { Calculated } \\
\text { intake }(\mu g / \text { day })^{2}\end{array}$ \\
\hline Meat, meat products and eggs & $20.9(13.7-28.1)$ & 18.4 \\
Mish and sea foods & $2.9(2.5-3.3)$ & 2.6 \\
Milk products and cheese & $9.7(8.5-10.9)$ & 10.7 \\
Cereal products & $25.3(19.5-31.1)$ & 30.4 \\
Miscellaneous & $11.1(8.6-13.6)$ & 10.1 \\
Total selenium & $69.9(60.2-79.6)$ & 72.2 \\
\hline
\end{tabular}

Mean ( 95 pexcent confidence interval) of ten market baskets.

2 Using table of selenium contents, with food composition identical to market basket.

Blood and toenail selenium

Blood samples were collected (for cases before surgery) and separated in plasma and erythrocytes. The selenium concentration in erythrocytes (packed cells) was determined by fluorimetry $(25)$. Each of the 20 laboratory runs contained samples from cases, controls and from a pool of erythrocytes. Each of the samples was determined in duplicate, with laboratory personnel unaware of the type of sample. the coefficient of variation was 8\% (6\% for a duplicate measurement and 5 ? between runs).

Plasma and toenail selenium concentrations were measured in lyophilized samples by newtron activation analysis 150-80 mg serum and $10-300 \mathrm{mg}$ toenall. clippings). Samples, standards and reference materials were irradiated in a flux (5 $\mathrm{x}^{10^{13}}$ neutrons.cm-2.s-1) of thermal neutrons for 5 or 20 seconds for plasma and clippings respectively, at the Netherlands Energy Research Foundation ECN, petten, the Netherlands. After a delay time of 5 seconds, gamma radiation from metastable-selenium-77 was measured for 20 seconds (26). Accuracy was monitored by analysis of the Standard Reference Material 1577A "Bovine Liver" (National Bureau of Standards, Washington, USA). Results were $0.72 \pm 0.03 \mu \mathrm{g} / \mathrm{g}$ (mean $\pm \mathrm{SD}$; $\mathrm{n}=19 \mathrm{l}$ ), while the NBS certificate carries the value of $0.72 \pm 0.08 \mu \mathrm{g} / \mathrm{g}$. Because a large proportion of subjects collected clippings from both the big toe as well as the other toenails, we compared whether this 
was related to selenium content. The selenium content did not differ between clippings of the big toe alone and clippings of all toes combined, but the amount of material did not permit separate analyses. Furthermore, the selenium content of toenails appeared to be independent of visible contamination with nail polish or gross debris. The coefficient of variation for the determination of selenium in plasma was $11 \%$ (98 within runs and $6 \%$ between runs). For selenium in toenails the coefficient of variation was 128 (118 within runs and 4 between runs).

Throughout all laboratory procedures, samples of cases and controls were treated identically, with laboratory personnel unaware of the health status. All runs contained both cases and controls.

\section{Data analysis}

Means and standard deviations of the exposure variables were calculated for cases and controls, stratified for age, and multiple linear regression analysis was used to study age-adjusted differences in selenium concentrations. Initial analyses were conducted separately for subjects aged 25-44 years (54 cases and 121 controls) and 55-64 years (79 cases and 117 controls). Results were similar for both age groups, and the data were pooled in further analyses.

odds ratios (OR) of breast cancer were calculated for selenium in diet and biomarkers with adjustment for potential confounders by unconditional multiple logistic regression with maximum likelihood estimation of the regression coefficients and their standard errors (27). Selenium (quartiles), age (four categories), area of residence (four categories) and season of data collection (four categories) were included in all logistic models. For the analysig of dietary selenium, the residual approach proposed by willett and stampfer (28) was used. Results were similar when quartiles of absolute selenium intake were used and energy intake was taken into account as a continuous variable. Results of both approaches were identical when selenium (or its residuals) and energy intake were entered in the model as contunuous variables (29).

In ordex to identify potential confounders for the association between dietary selenium and breast cancer, odds ratios were calculated for the following major risk factors: history of benign breast disease, first- and second-degree familial history, smoking habits, educational level, employment status, ever use of oral contraceptives, age at menarche, age at first full-term pregnancy, parity, body mass index, alcohol and fat intake. Addition of these factors to the logistic regression model, either separately or simultaneously, resulted in only minor changes of the odds ratio for intake of selenium (entered as a continuous variable). 
In our study population, breast cancer was associated with major Llsk factors. The odds ratios for breast cancer were higher for first-and second-degree familial history (OR $=1.6,95$ percent $C I=0.8-3.3$, and $O R=1.7,95$ percent $C I=1.0-3.0$, respectively). A late age at menarche $(\geq 15$ years $)$ was associated with a reduced risk of breast cancer $(\mathrm{OR}=0.6,95$ percent $\mathrm{CI}=0.3$ - 1.1) compared with early age at menarche ( $\leq 12$ years). Women with muliple births (three or more) had a lower risk foR $=0.6,95$ percent $\mathrm{cr}=0.3-1.2)$ compared with nulliparous women. Although these associations were not statistically significant, the direction was as expected. No important association was observed for the other major risk factors (table available on request from the authors). Mean daily intake of selenium, energy and energy-adjusted selenium intake of cases and controls as well as selenium concentrations in plasma, erythrocytes and toenails are presented in table 2, together with the corresponding age-adjusted case-control differences.

Table 2. Means (and standard deviations (SDs)) for daily intake of selenium and energy, and selenium concentration in plasma, erythrocytes and toenails among breast cancer cases and population controls, the Netherlands, 1985-1.987.

\begin{tabular}{|c|c|c|c|c|c|c|c|}
\hline \multirow{2}{*}{$\begin{array}{l}\text { Nutrient and } \\
\text { specimen type }\end{array}$} & \multicolumn{3}{|c|}{ Cases } & \multicolumn{2}{|c|}{ Controls } & \multirow{2}{*}{\multicolumn{2}{|c|}{$\begin{array}{l}\text { Age-adjusted } \\
\text { difference }\end{array}$}} \\
\hline & Mean & \pm & $\mathrm{SD}$ & Mean & $\pm S D$ & & \\
\hline \multicolumn{8}{|l|}{ Dietary intake } \\
\hline Selienium $(\mu g)^{2}$ & 56.0 & \pm & 13.0 & $55.9 \pm$ & 12.5 & 0.6 & $(-2.0,3.3)$ \\
\hline Energy $(M J)$ & 9.2 & \pm & 2.5 & $8.9 \pm$ & \pm 2.2 & 0.5 & $(0.1,1.0)$ \\
\hline Energy adjusted & & & & & & & \\
\hline selenium intake ( $\mu \mathrm{g})$ & 54.9 & \pm & 8.4 & $56.5 \pm$ & \pm 8.4 & -1.5 & $(-3.3,0.3)$ \\
\hline \multicolumn{8}{|l|}{ Selenium concentration ${ }^{3}$} \\
\hline Plasma $(\mu \mathrm{g} / \mathrm{L})$ & 89 & \pm & 14 & $93 \pm$ & \pm 15 & -3 & $(-7,1)$ \\
\hline Erythrocytes $(\mathrm{ng} / \mathrm{g})$ & 129 & \pm & 24 & $128 \pm$ & \pm 25 & +1 & $(-6,7)$ \\
\hline Toenails (ppm) & 0.63 & \pm & 0.12 & $0.65 \pm$ & \pm 0.18 & -0.02 & $(-0.06,0.01)$ \\
\hline
\end{tabular}

195 percent confidence interval in parentheses.

3 Excluding selenium supplements (used by 6 cases and 7 controls). Intake data from 133 cases and 238 controls.

3 Number of samples analysed (cases/controls): plasma (92/151), exythrocytes $(92 / 147)$, toenails (124/236). Missing data for blood (11. cases, 9-13 controls) and toenails ( 14 controls) due to breakage, hemolysis and shortage of material. 
Average daily selenium intake in cases and controls was similar. Energy intake in cases, however, was higher than in controls (ageadjusted difference $=0.5 \mathrm{MJ} ; 95$ percent $\mathrm{CI}=0.1-1.0 \mathrm{MJ}$ ). Because of the association between the intake of selenium and energy ( $r=0.75$ in controls), selenium intake was adjusted for energy. Consequently, energy-adjusted selenium intake in cases was slightly lower than in controls. We found no statistically significant ageadjusted difference in cases and controls for any of the biologic markers of selenium status.

The number of cases and controls by quartiles of selenium in the diet and in biologic markers, and the corresponding adjusted relative odds of breast cancer (with their 95 percent confidence intervals), are presented in Table 3. Although the relative odds in the lowest quartile of dietary selenium (after adjustment for energy) and plasma selenium was sightly elevated, none of these relative odds were significantly different from unity, as compared to the highest quartile. Furthermore, there was no statistically significant trend in the odds ratios for any of the four indicators of selenium. Results of the analyses were similar when subjects using selenium supplements were excluded (from analyses regarding diet) or when between-run variability of laboratory analyses was taken into account.

\section{Discussion}

In this case-control study, no important associations were observed between total amount of selenium in diet, short-term (plasma) and long-term markers of selenium (erythrocytes, toenails) and breast cancer.

In our study, apparently healthy controls were recruited from the hospitals catchment area. We compared among the total control group, breast cancer risk factors and food habits of the 289 extensively interviewed women and the 89 women who only responded to the mailed questionnaire. No major differences were observed with regard to age, age at first full-term pregnancy, parity, weight, height, body mass index, nor with regard to fat content of milk products, consumption frequency of eggs and fish, and food items used on bread. Furthermore, consumption frequency of bread was similar in both groups, but the interviewed controls tended to prefer wholewheat bread to white bread. Because of the higher selenium content of wholewheat bread, this may have contributed to glightly higher selenium levels in controls. In addition, the lowered selenium in plasma and exythrocytes in cases may partially be a consequence of the disease, rather than a cause. Indeed, plasma and erythrocyte selenium levels were lowered only in cases with tumors 
"Table 3. Odds ratios (ORs) (and 95 percent confidence intervals (CIs) for breast cancer for quartiles of selenium in diet, plasma, erythrocytes, and toenails, the Netherlands, 1985-1987.

\begin{tabular}{|c|c|c|c|c|c|}
\hline & \multicolumn{4}{|c|}{ Quartiles of selenium level } & \multirow{3}{*}{$\begin{array}{l}x^{2} \text { for } \\
\text { trend } \\
\text { ( } \mathrm{p}-\text {-value })\end{array}$} \\
\hline & lowest & & & highest & \\
\hline & 1 & 2 & 3 & 4 & \\
\hline \multicolumn{6}{|l|}{ Diet. ${ }^{2}$} \\
\hline Cases (no.) & 46 & 29 & 30 & 28 & \\
\hline Controls $(\mathrm{no})$. & 59 & 59 & 60 & 60 & \\
\hline OR adjusted $z$ & $\begin{array}{c}1.6 \\
(0.8-3.1)\end{array}$ & $\begin{array}{c}1.6 \\
(0.8-3.2)\end{array}$ & $\begin{array}{c}1.2 \\
(0.6-2.4)\end{array}$ & 1.0 & $\begin{array}{c}2.41 \\
(0.12)\end{array}$ \\
\hline OR multivarate ${ }^{3}$ & $\begin{array}{c}1.6 \\
(0.8-3.4)\end{array}$ & $\begin{array}{c}1.7 \\
(0.8-3.7)\end{array}$ & $\begin{array}{c}1.3 \\
(0.6-2.8)\end{array}$ & 1.0 & $\begin{array}{c}1.96 \\
(0.16)\end{array}$ \\
\hline \multicolumn{6}{|l|}{ Pliasma } \\
\hline Cases (no.) & 33 & 19 & 21 & 19 & \\
\hline Controls (no.) & 38 & 38 & 38 & 37 & \\
\hline OR adjusted 2 & $\begin{array}{c}2.0 \\
(0.9-4.4)\end{array}$ & $\begin{array}{c}1.2 \\
(0.5-2.8)\end{array}$ & $\begin{array}{c}1.3 \\
(0.6-3.0)\end{array}$ & 1.0 & $\begin{array}{l}3.04 \\
(0.08)\end{array}$ \\
\hline \multicolumn{6}{|l|}{ Erythrocytes } \\
\hline Cases (no.) & 21 & 23 & 25 & 23 & \\
\hline Controls (no.) & 37 & 37 & 36 & 37 & \\
\hline OR adjusted ${ }^{2}$ & $\begin{array}{c}0.9 \\
(0.4-1.9)\end{array}$ & $\begin{array}{c}1.1 \\
(0.5-2.4)\end{array}$ & $\begin{array}{c}1.2 \\
(0.6-2.6)\end{array}$ & 1.0 & $\begin{array}{c}0.18 \\
(0.67)\end{array}$ \\
\hline \multicolumn{6}{|l|}{ Toenalls } \\
\hline Cases (no.) & 42 & 24 & 26 & 32 & \\
\hline Controls (no.) & 59 & 60 & 56 & 61 & \\
\hline OR adjusted: & $\begin{array}{c}1.1 \\
(0.6-2.1)\end{array}$ & $\begin{array}{c}0.6 \\
(0.3-1.3)\end{array}$ & $\begin{array}{c}0.7 \\
(0.4-1.5)\end{array}$ & 1.0 & $\begin{array}{c}0.22 \\
(0.64)\end{array}$ \\
\hline
\end{tabular}

1 Quartiles of energy adjusted selenium intake fexcluding supplements).

adds ratio (95 percent confidence interval) adjusted for age, season and area of residence.

* Aditional adjustment for potential confounders/see Data analysis). 
of 2-5 cm. Moreover, because of a conservative attitude of surgeons with regard to preoperative blood collection, blood was avaliable more frequently from cases with larger tumors. Thus, the slightly lower dietary and plasma selenium in cases as compared to controls may partially have resulted from recrultment procedures of subjects and the presence of the tumor, rather than from an etiologic association between selenium and breast cancer.

The epidemiologic evidence of an inverse association between selenium and breast cancer is limited. In one ecologic study a significant association $(r=-0.80)$ between per capita selenium intake and breast cancer mortality has been reported (30). Decreased serum selenium levels in breast cancer cases compared with controls have been demonstrated in two small preliminary case-control studies $(11,12)$, but these results may also be attributed to the presence of tumors (31). Two other small studies with long-term markers of selenium have been reported from premenopausal women. Meyer (13) observed a mean erythrocyte selenium concentration of 0.176 ppm for breast cancer cases $(n=38)$ and of 0.174 ppm for controls $(n=116)$. He has found a relative risk of $0.5(95$ percent $C I=0.2-1.3)$ in the lowest tertile as compared to the highest. In a nested case-control study ( 61 cases and 290 controls) no association between toenail selenium levels and breast cancer risk has been found by Van Noord (14) comparing the upper and lower quartiles $1 \mathrm{OR}=1.1$; 95 percent $C I=0.5-2.91$.

It has been suggested that the protective effect of selenium on total cancer $x$ isk might be related to gastrointestinal cancer, and may not apply to estrogen-dependent sites $(2,3)$. In fact, in three (4-6) of five $(2-6)$ of the pxospective studies on serum selenium and cancer, the inverse association was found in men only. For total cancer, relative risks of 3.1 and 2.0 for low versus high selenium have been reported from Finland (3) and the USA (2) respectively. countries with low and high serum selenium concentrations compared to the Netherlands (18). We observed a relative odds of breast cancer of 2.0 for the lowest quartile of plasma selenium compared to the highest. Due to the limited size of our study, this estimate could result from either no association with breast cancer, or from an inverse association of size 2 to 3 as reported for total cancer $(2,3)$. The potential effect of a subclinical tumor on this shortterm marker (31), the larger availability of blood samples from cases with advanced disease, and the absence of an inverse association in the other markers, however, suggest that this estimate of the adds ratio is not of etiologic significance.

In conclusion, epidemiologic evidence for a protective effect of selenium on breast cancer risk in women ils essentially based on one cross-cultural correlation study (30) and two preliminary reports $(11,12)$. This case-control study on selenium and breast cancer 
included both short-tern and long-texm markers of selenium and more breast cancer cases were enrolled than in other epidemiologic studies on this topic. owerall, the results do not substantiate the inverse association between selenium and breast cancer.

\section{References}

1 Wdlett WC, Stampfer MJ. Selenium and cancer. Br Med J 1988;297: 573-4.

2 Wilett WC, Polk BF', Morris JS, et al. Prediagnostic serum selenium and risk of cancex. Lancet $1983 ; 2: 130-4$.

3 Sallonen JT, Alfthan $G$, Huttunen $J K$, et al. Association between serum selenium and the risk of cancer. Am J Epidemiol 1984;120: $342-9$

4 Salonen JTM, Salonen R, Lappeteläinen R, et al. Risk of cancer in relation to serum concentrations of selenium and vitamins $A$ and E: matched case-control analysis of prospective data. Br Med J $1985 ; 290: 417-20$.

5 Fex G, Pettersson B Akesson B. Low plasma selenium as a risk factor for cancer death in middle-aged men. Nutr Cancer 1987;10: $221-9$.

6 Kok FJ, Bruijn AM de, Hofman A, et al. Is serum selenium a risk factor for cancer in men only? Am J Epidemiol 1987;125:12-6.

7 Akesson B, Steen B. Plasma selenium and glutathione peroxidase in relation to cancer, angina pectoris and short-term mortality in 68-year-old men. Compr Gerantol A $1987 ; 1: 61-4$.

8 Coates RJ, Weiss NS, Daling JR, et al. Serum levels of selenium and retinol and the subsequent risk of cancer. Am $J$ Epidemiol $1988 ; 128: 5: 15-23$.

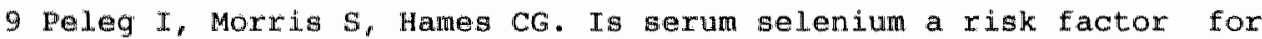
cancer? Med Oncol Tumor Pharmacother $1985 ; 2: 157-63$.

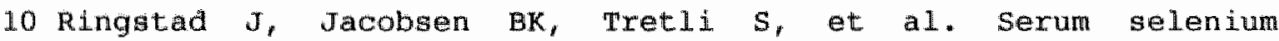
concentration associated with $x$ isk of cancer. J clin pathol $1988 ; 41: 454-7$.

11 McConnell K. Jager RM, Bland KI, et al. The relationship of dietary selenium and breast cancer. J Surg oncol 1980;15:67-70.

12 Chaitchik $S$, shenberg $C, N i r-E 1 Y$, et al. The distribution of selenium in human blood samples of Israeli population Compaxison between normal and breast cancer cases. Biol Trace E Lem Res $1988 ; 15: 205-12$.

13 Meyer $\mathbb{F}$, verreault $\mathbb{R}$. Erythrocyte selenium and breast cancer risk. An J Epidemiol 1987;125:917-9.

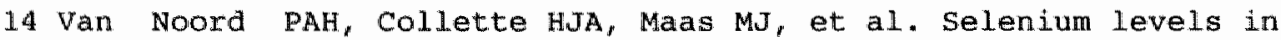
nails of premenopausal breast cancer patients assessed prediagnostically in a cohort-nested case-referent study among 
women screened in the DOM project. Int $\mathfrak{J}$ Epidemiol $1987 ; 16: 318-$ 22.

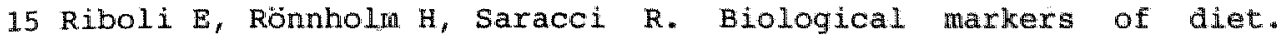
Cancer surveys $1987 ; 6: 685-718$.

16 Van Dokkum w, De Vos RH, Muys TH, et al. Minerals and trace elements in total diets in the Netherlands. Br J Nutr 1989;61:715.

17 Thorling EB, Overvad $K$, Geboers $J$. Selenium status in Europe Human data. A multicenter study. Ann Clin Res $1986 ; 18: 3-7$.

18 Thomson $C D$, Robinson MF. Selenium in human health and disease with emphasis on those aspects peculiar to New Zealand. Am J Clin Nutr 19,$80 ; 33: 303-23$.

19 Muir $C$, Waterhouse $J$, Mack $T$, et al (eds). Cancer incidence in five continents. Volume $V$. IARC scientific publication no. 88. IARC, Lyon, 1987.

20 Marris JS, Stampfer MJ, Willett WC. Dietary selenium in humans. Toenails as an indicator. Biol Trace Elem Res 1983;5:529-37.

21 Hautvast JGAJ. Commissie uniforme codering voedingsmiddelen: ontwikkeling van een systeem om gegevens van voedingsenquêtes met behulp van de computer te verwerken. Voeding $1975 ; 36: 356$.

22 Kommissie vCV. vitgebreide Voedingsmiddelentabel 1984. voorlichtingsbureau voor de voeding, The Hague, Netherlands, 1984 .

23 Bos PMJ, Egger RJ, Veer $P$ van " $t$, et al. Possible sources of variation in selenium content of whole-meal bread, white bread, and cow's milk in The Netherlands. Preliminary results. In: Baltes $W$, Czechik-Eysenberg PB, Deelstra $H$ et al (eds). Strategies in food quality assurance: analytical, industrial and legal aspects, Vol 2. De Sikkel, Antwerp, 1985, 23-8.

24 Luten JB, Ruiter A, Ritskes TM, Rauchbaar AB, et al. Mercury and selenium in marine- and freshwater fish. J Food Sci 1980;45*4169.

25 Koh TS, Benson TH. Metals and other elements; criticall reappraisal of fluorimetric method for determination of selenium in biological materials. J Assoc off Anal Chem 1983;66:918-26.

26 Woittiez JRW, Nieuwendijk BJT. Analysis of selenium in environmental and bilological samples by neutron activation. Journal of Radioanalytical and Nuclear Chemistry 1987;410:603-11.

27 Kleinbaum DG, Kupper LL, Morgenstern H. Epldemiologic research. Principles and quantitative methods. London: Lifetime Learning Publications, $1982,419-46$.

28 Willett $W C$, stampfer MJ. Total energy intake: Implications for epidemiologic analyses. Am J Epidemiol 1986;124:17-27.

29 pike MC, Bernstein L, Peters RK. Total energy intake: implications for epidemiolagic analyses. Am $J$ Epidemiol 1989; $129: 1312-3$ (reply). 
30 Schrauzer GN, white DA, Schneider CJ. Cancer mortality coxrelation studies-III: statistical associations ith dietary selenturn intakes. Bioinorg chem $1977 ; 7: 23-34$.

31. Broghamer Wh, McConnell KP, Blotcky AL. Relationship between serum selenium levels and patients with carcinoma. Cancer $1976 ; 37: 1384-8$. 
CONSUMPTION OF EERMENTED MILK PRODUCTS AND BREAST CANCER: A CASE-CONTROL STUDY IN THE NETHERLANDS

\author{
Pieter van 't Veer, Jacqueline M Dekker, Jos WJ Lamers, \\ Frans J Kok, Evert G Schouten, Henny AM Brants, \\ Ferd Sturmans, Rudolph JJ Fermus.
}

\begin{abstract}
In a case-control study in the Netherlands we observed a significantly lower consumption of fermented milk products (predominantly yogurt and buttermilk) among 133 incident breast cancer cases as compared to 289 population controls (mean \pm standard deviation among users only: $116 \pm 100$ versus $157 \pm 144$ g/day, $p<0.01$ ). The ageadjusted odds ratio of daily consumption of one and a half glass $(\geq 225 \mathrm{~g})$ of fermented milk versus none was 0.50 (958 confidence interval $C I=0.23-1.08)$. When fermented milk was entered as a continuous variable (per $g$ ) in either age-adjusted or multivariate analysis, the odds ratio expressed per $225 \mathrm{~g}$ was 0.63 (multivariateadjusted $95 \% \mathrm{CI}=0.41-0.96)$. After multivariate adjustment for intake of fat and other confounders a statistically significant decrease of breast cancer risk was also observed for increasing intake of Gouda cheese. The multivariate adjusted odds ratio expressed per $60 \mathrm{~g}$ of this fermented product was $0.56 \quad$ (95\% $C I=0.33-0.95)$. For daily intake of milk no statistically significant differences were observed between cases and controls. These results support the hypothesis that high consumption of fermented milk products may protect against breast cancer.
\end{abstract}

\title{
Introduction
}

Results of cross-cultural and regional correlation studies have shown that breast cancer mortality correlates positively with the consumption of milk products $(1,2)$. In two recent case-control studies, conducted in Italy (3) and France (4), a positive association was observed between consumption of dairy products and breast cancer. In the latter study, however, Lê et al (4) also observed an inverse relationship with the frequency of consumption of yogurt. This observation is of interest since feeding of fermented milk products diminished the development of sarcoma-180 and Ehrlich ascites tumors $(5-7)$. Iactic acid bacteria, used in fermentation

Cancer Research $1989 ; 49: 4020-3$. 
of milk pxoducts, may survive in the digestive tract $(8,9)$ and may interfere with other gut bacteria $(9,10)$. Goldin and Gorbach showed that the intestinal bacterial enzyme activity was altered during a pexiod of feeding milk supplemented with Lactobacillus acidophilus, in both rats (11) and humans (12). Such changes may influence the formation (13) and witharawal (14) of oestrogenic compounds, or alter bile acid metabolism $(15-17)$ in the enterohepatic cycle. Furthermore, micro-organisms provided by cultured dairy products may stinulate the immunological activity in the host $(18,19)$, possibly mediated by glycopeptides in the bacterial cell wall (6).

We studied the relation between breast cancer and the consumption of daixy products in the vetherlands. This country has a high incidence of breast cancer, the consumption of dairy products is high, and the consumption of fermented milk products is among the highest in the world (20) and varies considerably within the population.

Subjects and methods

\section{Cases}

The study was conducted in 1985-1987 among Dutch Caucasian women age 25-44 or 55-64 years, residing in the middle and southern part of the Netherlands. In order to address additional hypotheses, case ascertainment required collection of both pre-operative blood as well as interviews after hospital discharge. Consequently, study procedures were complicated and cooperation was obtained from aurgeons in 17 out of 35 hospitals in the study area, covering $55 \%$ of hospital admissions. From these hospitals 168 newly diagnosed eligible breast cancer cases (96\% histologically confirmed) were identified edther by the surgeons or by regional cancer registries. of the cases 80\% (134 women) responded positively on an invitation letter from our Institute. Data obtained from one case were judged unreliable and excluded from the analysis.

\section{Controls}

A total of 548 women, reflecting the age distribution of cases, were sampled randomly from municipal population registries in the same area as the hospitals. All registries supplied names and addresses of women, who were subsequently invited by a letter that explained the alm, design, and procedures of the study and asked for participation in the $2-\mathrm{h}$ interview at home. When a woman did not respond within 2 weeks, she was called (up to 3 times) or visited (once). Eight subjects appeared to be imeligible and 11 could not be reached, leaving 529 control subjects. A total of 223 subjects (42\%) 
immediately agreed to cooperate, 66 subjects (12) agreed after the telephone call, while 89 subjects (178) were willing to return a shortened mailed questionnaire. The remaining 151 subjects (29\%) refused any form of participation. Thus, a total of 289 controls was included in the data analysis.

\section{Data collection}

Cases and controls were interviewed by two well-trained, registered dietitians in a $2-h$ home visit. Cases were interviewed $3-6$ months after hospital discharge when they were feeling well again (e.9." not during chemotherapy treatment). To exclude the possibility that altered food habits occurring after diagnosis would influence the results, the interview of the cases referred to the 12-month period before diagnosis. Interviewing the controls started 3-4 months before the case interviews and referred to the 12 -month period preceding the interview date, i.e., the interviews with cases and controls covered the same periad of time.

To obtain data on average daily food consumption, a structured dietary history interview was conducted covering the complete dietary pattern. Consumption frequency and amount were recorded for all of the 236 items in the questionnaire, which included all major dairy products used in the Netherlands. In order to obtain an accurate quantification of the usual amounts ingested, portion sizes of the most frequently used household utensils were measured in the kitchen at the end of each interview. This included measurement of the fluid content of cups, glasses and small dishes used to consume milk and yogurt. Average daily intake of fat and other nutrients was calculated with the standardized Dutch Uniform Encoding system (21) and the 1984 release of the computerized Dutch Nutrient Data Bank (22). The questionnaire also addressed stability of food habits, smoking habits, demographic and socio-economic characteristics, reproductive history, previous breast diseases, orall contraceptive and other hormone use, and prediagnostic weight. In addition, anthropometry was performed, toenall clippings were collected and a blood sample was drawn (for cases before surgery).

\section{Data Analysis}

In this analysis emphasis was on three groups of dairy products: fermented milk products (i.e., yogurt, buttermilk, curds and kefir); Gouda cheese; and milk i.e., skimmed, partly skimmed and full-cream milk). Consumption of several milk products and fat intake were compared between cases and controls among the women aged 25-44 and those aged 55-64. Since the differences were similar in both age groups, the overall difference of means and their 95 confidence 
intervals are presented. In further analyses the intake of dairy products was expressed in 9 , either in categories of 20 or 759 (helf a glass) or as continuous variables. odds ratios and their 95: confidence intervals were calculated, with adjustment for age using indicator variables (categories: 25-39, 40-44, 55-59 and 60-64 years). Potential confounders were controlled individually and almutaneously by means of multiple logistic regression. The following variables were considered as potential confounders: age, dietary fat intake, alcohol intake, history of benign breast disease, first-and second-degree familial history, smoking habits, educational level of the woman, use of oral contraceptives, age at menarche, age at Eirst full-term pregnancy, parity, body mass index and geographical area.

\section{Results}

Age-adjusted odds ratios and 95\% confidence intervals for major risk factors of breast cancer are shown in Table $\mathbb{1}$. Although none of these variables had a significant impact on the risk of breast cancer in this study, the direction of most associations is as expected.

The consumption of fermented milk products was significantly higher among controls than anong cases (Table 2$)$. The differences were in the same direction in both the younger (25-44 yr) and older (55-64 yr) age group (data not shown). Although cases also consumed slightly less Gouda cheese and milk than did controls, these differences were not statistically significant.

As compared to nonusers, the age-adjusted adds ratio of consumption of more than 1.5 glasses (>225 g) of fermented milk was 0.50 (95\% confidence interval $0.23-1.08$ ), but slightly exceeded 1.00 for lower levels of consumption (Table 3). This result was not materially affected by multivariate analysis. When fermented milk was included as a continuous variable (in g) in the logistic regression modell, the odds ratio of breast cancer expressed per $225 \mathrm{~g}$ fermented milk daily (one and a half glass versus none) was 0.63 in both the age-adjusted and multivariate model and the corresponding 95 confidence intervals did not include 1.00 .

Consumption of Gouda cheese showed a lower adds ratio at higher intake, but this association was not statistically significant. However, since fat intake was associated with both the consumption of Gouda cheese (Pearson coeficient of correlation $=0.34$ ) and breast cancer (Table 2), it might have obscured a protective effect. Indeed, in multivariate analysis the association became more pronounced, and in the model specifying Gouda cheese as a continuous 
Table 1. Age-adjusted adas ratios and 958 comfidence interval for major risk factors of breast cancer, for 133 incident cases and 289 population controls.

\begin{tabular}{|c|c|c|c|}
\hline Risk factor & Level & $\begin{array}{l}\text { odds } \\
\text { ratio }\end{array}$ & $\begin{array}{l}95 \text { confidence } \\
\text { interval }\end{array}$ \\
\hline Age at menarche (year) & $\begin{array}{l}\leq 121 \\
13-14 \\
\geq 15\end{array}$ & $\begin{array}{l}1.00 \\
0.79 \\
0.60\end{array}$ & $\begin{array}{l}0.48-1.27 \\
0.32-1.12\end{array}$ \\
\hline $\begin{array}{l}\text { Age at fixst fuld- } \\
\text { term pregnancy (yr) }\end{array}$ & $\begin{array}{l}\text { nu } 11 \text { iparous } 1 \\
\leq 26 \\
>26\end{array}$ & $\begin{array}{l}1.00 \\
0.96 \\
1.14\end{array}$ & $\begin{array}{l}0.51-1.80 \\
0.60-2.17\end{array}$ \\
\hline $\begin{array}{l}\text { Parity (no. } \\
\text { of children) }\end{array}$ & $\begin{array}{l}\text { nu11 iparous } 1 \\
1-2 \\
\geq 3\end{array}$ & $\begin{array}{l}1.00 \\
1.42 \\
0.62\end{array}$ & $\begin{array}{l}0.76-2.64 \\
0.31-1.22\end{array}$ \\
\hline $\begin{array}{l}\text { First-degree } \\
\text { familial history }\end{array}$ & $\begin{array}{l}\text { negative } 1 \\
\text { positive }\end{array}$ & $\begin{array}{l}1.00 \\
1.65\end{array}$ & $0.81-3.33$ \\
\hline $\begin{array}{l}\text { Second-degree } \\
\text { familial history }\end{array}$ & $\begin{array}{l}\text { negative } \\
\text { positive }\end{array}$ & $\begin{array}{l}1.00 \\
1.72\end{array}$ & $1.00-2.97$ \\
\hline $\begin{array}{l}\text { History of benign } \\
\text { breast disease }\end{array}$ & $\begin{array}{l}\text { negative } \\
\text { positive }\end{array}$ & $\begin{array}{l}1.00 \\
1.13\end{array}$ & $0.67-1.90$ \\
\hline $\begin{array}{l}\text { Use of oral } \\
\text { contraceptives }\end{array}$ & $\begin{array}{l}\text { never } \\
\text { ever }\end{array}$ & $\begin{array}{l}1.00 \\
1.07\end{array}$ & $0.64-1.78$ \\
\hline $\begin{array}{l}\text { Body mass index } \\
\left(\mathrm{kg} / \mathrm{m}^{2}\right)\end{array}$ & $\begin{array}{l}\leq 30^{1} \\
>30^{\prime}\end{array}$ & $\begin{array}{l}1.00 \\
1.18\end{array}$ & $0.63-2.22$ \\
\hline Educational leve 1 & $\begin{array}{l}\text { Low } 1 \\
\text { medium } \\
\text { high }\end{array}$ & $\begin{array}{l}1.00 \\
1.06 \\
1.46\end{array}$ & $\begin{array}{l}0.65-1.73 \\
0.79-2.68\end{array}$ \\
\hline $\begin{array}{l}\text { No. of cigarettes } \\
\text { smoked daily }\end{array}$ & $\begin{array}{l}0 \\
1-10 \\
\geq 11\end{array}$ & $\begin{array}{l}1.00 \\
0.99 \\
1.41\end{array}$ & $\begin{array}{l}0.59-1.65 \\
0.81-2.47\end{array}$ \\
\hline
\end{tabular}

1 Reference category. 
Table 2. Consumption of milk products and fat intake of 133 breast cancer cases and 289 control subjects.

\begin{tabular}{|c|c|c|c|c|c|}
\hline Milk product & $\begin{array}{l}\text { nont } \\
\text { Cases }\end{array}$ & $\begin{array}{l}\text { tsers } \\
\text { Con- } \\
\text { trols }\end{array}$ & $\begin{array}{l}\text { Intake ar } \\
\text { Cases }\end{array}$ & $\begin{array}{l}\text { ong users } \\
\text { Controls }\end{array}$ & $\begin{array}{l}\text { Difference } \\
\text { (95: CI) }\end{array}$ \\
\hline \multicolumn{6}{|l|}{ Fermented milk } \\
\hline Yogurt & 32 & 33 & $64 \pm 55$ & $74 \pm 70$ & $10(-7,26)$ \\
\hline Buttermilik & 59 & 54 & $106 \pm 92$ & $150 \pm 130$ & $(6,82)$ \\
\hline Curds & 77 & 80 & $18 \pm 18$ & $30 \pm 66$ & $12(-12,36)$ \\
\hline Kefir & 99 & 100 & $84 \pm 4$ & $86 \pm 0$ & $2 \quad-$ \\
\hline Total 3 & 21 & 21 & $116 \pm 100$ & $157 \pm 144$ & $9,72)$ \\
\hline Gouda cheese & 5 & 3 & $39 \pm 27$ & $43 \pm 29$ & $(-2,10)$ \\
\hline Milk & 28 & 24 & $189 \pm 154$ & $203 \pm 80$ & $14(-27,56)$ \\
\hline Total fat intake & $-*$ & - & $100 \# 36$ & $92 \pm 30$ & $8(1,14)$ \\
\hline
\end{tabular}

1 Mean \pm standard deviation ( $g /$ day) among users only.

2 Mean difference (95\% confidence interval) among users only.

3 Sum of fermented $\mathrm{milk}$ products: yogurt, buttermilk, curds and kefir.

* Not applicable.

variable the association became statistically significant (Table 3 ). Consumption of milk was not significantly associated with the odds ratio for breast cancex in either the age-adjusted or the multivariate model.

\section{Discussion}

Our results suggest that consumption of a high amount of fermented inilk products may have a protective effect on the risk of breast cancer. After allowance for fat intake, a similar relationship was observed for Gouda cheese, which is also a cultured milk product. No statistically significant relationship was observed between consumption of milk and breast cancer.

Until. now, only one epidemiological study (4) has addressed the consumption of a fermented milk product, i.e. yogurt, in relation to breast cancer. In most studies conducted so far, no distinction has been made between fermented and nonfermented dairy praducts. In our study, we distinguished different types of milk products, we inquired about consumption frequency and number of glasses or dishes, we actually measured the contents of relevant household 
utensils, and we conducted analyses using average daily intakes with and without adjustment for total fat intake and other potential. confounders.

We considered whether the inverse association with fermented milk products might be explained by confounding or other sources of bias. adjustment for a large number of breast cancer risk factors (see "Subjects and Methods"), and the most widely discussed dietary factors with regard to breast cancer, i.e. fat and alcohol intake $(23,24)$, however, did not appreciably affect the results. Furthermore, it was considered that response could be related to socioeconomic status and food habits. However, when intake of fermented milk of cases and controls was stratified according to the educational level of the women (who generally buy and prepare the food) or their partners, cases consumed less fermented milk products than controls in all strata. Results of the multivariate analysis were similar when education level of the partners (rather than the women) was included in the model. Finally, no major differences were abserved between partial $(n=89)$ and complete responders ( $n=289$; see 'Subjects and Methods'), neither with regard to age, age at first full-term pregnancy, parity, height, weight and body mass index, nor with regard to fat content of milk products and food items used on bread, usual consumption of bread, eggs and fish.

The inverse association between consumption of Gouda cheese and breast cancer seems to disagree with the results of Le et al. (4), who abserved a positive association with the frequency of consumption of French cheese. Their data, however, required extensive classification of many types of cheese, while our analysis could be restricted to Gouda cheese, accounting for more than $90 \%$ of total cheese consumption in our study population. Moxeover, the inverse association appeared after adjustment for total daily fat intake, which was not taken into account by Lê et al. "The association, however, can also partially be attributed to the small. number of nonusers and was weakened when educational level of the partner (instead of the women), was included in the multivariate model (data not shown). Because microorganisms used in fermentation of Gouda cheese are similar to those in some other fermented milk products, this association is in line with the study hypothesis.

Biological evidence supporting the hypothesis that fermented milk products may protect against breast cancer points to lactic bacteria interfering with the enterohepatic circulation $(13-17)$ or stimulating immunological activity $(6,18,19)$ * Lactobacillus bulgaricus and streptococcus thermophilus play an important role in the production of yogurt, while other lactic acid bacteria (Streptococcus spp. and Leuconostoc spp.) are used in the production of buttermilk and Gouda cheese $(25,26)$. In our data, the lowered 
Table 3. Relation between consumption of fermented milk products (sum of yogurt, buttermilk, curds, kefir), Gouda cheese, and milk and breast cancer for 133 cases and 289 population controls, assessed by age-adjusted and multivariate logistic regression.

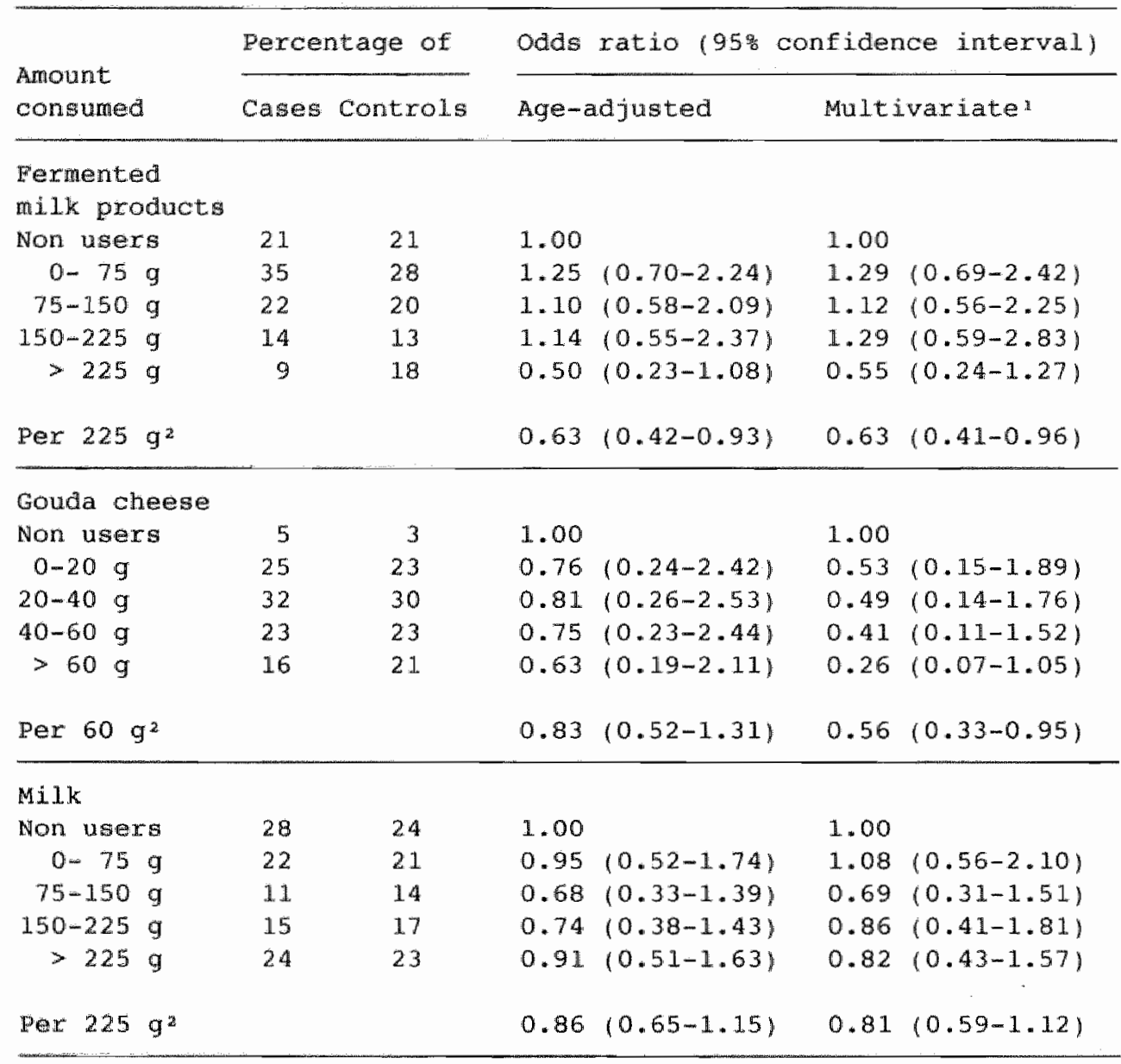

- Adjusted for age, fat and alcohol intake, history of benign breast disease, first- and second-degree familial history, number of cigarettes smoked daily, womans educational level, ever use of oral contraceptives, age at menarche, age at first full-term pregnancy, parity, body mass index, geographic area.

2 Derived from the logistic regression model, with intake specified in 9 . An average cup of milk contains about $150 \mathrm{~g}$. 
odds ratio at high intake of fermented milk can be attributed, to a large extent to buttermilk (Table 2). For Gouda cheese, with an initially higher concentration of live bacteria, the decreased odds ratio was observed at a lower intake. Since the number of live bacteria in Gouda cheese decreases considerably during storage this suggests that the protective effect of fermented milk products might not be limited to live lactic acid bacteria from yogurt, but could extend to the microorganisms (not necessarily Live) in these other fermented products.

In conclusion, our results are in agreement with the observations of Lê et al. (4), and support experimental research suggesting favorable effects of lactic acid-forming bacteria on the intestinal microflora and the immune system. The suggested protective effect of a high intake of fermented milk products (including Gouda cheese) on the risk of breast cancer needs to be substantiated by further observational and experimental research.

\section{References}

1 Armstrong $B$, Doll R. Environmental factors and cancer incidence and mortality in different countries, with special reference to dietary practices. Int J Cancer, 1975;15:617-31.

2 Gaskill SP, McGuire WL, osborne CK, Stern MP Breast cancer mortality and diet in the united states. Cancer Res, $1979 ; 39: 3628-37$.

3 Talanini R, La Vecchia C, Decarli. A, et al. Social factors, diet and breast cancex in a northern Italian population. Br $\mathrm{J}$ Cancer, $1984 ; 49: 723-9$.

4 Lê MG, Moulton LH, Hill C, Kramar A. Consumption of dairy produce and alcohol in a case-control study of breast cancer. I Natl Cancex Inst, $1986 ; 77: 633-6$.

5 Reddy GV, Friend BA, Shahani KM, Farmer RE, et al. Antitumor activity of yogurt components. I Food Prot, $1983 ; 46: 8-1.1$.

6 Bogdanow IG, Velichkov VI, Gurevich AI, et al. Antitumor action of glycopeptides from the cell wall of Lactobacllius bulgaricus. Bull Exp Biol Med, $1978 ; 84: 1750-3$.

7 Friend BA, Shahani KM. Antitumor properties of lactobacilli and dairy products fermented by lactobacilli. I food prot $1984 ; 47: 717-23$.

8 Robins-Browne RM, Levine MM. The fate of ingested lactobacilii in the proximal small intestine. An J Clin Nutr 1981;34:514-9.

9 Shahani KM, Ayebo AD. Role of dietary lactobacilli in gastro intestina $\mathbb{H}$ microecology. Am $J$ CI in Nutr, 1980;33:2448-57.

10 Rao DR, pulusani SR, Chawan $C B$ Natural inbibitors of carcinagenesis: fermented milk products. In: Reddy BS, Cohen LA. 
(eds). Diet, nutrition and cancer: critical evaluation, vol 2. Boca Raton: CRC Press Inc., 1986, 63-75.

11 Goldin BR, Gorbach $5 \mathrm{~L}$. Alterations in fecal microflora enzymes related to diet, age, lactobacillus supplements, and dimethylhydrazine. Cancer 1977;40:2421-6.

12 Goldin BR, Gorbach SL. The effect of milk and lactobacillus feeding on human intestinal bacterial enzyme activity. Am J Clin Nuter $1984 ; 39: 756-61$.

$13 \mathrm{Hill} \mathrm{MJ,} \mathrm{Goddard} \mathrm{P,} \mathrm{Williams} \mathrm{REO.} \mathrm{Gut} \mathrm{bacteria} \mathrm{and} \mathrm{aetiology} \mathrm{of}$ cancer of the breast. Lancet, 1971;2:472-3.

14 Gorbach SL. Estrogens, breast cancer, and intestinal flora. Rev Infect Dis $1984 ; 6: \$ 85-90$.

15 Murray WR, Blackwood A, Calman KC, Mackay C. Faecal bile acids and clostridia in patients with breast cancer. Br J Cancer 1980; $42: 856-60$.

16 Papatestas AE, Panvelliwalla D, Tartter PI, Miler S, pertsemlidis D, Aufses AH. Fecal steroid metabolites and breast cancer risk. Cancer (Phila), 1982;49:1201-5.

17 MLller $S R$, Papatestas AE, Panvelliwalla D, Pertsemlidis D, Aufses AH. Fecal steroid excretion and degradation and breast cancer stage. J Surg Res 1983;34:555-9.

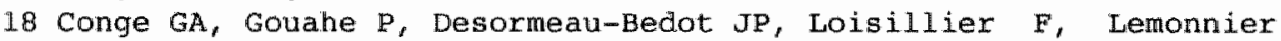
D. Effets comparés d'un régime enrichi en yoghourt vivant ou thermisé sux le systëme immunitaire de la souris. Reprod Nutr Dévelop $1980 ; 20: 929-38$.

19 De Simone C, Salvador 1 BB, Negri $R_{f}$ Ferrazzi M, Baldinelli $L$, Vesely R. The adjuvant effect of yogurt on production of gamminterferon by con a-stimulated human peripheral blood 1ymphocytes. Nutr Rep Int 1986;33:419-33.

20 Kurmann JA. The production of fermented milk in the world. I. Statisticg. Bulletin of the International Dairy Federation $1984 ; 1.79: 8-15$.

21. Hautvast JGAJ. Commissie uniforme codering voedingsmiddelen: ontwikkeling van een systeem om gegevens van voedingsenquêtes met behulp van de computer te verwerken. Voeding 1975;36:356.

22 Uitgebreide Voedingsmiddelentabel. Kommissie UCV. Voorlichtingsbureau voor de Voeding, The Hague, 1984.

23 Goodwin PJ, Boyd NF. Critical appraisal that dietary fat intake is related to breast cancer risk in humans. J Natl Canc Inst $1987 ; 79: 473-85$.

24 Longnecker MP, Berlin JA, orza MJ, Chalmers TC. A meta-analysis of alcohol consumption in relation to risk of breast cancer. J Am Med Assoc $1988 ; 260: 652-6$.

25 Puhan $Z$. Results of the questionnaire $1785 \mathrm{~B}$ "Fermented milks". Bulletin of the International Dairy Federation $1988 ; 227: 138-64$. 
Fermented milk products

26 Galloway JH, Crawford JM. Cheese fermentations. In: Wood BJB (ed). Microbiology of fermented foods, Vol 1. London, Elsevier, 1985, $111-65$. 

DIETARY FIBER, BETA-CAROTENE AND BREAST CANCER: RESULTS FROM A CASE-CONTROL STUDY 1

\begin{abstract}
Pieter wan "t Veer, Corine M Kolb, Petra Verhoef, Frans I Kok, Evert G Schouten, Rudolph JJ Hermus, Ferd Sturmans.
\end{abstract}

\title{
Abstract
}

To study the association between dietary fiber, beta-carotene and breast cancer the average daily intake of these dietary components was compared among 133 incident breast cancer cases and 238 population controls. Average daily intake of cereal products, fruit and vegetables was also studied. A statistically significant lower energy adjusted intake of dietary fiber was observed in cases compared to controls (mean \pm standard deviation: $25.4 \pm 6.7 \mathrm{~g}$ versus $27.7 \pm 7.4 \mathrm{~g}, 95$ per cent confidence interval (CI) of the ageadjusted difference $=-3.8,-0.8$ ). Intake of beta-carotene was similar for cases and controls. The multivariate adjusted odds ratio (OR) of breast cancer among women in the highest quartile of intake of cereal products, as compared to those in the lowest quartile was $0.42(95 \% \quad C I=0.19-0.92)$ and the trend was statistically significant $(p=0.03)$. The corresponding or for intake of dietary fiber was $0.55(95 \% \quad C I=0.26-1.17)$ but the trend was not statistically significant. The oR for the highest quartile of intake of beta-carotene, fruit, vegetables, and all vegetable products combined was less than unity, but there was no significant inverse trend.

These results suggest that high intake of cereal products, especially those rich in fiber may be inversely related to breast cancer.

\section{Introduction}

Fat and energy intake have been emphasized as etiological Eactors increasing the risk of breast cancer $(1,2)$, but the biological mechanism has not been elucidated $(3,4)$. other dietary components, not contributing to energy, e.g., dietary fiber and beta-carotene, have been suggested to reduce cancer risk (5-7). In a case-control study in Israel, Lubin et al. found that a high intake of dietary fiber was associated with decreased risk of breast cancer (8). From a case-control study in Australia an inverse association between

International Journal of Cancer 1990 (in press). 
intake of betamcarotene and breast cancer risk was reported (9). It is supposed that dietary fiber could influence breast cancer risk by modifying oestrogen metabolism $(10-13)$. Beta-carotene may protect against breast cancer either directly through its antioxidant function of indirectly through its provitamin $A$ activity $(6,14)$.

In this case-control study the relation between breast cancer and intake of dietary fiber, beta-carotene and their major dietary sources (cereal products, fruit and vegetables) has been investigated.

Subjects and methods

\section{Study population}

Dutch Caucasian women, 25-44 and 55-64 years of age, residing in the middle and southern part of the Netherlands were eligible for the case-control study. In order to address additional hypotheses, caseascertainment included preoperative blood collection as well as interviews after hospital discharge. Consequently, study procedures were complicated and cooperation was obtained from 17 of 35 hospitals in the study area, covering 55 percent of hospital admissions. Non-cooperation among surgical units was related to matters of privacy and feasibility of study procedures. It seems unlikely that these factors are related to dietary factors in the study population residing in the hospitals' catchment areas. Moreover, coverage of case recruitment was independent of age and degree of urbanization of residence. During 1985-87, 168 newly diagnosed eligible breast cancer patients were enrolled, either by cooperating surgeons or by regional cancer registries. of these patients 80 pexcent ( 134 women) were willing to cooperate. Data from one case were considered unreliable and excluded from the analysis. population controls $(n=548)$, with age distribution similar to the cases, were sampled from the municipal population registries in the same area as the cooperating hospitals. Complete interview data were obtained from 289 controls. Since the dietary questionnaire initially did not completely cover sugar intake (no questions were asked concerning sugar added to coffee and tea or soft drinks), 51 controls with incomplete data on energy intake were excluded, Leaving 238 controls for data analysis. In order to evaluate representativeness of the control group, the entire control sample was asked to complete a short postal questionnaire. This questionnaire was returned by virtually all responding and 89 of the non-responding controls. 
During 1985-1987 the breast cancer cases and controls were interviewed by two well-trained, registered dietitians in the course of a two-hour home visit. Most cases (91) were interviewed within six months of diagnosis. No interviews were conducted during periods of chemotherapy treatment. To assess average daily food intake, a structured dietary history interview was conducted comprising 236 separate food items including all major vegetable products used, and referring to the twelve-month period preceding diagnosis (for cases) or interview date (for controls). In order to check the reported consumption frequencies of vegetable products, their cumulative frequency was compared with the reported frequency of hot meals containing these products, and adjusted accordingly. The content of the most commonly used household utensils (spoons, cups, glasses, dishes) was measured to obtain a more accurate quantification of the portion sizes. Average daily nutrient intake was calculated using the 1984 release of the computerized Dutch Nutrient Data Bank (15). Beta-carotene intake was caiculated as six times the amount of retinol provided by fruits and vegetables.

In addition to dietary habits, the questionnaire also addressed smoking habits, demographic and socio-economic characteristics, reproductive history, history of previous breast diseases, use of oral contraceptives and other hormones, and pre-diagnostic weight.

\section{Reproducibility and validity of dietary assessment}

In order to assess the reproducibility of nutrient intake as estimated by the interview, it was repeated in a sample of 39 subjects one year after the first interview. Although true changes In diet might have occurred, mean intakes of retinol equivalents and dietary fiber differed less than 2 between both occasions, and the pearson coefficient of correlation for retinol equivalents and dietary fiber was 0.52 and 0.65 , respectively. Validity was assessed by comparison of dietary intake and plasma concentration of carotenoids and retinoids in controls (Table 1). Beta-carotene intake was positively associated with plasma concentrations of betacarotene and total carotenoids, supporting the validity of the questionnaire and of the food tables used. No statistically significant association was apparent with plasma retinol. Moreover, as expected in a population with adequate vitamin $A$ supply no association was observed between dietary and plasma retinol (16) (data not shown). 
Table 1. Relation between carotenoids and retinol in diet and plasma of controls.

Dietary intake of beta carotene
Plasma concentration ( $4 m o l / 1)$ of Beta-carotene carotenoids Retinol $(n=149) \quad(n=118)$

$\begin{array}{rlllllll} & \leq 1.5(1.2) \mathrm{mg}^{1} & 0.28(0.04)^{2} & 1.35 & (0.09) & 1.57(0.07) \\ 1.5 & =2.0(1.7) \mathrm{mg} & 0.31(0.05) & 1.33(0.12) & 1.51(0.07) \\ 2.0-2.8(2.4) \mathrm{mg} & 0.30(0.03) & 1.74(0.10) & 1.69(0.07) \\ >2.8(4.2) \mathrm{mg} & 0.43(0.09) & 1.88(0.20) & 1.70(0.06)\end{array}$

Pearson coefficient of correlation 0.553 $0.45^{3}$ 0.10

1 Categories similar to Table 3 ; mean intake in categories in parentheses.

2 Mean (standard error of the mean).

$3 p<0.05$.

\section{Data analysis}

Crude mean intake (and standard deviation) were calculated for cases and controls and age-adjusted differences of means and their $95 \%$ confidence intervals were obtained from multiple regression analyses. In order to obtain estimates of the relative odds, categories of duetaxy variables were formed, based on quartiles of the distibution of intake in controls. Age-adjusted and multivariate odds ratios and their standard errors were derived from logistic regression analysis. The following risk factors of breast cancer were considered as potential confounders: history of benign breast disease, first and second degree of family history, smoking habits, educational level, ever use of oral contraceptives, age at menarche, age at first full-term pregnancy and/or parity, body mass index, energy intake, alcohol intake, and geographical area. Most of these variables were weakly associated with breast cancer, but the direction of most associations was as expected (Table available upon request). When these variables were added to the logistic model either separately or simultaneous $1 \mathrm{y}$, energy intake appeared to be the only important confounder. Linear trend in the adds ratios was tested by scoring the quartiles 1 to 4 , and entering this score as a continuous variable. 
Results

Average daily intake of energy, dietary fiber, beta-carotene and the major vegetable food groups is shown in Table 2. Although energy intake of cases was higher than that of controls, the intake of the vegetable constituents and food groups tended to be lower among cases. The age-adjusted difference for the absolute intake of dietary fiber was of borderline significance. When energy intake was taken into account, however, the $95 \%$ confidence interval did not include the null-value. The intake of beta-carotene was similar for cases and controls, whether or not energy intake was taken into account. In the study population, the average daily intake of dietary fiber was accounted for by cereal products (35\%), vegetables $(27 \%)$ and fruit (20\%). Vegetables were the major source of betacarotene, accounting for $89 \%$ of daily intake, while fruit accounted for the remaining 118 . Although cases tended to have lower mean

Table 2. Intake of energy, dietary fiber, beta-carotene and vegetable products in breast cancer cases and population controls.

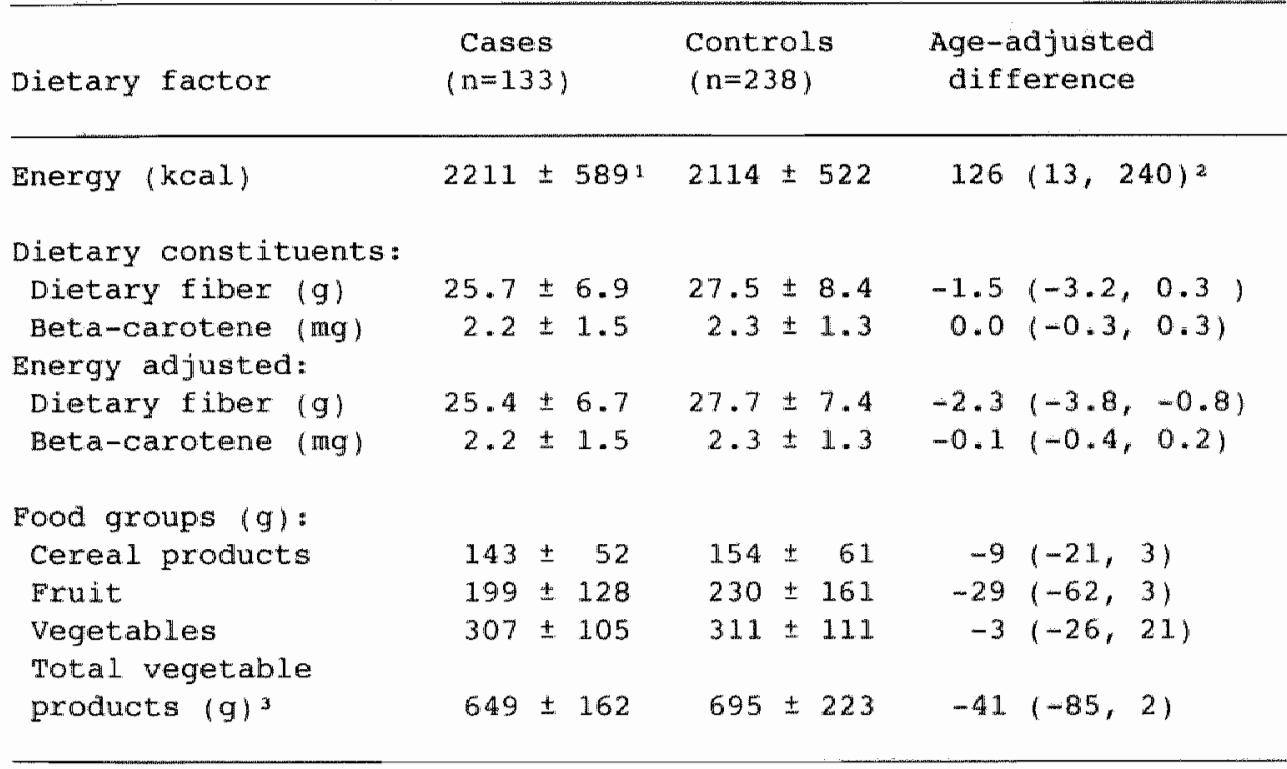

1 Means I standard deviation.

$295 \%$ confidence interval in parentheses.

3 total of cereal products, fruit (fresh and canned) and vegetables (including potatoes). 
intakes, especially for cereals and fruit, the age-adjusted differences were not statistically significant. Bread consumption accounted for about $90 \%$ of the intake of cereal products, whereas other cereals (e.g., rice, pasta) accounted for about 10\% only. The age-adjusted case-control difference for bread was $-3.6 \mathrm{~g} / \mathrm{day} / 95 \%$ confidence interval $\mathrm{CI}=-15.1,8.0)$, while this was $-5.5 \mathrm{~g} /$ day (95: CI $=-11.6,0.7)$ fox other cereals products.

Estimates of the relative odds of breast cancer for quartiles of intake of dietary fiber, beta-carotene and vegetable products are shown in Table 3. A decreasing trend was observed with increasing intake of dietary fiber $(\operatorname{chi} z=2.71, \mathrm{p}=0.10)$. The age-adjusted relative odds of breast cancer among women in the highest quartile of dietary fiber intake as compared to women in the lowest quartile was $0.71(95 \% \mathrm{CI}=0.37-1.36)$; the corresponding multivariate odds ratio was $0.55(95 \% \mathrm{CI}=0.26-1.17)$. For beta-carotene the ageadjusted relative odds for the highest versus the lowest quartile of intake was $0.73(95 \% \mathrm{CI}=0.38-1.38)$, which was reduced to 0.63 $(95 \% \mathrm{CI}=0.31-1.26)$ upon multivariate analysis, but the trend was not statistically significant. Because of the common dietary sources, there was a positive correlation between the intake of dietary fiber and beta-carotene (Pearson coefficient of correlation $r=0.42$ among controls, $p<0.001$ ). However, when entered simultaneously in the multivariate logistic regression model (both of them represented by three indicator variables), their odds ratios remained nearly unchanged.

For women in the highest quartile of intake of cereal products, the age-adjusted odds ratio was $0.67(95 \% \mathrm{CI}=0.34-1.29)$; the multivariate odds ratio was $0.42(95 \% \mathrm{CI}=0.19-0.92)$ and the test for trend was statistically significant. For the intake of fruit and vegetables, no statistically significant decreasing trends were observed. For all vegetable products taken together, the multivariate relative odds of breast cancer for the highest versus the lowest quartile was $0.63(95 \% \mathrm{CI}=0.30-1.32)$, but the trend did not reach statistical significance.

\section{Discussion}

In our case-control study, we observed an inverse association between intake of cereal products and, possibly, dietary fiber with breast cancer. Except for vegetable consumption, the odds ratio in the highest quartile of consumption was below unity for all dietary factors considered. Although no inverse trend was observed, this pattern became more pronounced when other risk factors of breast cancer were taken into account in multivariate analysis. 
Table 3. Odds ratio (OR) of breast cancer for quartiles of intake of dietary fiber, beta-carotene and vegetable products, in 133 breast cancer cases and 238 population controls.

\begin{tabular}{lllll}
\hline & $1^{1}$ & Level of consumption & $x^{2}$ trend \\
Dietary factor & 2 & 3 & 4 & $(p-v a l u e)$
\end{tabular}

Dietary fiber

no of cases/controls

age-adjusted $\mathrm{OR}$

multivariate $O R^{2}$

Beta-carotene

no of cases/controls

age-adjusted $O R$

multivariate $O R^{2}$

Cereal products

no of cases/controls

age-adjusted $O R$

multivariate $\mathrm{OR}^{2}$

Fruit

no of cases/controls

age-adjusted or

multivariate $\mathrm{OR}^{2}$

$\begin{array}{rrrr}33 / 59 & 42 / 60 & 36 / 60 & 22 / 59 \\ 1.00 & 1.24 & 1.04 & 0.71 \\ 1.00 & 1.34 & 0.98 & 0.55\end{array}$

$\begin{array}{rrrr}34 / 59 & 38 / 60 & 37 / 60 & 24 / 59 \\ 1.00 & 1.20 & 1.12 & 0.73 \\ 1.00 & 1.08 & 1.09 & 0.63\end{array}$

$1.41(0.23)$

$\begin{array}{rrlr}36 / 60 & 43 / 60 & 32 / 59 & 22 / 59 \\ 1.00 & 1.25 & 0.93 & 0.67 \\ 1.00 & 1.25 & 0.87 & 0.42\end{array}$

$4.99(0.03)$

\section{$36 / 57$}

1.00

$29 / 62$

1.00

0.73

0.82

$\begin{array}{rr}29 / 60 & 34 / 59 \\ 1.00 & 1.30 \\ 1.00 & 1.08\end{array}$

$34 / 60$

$32 / 59$

1.12

1.03

1. 17

0.86

$47 / 61 \quad 21 / 58$

1.21

0.56

0.55

$0.88(0.35)$

$0.19(0.66)$

Vegetables

age-adjusted oR

multivariate $O R^{2}$

Total vegetable products

no of cases/controls

age-adjusted or

multivariate $\mathrm{OR}^{2}$

$34 / 59$
1.00
1.00

$41 / 60$

$31 / 60$

$27 / 59$

1. 22

0.90

0.84

1. 31

0.84

0.63

- Reference category, lowest consumption category.

* Adjusted for age, history of benign breast disease, first and second degree of family history, number of cigarettes smoked daily, educational level, ever use of oral contraceptives, age at menarche, age at first full-term pregnancy, body mass index, energy intake and alcohol intake. 
we considered whethex the inverse association with dietary fiber and vegetable foods might be explained by confounding factors or other potential sources of bias. First, the intake of dietary fiber was positively associated with fat and energy (Pearson $r$ in controls is 0.32 and 0.48 respectively). Despite their higher energy and fat intake, however, cases used on avexage less dietary fiber and vegetable foods. Moreover, when energy intake was taken into account in multivariate analysis, odds ratios in the highest intake categories decreased for all variables considered. Second, we compared dietary and life style factors in responders and nonresponders in the controll group, together representing 718 of the inftial. sample from the municipal population registries. Daily amount of bread was similar for responders and non-responders $(3.9$ and 4.0 slices per day), but responders tended to prefer whole meal bread $(\mathrm{p}=0.07)$, which may have si.ightly strengthened the inverse assoclation with dietary fiber. Fuxthermore, daily intake of fat from dairy products and food items on bread, and consumption frequency of eggs and fish was similar in responders and nonresponders, and no differences were observed with regard to age, age at fixst full term pregnancy, weight, height and body mass index. Therefore, life style and risk profile of responding and nonresponding controls are considered to be similar.

Previous case-control studies have also suggested an inverse association between breast cancer risk and intake of dietary fiber. In Israel, Lubin et al. reported that consumption frequency of fiber-rich foods was inversely associated with breast cancer, especially at high levels of fat and animal protein intake (8). In a case-control study in Australia, Rohan et al. found a lowered odds ratio for breast cancer at high dietary fiber intake compared to the lowest quintile (9). Although our study was of linited size, results for cereal products and dietary fiber may refiect the same association as in these other studies.

The biological mechanism explaining the inverse association between dietary fiber and breast cancer is essentially based on its potential effect on the intestinal microflora, leading to altered production and conversion of steroids $(12,17)$, and fiber related lignans (18). This affects the pattern of faecal excretion of these substances $(10,11)$ and, possibly, the oestrogenic stimulus to the breast (12). Dietary tiber may influence the concentration of intestinal oestrogens and (prelcarcinogens by sequestrating biliary oestrogens (19), increased faecal mass by water binding properties of cereal fiber, and altered enzymatic activity of the colonic microflora by fermentable fiber from fruit and vegetables $(20,21)$. one can speculate that the inverse relation of breast cancer with cereal products rather than fruit and vegetables, may be related to 
their different chemical characteristics. In order to substantiate this, however, more quantitative information is needed on the effect of dietary factors on intestinal sterold metabolism, on specific fiber content of foods, and on validity of dietary methods with respect to specific food groups.

Beta-carotene may protect against breast cancer either directly through its anti-oxidant function $(14,22)$ or indirectly after conversion into retinol (vitamin A activity) $(6,23)$. Both biomarkers and dietary intakes have been used to evaluate the beta-carotene hypothesis in epidemiological studies. The relation between dietary intake and plasma levels of carotene is generally weak, however (24), and study results may depend on the method used for betacarotene assessment. Wald et al. reported a tendency to lower plasma levels of beta-carotene in women who subsequently developed breast cancer (25). Willett and colleagues did not find lowered plasma carotenoids in future breast cancer cases compared to controls, either before or after lipid adjustment (22). In a case-control study in Australia, Rohan et al. observed an inverse association between intake of beta-carotene and breast cancer (9). In our study population, a lowered adds ratio $(O R=0.63)$ was observed in the upper quartile of beta-carotene intake, in which plasma betacarotene was increased as well. Dietary beta-carotene was also positively associated with total plasma carotenoids and (weakly) with plasma retinol, however. Thus, the observed association with disease may also be attributed to other factors associated with beta-carotene intake, e.g. plasma retinol (Table 1 ) or constituents of a vegetable rich diet.

In conclusion, our results suggest that a diet rich in vegetable products may lower breast cancer risk. Although this association was most clearly observed for cereal products, a possible protective effect of ather constituents of vegetable products cannot be excluded. Biological explanations for a protective effect of vegetable products are generally based on a possible relation between fiber and oestrogen metabolism, or the anti-oxidant capacity of carotenoids. In addition to dietary assessment, future epidemiologic research on diet and cancex, will need both clinical experiments on specific dietary components (26), and more extensive use of biomaxkers of exposure in observational studies.

References

I Rohan TE, Bain CJ. Diet in the etiology of breast cancer. Epidemiol Rev $1987 ; 9: 120-45$. 
2 Goodwin $\mathbb{P}$, Boyd MF. Critical appraisal of the evidence that dietary fat intake is related to breast cancer risk in humans. J Wat 1 Canc Inst $1987 ; 79: 473-85$.

3 Graham 5 . Mypotheses regarding caloric intake in cancer development. Cancer 1986:58:1814-7.

4 welsch $\mathrm{cW}$, Enhancenent of mammary tumorigenesis by dietary fat: review of potential mechanisms. Am J Clin Nutr 1987;45:192-202.

5 Correa P. Epidemiological correlations between diet and cancer frequency. Cancer Res 1981;41:3685-90.

6 Peto R, Doll R, Buckley JD, Sporn MB. Can dietary beta-carotene materially reduce human cancer rates? Nature 1981;290:201-8.

7 Watson RR, Leonard TK. Selenium and witamin $A, E$, and $C$ : nutrients with cancer prevention properties. I Am Diet Ass $1986: 86: 505-10$.

8 Lubin $F$, Wax $X$, Modan $B$. Role of fat, animal protein, and dietary fiber in breast cancer etiology: a case-control study. I Natl Canc Inst $1986 ; 77: 605-12$.

9 Rohan TE, MoMichael AJ, Baghurst PA. A population-based casecontrol study of diet and breast cancer in Australia. Am J Epidemiol $1988 ; 128: 478-89$.

10 Adlercreutz $H$, Fotsis $T$, Heikkinen $R$, Dwyer JT, woods $M_{*}$ Goldin $B R$, Gorbach SL. Excretion of the lignans enterolactone and enterodiol and of equol in omivorous and vegetarian women and in women with breast cancer. Lancet $1982 ; 2,1295-8$.

11 Goldin BR, Adlercreutz H, Dwyer JT, Swenson $\mathrm{L}_{\text {, Warram JH, Gorbach }}$ LS. Effect of diet on excretion of estrogens in pre- and postmenopausal women. Cancer Res 1981;41:3771-3.

12 Goldin BR, Adlercreutz $H$, Gorbach SL, Warram JH, Dwyer JT,

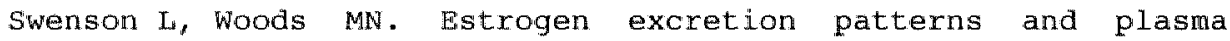
levels in vegetarian and omnivorous women. $\mathbb{N}$ Engl $J$ Med $1982 ; 307: 1542-7$.

1.3 Goldin BR, Adlercreutz H, Gorbach SL, Woods MN, Dwyer IT, Conlon $\mathrm{I}$, Bohn $\mathrm{E}$, Gershoff $\mathrm{SN}$. The rellationship between estrogen levels and diets of Caucasian American and oriental immigrant women. Am J Clin Nutx 1986;44:945-53.

14 Burton Gw, Ingold KU. Beta-carotene: an unusual type of lipid antioxidant. Science $1984 ; 224: 569-73$.

15 Kommissie UCV. Uitgebreide voedingsmiddelentabel 1984. Voorlichtingsbureau voor de voeding, The Hague, Netherlands, 1984 .

16 OLson $\pi$. Serum levels of vitamin A and carotenoids as reflectors of nutritional status. J Nat 1 Canc Inst $1984 ; 73: 1439-44$.

1.7 Goddard $\mathrm{P}$, Hill $\mathrm{MJ}$. The in vivo metabolism of cholesterol by gut bacteria in the rat and guinea pig. J Steroid Biochem $1974 ; 5: 569-$ 72 . 
18 Setchel1 KDR, Adlercreutz H. Mammalian lignans and phytooestrogens. Recent studies on their formation, metabolism and biological role in health and disease. In: Rowland, $\mathrm{X} . \mathbb{R}$. (ed), Role of the gut flora in toxicity and cancer, Academic press, London, $1988,315-45$.

19 Schultz TD, Howie BJ. In vitro binding of stexoid hormones by natural and purified fibers. Nutr Cancer $1986 ; 8: 141-7$.

20 Eastwood $M$. Dietary fiber and the risk of cancer. Nutr Reviews $1987 ; 45: 193-7$.

21 Council on Scientific Affairs. Dietary fiber and health. A Am Med Assoc $1989 ; 262: 542-6$.

22 Willett WC, Polk BF, Underwood BA, Stampfer MJ, Pressel. S, Rosnex $B$, Taylor Jo, Schneider $K$, Hames $C G$. Relation of serum vitamins $A$ and $\mathrm{E}$ and carotenoids to the risk of cancer. $\mathbb{N}$ Engl. $\mathrm{J}$ Med $1984 ; 310: 430-4$.

23 sporn $M B$, Roberts $A B$. Role of retinoids in differentiation and carcinogenesis. Cancer Res $1983 ; 43: 3034-40$.

24 Brown $E D$, Micozzi MS, craft NE, Bieri JG, Beecher $G$, Edwards BK, Rose A, Taylor PR, Smith JC. Plasma carotenoids in normal men after single ingestion of vegetables or purified beta-carotene. Am J Clin Nutr 1989;49:1258-65.

25 Wald NJ, Boreham J, Hayward JL, Bulbrook RD. Plasma retinol, beta-carotene and vitamin $\mathbb{E}$ levels in relation to the future risk of breast cancer. Br J Cancer 1984;49:321-4.

26 De vet HCW, Knipschild PG, Willebrand D, Schouten HJA, Sturmans F. The effect of beta-carotene on the regression and progression of cervical dysplasia: a clinical experiment (submitted). 


ALCOHOL DOSE, FREQUENCY AND AGE AT FIRST EXPOSURE IN
RELATION TO THE RISK OF BREAST CANCER Pieter van 't Veer, Frans I. Kok, Rudolph J.j. Hermus,
Ferd Sturmans.

Abstract

Habitual alcohol consumption, in terms of dose and frequency, average daily intake, as well as drinking alcohol at age 25 were compared between 120 incident breast cancer cases and 164 population controls in the Netherlands. Dietary and life style factors, past and present alcohol consumption were established in 1985-1987 in home interviews.

In premenopausal women a protective effect of low alcohol consumption ( $1-4 \mathrm{~g} /$ day) as compared to non-drinkers was suggested. The multivariate adjusted adds ratio (OR) comparing women drinking $\geq 30 \mathrm{~g}$ with women drinking 1 to $4 \mathrm{~g}$ alcohol daily was 8.5 (95\% confidence interval: $\mathrm{CI}=1.1-65.1)$. The oR for a dose of alcohol of $\geq 15 \mathrm{ks} 1-14 \mathrm{~g}$ was 4.0 (CI $=1.0-15.6$ ) and for drinking more versus less than 3 times a week the OR was 2.8 (CI $=0.8-9.8$ ). In postmenopausal women no association was observed between recent drinking habits and breast cancer risk. In these women, however, the adjusted or for drinking alcohol before the age of 25 was 2.4 $(C I=1.0-5.6)$.

Although causal inference is hampered by cultural aspects of drinking habits, the results suggest that moderate drinking does not increase risk. Drinking more than $30 \mathrm{~g}$ daily or a high dose may enhance risk in premenopausal women. Furthermore, an early start of drinking alcohol may increase the relative risk for breast canod. even beyond menopause.

\section{Introduction}

Epidemialogical studies have reported an increased risk of breast cancer of about 50 to 100 \% at an alcohol consumption of $10 \mathrm{~g}$ daily, e.g., about one glass per day (1). "The alcohol-breast cancer topic was introduced by two cross-cultural studies $(2,3)$ and one casecontrol study using inter-cancer comparisons (4). The key article of Rosenberg et al. (5) was soon followed by four negative case-control. studies, three of these using incident cases and hospital controls

International Journal of Epidemiology 1989;18:511-7. 
$(6-8)$, the other one prevalent cases and population controls (9). Since then, both hospital $(10-14)$ and population-based case-control studies $(15,16)$ as well as cohort studies have been published $(17-20)$, generally with positive findings.

The pathobiological action of alcohol, if any, is not necessarily related to the average daily intake, and frequency and dose may act differently. Regulax mild drinking may exert effects dissimilar to those caused by "binge" drinking (21) and moderate alcohol consumption may be beneficial in relation to cardiovascular disease in men (22). Alcohol may affect fat and hormone metabolism, vitamin and micronutrient status, the functioning of proteins and eicosanoid metabolism (23) resulting in either beneficial or harmful effects on breast tissue. Besides an increased breast cancer risk due to recent alcohol consumption, results of three case-control studies $(10,15,16)$ have suggested harmful effects of alcohol exposure at younger age, possibly because of higher susceptibility of breast tissue.

We have compared habitual alcohol consumption, both in terms of dose and frequency, and in terms of average daily intake i.e., dose times Erequency, as well as drinking at the age of 25,35 and 50 years, between incldent breast cancer cases and population controls in a case-control study in The Netherlands.

\section{Subjects and methods}

\section{Study population}

This study was conducted in 1985-1987. The recruitment of cases and controls was restricted to 25-44 and 55-64 year-old women, in order to stratify on menopausal status. Caucasians with newly diagnosed breast cancer and Dutch nationality, were eligible. A total of 168 wuch cases were identified from 17 hospitals and of these 134 (80\%) participated in the study. The diagnosis was histologically confirmed in 96\% of the cases. population controls ( $n=548)$ were sampled from the municipal population registry in the catchment area of the hospltals; 19 subjects were excluded because they either did not fulfil the eligibility criteria $(n=8)$, or because of an incorrect address $(\mathrm{n}=11)$. Two hundred and eighty nine (55\%) control subjects participated, with eligibility criteria, age distribution and period of investigation similar to the cases. In order to evaluate uniformity of the control group, 89 (37\%) of the nonresponding controls completed a postal questionnaire. No major difference were observed between responders and non-responders with regard to age, age at first full-term pregnancy, parity, weight, height and body mass index. 
Al1 cases were interviewed within one year after diagnosis, 91\% within six months. No interviews were conducted during periods of chemotherapy treatment. The interviews were carried out by two welltrained, registered dieticians in a two-hour home visit. The questions on drinking habits covered the year before diagnosis (cases) or the interview date (controls). Furthermore, the questionnaire inquired after dietary habits; smoking habits; demographic and socioeconomic characteristics; reproductive history and previous breast diseases; oral contraceptive and other hormone use; (pre-diagnostic) weight. Finally, anthropometrical measurements were obtained, toenail clippings were taken and a blood sample was drawn (for cases before surgery).

Habitual (recent) alcohol consumption was established accoraing to type (beer, wine, spirits; over 10 different types were distinguished), Erequency (if at least one drink per month was taken), and number of glasses per day. The liquid content of the drinking glasses used most frequently was measured at the end of the interview. Average daily alcohol intake was calculated, taking into account the different alcohol concentrations of the drinks and the content of the subjects" glasses. Questions on past drinking habits were added to the interview five months after the beginning of the study. Because of the time interval between diagnosis and interview, these data are available for 120 cases (90\% of interviews) and 164 control subjects (57\% of interviews). The data on past drinking habits were recorded as frequency and number of glasses of beer, wine and/or spirits usually drunk at age 25,35 and 50 , if applicable.

\section{Data analysis}

Analyses were carried out for pre- and postmenopausal women separately and restricted to subjects who were interviewed an both present and past arinking habits. Differences between cases and controls in exposure to major risk factors for breast cancer were tested by chi-square-, student t-test or test for trend. Habitual alcohol consumption was analyzed in terms of either average daily alcohol intake or frequency and dose, the llatter calculated by dividing average daily alcohol intake by cumulative frequency of all alcoholic drinks. Tests for effect of drinking frequency conditional. on dose, dose conditional on frequency and for a trend of the average daily intake were carried out using indicator variables in a logistic model. In the analyses both the traditional risk factors (age at menarche, reproductive history, use of oral contraceptives, history of benign breast disease, first and second degree familial. 


\section{Alcohol}

history, education, employment and smoking habitsl, and diet-related

Eactors (energy per cent fat intake, body mass index) were considered as potential confounders. Reproductive history was represented by durny variables, indicating whether or not the subject had children and, if so, how many (1-2 or more than 3$)$, and at what age the first child was born (before or after age 26). A variable was considered a confounder if it changed the rellative risk, as estinated by the odds ratio (24), by 10 s or more for any exposture category of alcohol in either pre- or postmenopausal women. Because drinking habits may differ between seasons and geographical regions, these factors were included in the multivariate analyses; age was included in all models.

The association of past drinking habits and breast cancer risk was evaluated in the postmenopausal group by multiple logistic regression analysis, controling for the same factors as in the previous analysis, except for the recent exposures (energy per cent fat intake and body mass index). Additionally, the following factors were considered as potential confounders by introducing them into the logistic model (one at a time): time-integrated alcohol intake (integrated from age 20), recent alcohol intake, energy per cent fat intake and body mass index. They did not appear to influence the odds ratio substantially. Analyses were carried out with BMDP statistical software (25).

\section{Results}

In the premenopausal women $91 \%$ of the cases and 95 of the controls had menses regulary, and $4 \%$ and $3 \%$ of the postmenopausal women respectively. Mean age of cases and controls was 38.3 (standard deviation $(S D)=4.0)$ and $39.4(S D=4.3)$ years for premenopausal women, respectively, and $60.2(\mathrm{SD}=3.2)$ and $60.4(\mathrm{SD}=3.2)$ years for postmenopausal women, respectively. Major risk factors for breast cancer in cases and controls are sumarized in Table 1 . In both the pre- and postmenopausal women a higher proportion of cases than controls reported having relatives with breast cancer. Age at first full-term pregnancy was only slightly associated with breast cancer, but the cases were less likely to have more than three children as compared to controls. In postmenopausal subjects, few women had a high educational level; in premenopausal women, however, educational level was generally higher, and associated with breast cancer.

Premenopausal. controls generally consumed more alcohol than postmenopausal controls, both with regard to average daily alcohol as well as dose of alcohol (Table 2). A similar difference was observed between premenopausal cases as compared to controls. Whthin 
Alcohol

Table 1. Major risk factors for breast cancer in cases and controls.

\begin{tabular}{|c|c|c|c|c|}
\hline \multirow[t]{2}{*}{ Risk factor } & \multicolumn{2}{|c|}{ Premenopausal women } & \multicolumn{2}{|c|}{ Postmenopausa 1 women } \\
\hline & $\begin{array}{l}\text { Cases } \\
(n=47)\end{array}$ & $\begin{array}{c}\text { Controls } \\
(n=85)\end{array}$ & $\begin{array}{l}\text { Cases } \\
(n=73)\end{array}$ & $\begin{array}{c}\text { Controls } \\
(n=79)\end{array}$ \\
\hline \multicolumn{5}{|l|}{$\begin{array}{l}\text { Proportion of women withl } \\
\text { First degree }\end{array}$} \\
\hline familial history ${ }^{2}$ & 11 & $2^{3}$ & 15 & 10 \\
\hline \multicolumn{5}{|l|}{ Second degree } \\
\hline familial history & 19 & 13 & 22 & 14 \\
\hline \multicolumn{5}{|l|}{ Reproductive history } \\
\hline Nulliparous & 15 & 22 & 15 & 10 \\
\hline First birth after $26 y$ & 23 & 25 & 40 & 46 \\
\hline Three or more children & 8 & 22 & 38 & $56 *$ \\
\hline \multirow{2}{*}{$\begin{aligned} \text { Education Low level } & \\
& \text { High Level }\end{aligned}$} & 30 & 45 & 64 & 62 \\
\hline & 23 & 1.3 & 4 & 9 \\
\hline Employment & 49 & 58 & 14 & 20 \\
\hline Current smoking & 45 & 35 & 25 & 20 \\
\hline \multicolumn{5}{|l|}{ History of benign } \\
\hline breast disease & 28 & 28 & 21 & 21 \\
\hline \multicolumn{5}{|l|}{ Ever use oral } \\
\hline contraceptives & 80 & 81 & 25 & 25 \\
\hline \multicolumn{5}{|l|}{$\begin{array}{l}\text { Mean and standard } \\
\text { deviation of: }\end{array}$} \\
\hline Age at menarche & $12 \cdot 9 \pm 1 \cdot 3$ & $13.2 \pm 1.4$ & $1.3 .4 \pm 1.7$ & $13.4 \pm 1.6$ \\
\hline \multicolumn{5}{|l|}{ Age at first } \\
\hline full-term pregnancy & $25.0 \pm 3.4$ & $25.3 \pm 3.7$ & $27.6 \pm 3.8$ & $27.7 \pm 4.4$ \\
\hline Body weight ( $\mathrm{kg}$ ) & $66.2 \pm 11.6$ & $65.8 \pm 12.5$ & $69.0 \pm 11.9$ & $71.2 \pm 10.3$ \\
\hline Body mass index $\left(\mathrm{kg} / \mathrm{m}^{2}\right)$ & $24.0 \pm 4.1$ & $23.9 \pm 4.9$ & $26.6 \pm 4.5$ & $26.3 \pm 3.4$ \\
\hline Energy intake (Kcal/day) & $2381 \pm 617$ & $2287 \pm 502$ & $21.39 \pm 554$ & $2009 \pm 520$ \\
\hline Fat intake (g/day) & $108 \pm 39$ & $97 \pm 28$ & $98 \pm 34$ & $86 \pm 3 I^{3}$ \\
\hline Energy fat intake & $40.1 \pm 7.1$ & $37.9 \pm 5.73$ & $40.5 \pm 5.9$ & $37.9 \pm 6.63$ \\
\hline
\end{tabular}

1 Per cent of subjects in the exposed category.

2 For familial history, missing values (2 and $28 \%$ respectively) were treated as having no familial history of breast cancer.

3 p 50.05 ; Chi-square- or t-test.

* Test for trend for parity in postmenopausal women significant at $p=0.05$. 
the postmenopausal subjects such differences were not observed. cross-classification according to frequency and dose showed an assciation with frequency and dose within premenopausal women only. Average daily alcohol intake in the frequency by dose categorles was $1.8 \mathrm{~g}$ in the lowest and $31.6 \mathrm{~g}$ in the highest category of drinkers. Frequency and dose represented a $\mathrm{six}$ - and three-fold contrast in average daily alcohol intake approximately.

Table 2. Distribution of exposure to alcohol in cases and controls.

\begin{tabular}{|c|c|c|c|c|}
\hline \multirow[t]{2}{*}{ Exposure to alcohol } & \multicolumn{2}{|c|}{ Premenopausal women } & \multicolumn{2}{|c|}{ Postmenopausal women } \\
\hline & $\begin{array}{l}\text { Cases } \\
(n=47)\end{array}$ & $\begin{array}{c}\text { Controls } \\
(\mathrm{n}=85)\end{array}$ & $\begin{array}{l}\text { Cases } \\
(n=73)\end{array}$ & $\begin{array}{c}\text { Controls } \\
(n=79)\end{array}$ \\
\hline Ex-drinkers & 01 & 1 & 5 & 3 \\
\hline Non-drinkers & 19 & 11 & 23 & 19 \\
\hline Current drimkers & 81 & 88 & 71 & 78 \\
\hline Average daily intake $(g)^{2}$ & $\begin{array}{c}20.2 \\
(23.1)\end{array}$ & $\begin{array}{l}15.0 \\
(16.9)\end{array}$ & $\begin{array}{l}11.6 \\
(13.8)\end{array}$ & $\begin{array}{l}11.7 \\
(14.1)\end{array}$ \\
\hline Dose of alcohol $(g)^{2}$ & $\begin{array}{c}26.7 \\
(23.2)\end{array}$ & $\begin{array}{l}19.6 \\
(11.3)\end{array}$ & $\begin{array}{l}17.5 \\
(12.0)\end{array}$ & $\begin{array}{l}17.1 \\
(8.7)\end{array}$ \\
\hline $\begin{array}{l}\text { Categories of average } \\
\text { da } 11 y \text { intake }(g)\end{array}$ & & & & \\
\hline Non-drinkers & $19^{3}$ & 12 & 25 & 20 \\
\hline $0-4$ & 23 & 33 & 38 & 40 \\
\hline $5-14$ & 19 & 26 & 16 & 14 \\
\hline $15-29$ & 26 & 15 & 14 & 16 \\
\hline$\geq 30$ & 13 & 14 & 7 & 10 \\
\hline $\begin{array}{l}\text { Categories of } \\
\text { Erequency by dose }\end{array}$ & & & & \\
\hline Non-drinkers & $19^{3}$ & 12 & 25 & 20 \\
\hline $\begin{array}{r}\text { Freq } \leq 3 \text { per week, } \\
\text { dose }<15 \mathrm{~g} \\
\text { dose } 15 \mathrm{q}\end{array}$ & $\begin{array}{l}13 \\
19\end{array}$ & $\begin{array}{l}25 \\
23\end{array}$ & $\begin{array}{l}35 \\
12\end{array}$ & $\begin{array}{l}26 \\
19\end{array}$ \\
\hline $\begin{aligned} \text { Freq } \geq 4 & \text { per week } \\
& \text { dose }<15 \mathrm{~g} \\
& \text { dose } \geq 15 \mathrm{~g}\end{aligned}$ & $\begin{array}{l}13 \\
36\end{array}$ & $\begin{array}{l}14 \\
27\end{array}$ & $\begin{array}{r}7 \\
22\end{array}$ & $\begin{array}{r}8 \\
27\end{array}$ \\
\hline
\end{tabular}

1 Per cent of subjects.

a Mean (standard deviation); non-drinkers excluded.

$s$ Per cent of subjects, ex-drinkers excluded. 
The odds ratios for breast cancer according to categories of average daily alcohol intake are presented in Table 3 . In the simple model (adjusted for age, season, region), no clear association was observed in either pre- or postmenopausal women. Multivariate adjustment for confounders, however, revealed an odds ratio for the highest drinking category $(\geq 30 \mathrm{~g}$ daily) as compared to the lowest $(1-4 \mathrm{~g}$ daily) of $8.5(95 \% \mathrm{CI}=1.1-65.1)$ and a positive trend was observed within drinkers $(p<0.04)$. These statistically significant findings disappeared, however, when both pre- and postmenopausal. women were analyzed simultaneously in one logistic model with menopausal status included as an effect modifier (p-value for interaction $\mathrm{p}<0.82)$.

Table 3. Odds ratio for breast cancer according to average daily intake of alcohol, in pre- and postmenopausal women.

Relative risk (95\% confidence interval)

\begin{tabular}{|c|c|c|c|c|}
\hline \multirow{2}{*}{$\begin{array}{l}\text { Alcohol } \\
\text { intake (9) }\end{array}$} & \multicolumn{2}{|c|}{ Premenopausal } & \multicolumn{2}{|c|}{ Postmenopausal } \\
\hline & Simple & Multivariate 2 & Simple 1 & Multivariate \\
\hline None & 1.0 & 1.0 & 1.0 & 1.0 \\
\hline $1-4$ & 0.6 & $0.3(0.0-1.7)$ & 0.9 & $0.8(0.3-2.3)$ \\
\hline $5-14$ & 0.5 & $0.5(0.1-2.9)$ & 1.2 & $1.0(0.3-3.6)$ \\
\hline $15-29$ & 1.0 & $0.8(0.1-4.9)$ & 1.0 & $1.1(0.3-4.3)$ \\
\hline$\geq 30$ & 0.7 & $2.3(0.3-19.1)$ & 0.7 & $0.9(0.2-4.5)$ \\
\hline Drinking vs none & & $0.6(0.1-2.7)$ & & $0.9(0.3-2.3)$ \\
\hline$\geq 30$ vs $1-4 \mathrm{~g}$ & & $8.5(1.1-65.1)$ & & $1.1(0.5-2.4)$ \\
\hline Trend within & & & & \\
\hline drinkers 3 & & $p<0.04$ & & $p<0.37$ \\
\hline
\end{tabular}

"Adjusted for age, region, season.

2 Adjusted for age, region, season, reproductive history, level of education, first degree familial history, smoking habits, body mass index, energy pex cent fat intake.

* P-value for trend within drinkers (categories scored $1,2,3$ and 4 ).

When drinking habits were expressed in terns of arinking frequency and dose, the simple model did not show statistically significant results in either group of women (Table 4 . As in the former analysis, multivariate adjustment increased the estimates of the odds ratio, especially in the premenopausal women. When the data of both groups were analysed simultaneously, the interaction term of dose and menopausal status reached borderline significance $(p<0.05)$, 
Alcohol

Table 4. Odds ratios for breast cancer according to frequency of drinking and dose of alcohol, stratified for menopausal status.

\begin{tabular}{|c|c|c|c|c|}
\hline \multirow[b]{2}{*}{ Contrast ${ }^{3}$} & \multicolumn{2}{|c|}{ Eremenopausal } & \multicolumn{2}{|c|}{ Postmenopausal } \\
\hline & Simple & Multivariate 2 & Simple & Multivariate 2 \\
\hline Frequency & 1.2 & $2.8(0.8-9.8)$ & 1.1 & $1.7(0.6-4.8)$ \\
\hline Dose & 2.0 & $4.0(1.0-15.6)$ & 0.6 & $0.4(0.2-1.2)$ \\
\hline Interaction & & & & \\
\hline Erequency* Dose & $\mathrm{p}<0.95$ & $p<0.91$ & $\mathrm{p}<0.69$ & $p<0.57$ \\
\hline
\end{tabular}

1 Adjusted for age, region, season.

z Adjusted for age, region, season, reproductive history, level of education, first degree familial history, smoking habits, body mass index, energy fat intake.

3 High versus low frequency (exceeding 4 versus less than 3 times per week) and high versus low dose (exceeding 15 versus $1-14 \mathrm{~g}$ ); both terms in model.

indicating a dose effect in pre- rather than postmenopausal women. In this model, however, the adds ratio in the premenopausal women did not differ significantly from 1.0 lodds ratio $=2.0 ; 95 \%$ $C I=0.7-5.4$ ).

In premenopausal women, a decreased odds ratio for an average daily intake of $1-4 \mathrm{~g}$ of alcohol was observed (Table 3). Furthermore, the mulivariate adjusted odds ratio for subjects drinking less than three times per week an amount of less than $15 \mathrm{~g}$ of alcohol, as compared to non drinkers was $0.13(95 \% \mathrm{CI}=0.02-1.02)$. It appeared that several $r$ isk factors in de premenopausal non-drinkers resembled the postmenopausal rather than the premenopausal lifestyle, e.g., lower education, less often employed, smoked less, later age at menarche, earliew first pregnancy and higher parity.

Table 5 shows the number of postmenopausal cases and controls who reported start of alcohol use before age 25, 35, 50 or thereafter. After adjustment for confounding, and grouping together subjects not arinking before age 25 , women who started drinking alcohol before age 25 appeared to be at increased risk. This association was not materially affected upon adjustment for either time-integrated alcohol intake, habitual alcohol intake, energy per cent fat intake or body mass index. 
Table 5. Odds ratios for breast cancer in postmenopausal women according to age at first exposure to alcohol.

\begin{tabular}{|c|c|c|c|c|c|}
\hline $\begin{array}{l}\text { Age at first } \\
\text { exposure (yr) }\end{array}$ & $\begin{array}{l}\text { No. of } \\
\text { Cases }\end{array}$ & $\begin{array}{l}\text { subjects } \\
\text { controls }\end{array}$ & $\begin{array}{l}\text { Relat } \\
\text { Crude }\end{array}$ & $\begin{array}{l}\text { We risk } \\
\text { Adjusted2 }\end{array}$ & \\
\hline$\leq 25$ & 25 & 20 & 1.1 & $1.8(0.6-1.7)^{3}$ & $2.4(1.0-5.6)$ \\
\hline $26-35$ & 9 & 18 & 0.4 & $0.6(0.2-2.2)$ & \\
\hline $36-50$ & 17 & 18 & 0.8 & $0.7(0.2-2.3)$ & \\
\hline $55-64$ & 7 & 8 & 0.8 & $0.8(0.2-3.5)$ & 1.01 \\
\hline $\begin{array}{l}\text { Never } \\
\text { drinkers }\end{array}$ & $\frac{15}{73}$ & $\frac{13}{77 *}$ & $1.0^{1}$ & $1.0^{1}$ & \\
\hline
\end{tabular}

3 Reference category.

2 Adjusted for reproductive history, level of education, first degree familial history, smoking habits, age, season, geographical area.

3. 95 per cent confidence interval in parentheses.

* Two subjects did not remember age exposure started.

\section{Discussion}

Our results indicate that moderate drinking of alcohol, up to three glasses a day probably does not increase breast cancer risk. On the other hand, starting the use of alcohol before age 25, or drinking more than three glasses daily may be associated with increased breast cancer risk.

Because short-cut and written questionnaires on alcohol use can be sensitive to biases and may need validation (18), we have used a standardized interview method at the end of which the use of alcohol. was naturally integrated among questions on other arinks (soft drinks, juices etc.). In contrast to most previous studies, the interview recorded both frequency and number of glasses of alcohol; the data were collected by two experienced dietitians who checked for inconsistencies in the answers, and the liquid content of the subjects usual drinking-glasses was measured afterwards. This approach is believed to reduce underreporting and misclassification of exposure (26). Furthermore, since the study was presented as a study on diet, life-style and the risk of breast cancer without any reference to alcohol, we do not consider selection bias to be a serious problem in our study.

Although a slightly reduced relative $x$ isk for breast cancer at low alcohol intake is also suggested by several other studies $(6,8,18)$ it is not clear to what extent our results reflect a cohort effect 
or a blological association. The data indicate, however, that in the Netherlands the maked increase in alcohol consumption after world War II has been an indicator of well being and an affluent lifestyle (27). As corripared to the postmenopausal women, the premenopausal cohort started drinking alcohol at a younger age and had a higher level of education. whe subjects were more often employed, smoked more, had an earlier menarche, postponed pregnancies and lower parity. Purthermore, the premenopausal non-drinkers resembled the postmenopausal women rather than their premenopausal counterparts. Thus, although our results may be attributed to the paucity of data and extensive adjustment for confounding both in the pre- and postmenopausal stratum, they may also point to the importance of lifestyle factors associated with drinking habits.

The increased risk associated with drinking alcohol before age 25 is consistent with two other recent publications $(10,15)$ and fits into epidemiologic findings indicating the importance of exposures at young age, e.g., age at menarche, first full-term pregnancy, radiation and migration. In our case-control study, the assaciation with arinking habits before age 25 gradually became apparent upon adjustment for other factors indicating early life circumstances (education, reproductive history, first degree familial history). This suggests that these factors are associated with some unknown factor operating in early life. Like the results described by Harvey (16) the association with early drinking habits in postmenopausal women was moxe pronounced than the association with recent drinking habits. Oux analysis also suggests that adjustment for recent dietary factors, e.g., energy per cent fat intake, does not eliminate this result.

As the other studies, causal inference from our study is hampered by the absence of a sound biological explanation as well as the different sociological influences relating to alcohol use in the population studied. In France and Italy, arinking alcohol is generally accepted. In Italy, wine is 'usually drunk during meals from early adulthood onwards' (10). The USA have experienced an alcohol prohibition exa, and this may still influence the drinking habits of the oldex generation (7). Unlike France and Italy, drinking alcohol in the Netherlands is usually practised at parties, social encounters and in the evening, rather than at meals. In contrast to the USA $(15,18)$, wine is the most important source of alcohol for women in European countries $(10,13)$. In our study population, wine was used by at least 90\% of women drinking alcohol, while beer or spirits were drunk by less than $30 \%$ of the women. Furthermore, our study as well as three other European studies included a category consuming more than 30 grams of alcohol daily 
(10-13), whereas only foux of eleven non-European studies did this $(8,11,19,20)$.

As the habit of drinking alcohol is becoming more comon un the young, the finding of an elevated risk for breast cancer when drinking alcohol before the age of 25 , and the positive association within premenopausal drinkers deserves further explanation. This observation is consistent with other factors in breast cancer aetiology, which have their greatest impact duing early life. studies on the bialogical and biochemical consequences of alcohol consumption are needed. Epidemiological studies should address lifetime alcohol exposure specified according to type, frequency. and dose. Careful control for socio-biologically relevant factors, e.g., reproductive factors, is required.

\section{References}

1 Graham S. A.lcohol and breast cancer. Editorial. N Engl J Med $1987 ; 316: 1211-3$.

2 Breslow NE, Enstrom JE. Geographic correlations between cancex mortality rates and alcohol-tabacco consumption in the United States. I Nat1 Cancer 1974;53:631-9.

3. Kono S, Ikeda $M$. Correlation between cancer mortality and alcoholic beverage in Japan. Br J Cancer 1979;40:449-55.

4 Williams RR, Horm JW. Association of cancer sites with tobacco and alcohol consumption and socioeconomic status of patients: Interview study from the Third National Cancer survey. I Nat 1 Cancer Inst $1977 ; 58: 525-47$.

5 Rosenberg L, Slone D, Shapiro $S$, et al. Breast cancer and alcoholic beverage consumption. Lancet $1982 ; 1: 267-70$.

6 Begg $C B$, walker AM, wessen B, zelen $M$. Alcohol consumption and breast cancer. Lancet $1983 ; 1: 293-4$.

7 Byers $T$, Funch DP. Alcohol and breast cancer. Lancet 1982;1:799800 .

8 Webster LA, Layde PM, Wingo PA, et al. Alcohol consumption and risk of breast cancer. Lancet $1983 ; 2: 724-6$.

9 Paganini-Hill A, Ross RK. Breast cancer and alcohol consurption. Lancet $1983 ; 1: 626-7$.

10 La Vecchia $C$, Decarli. A, Franceschi S, Fampallona S, Tognoni. G. Alcohol consumption and the risk of breast cancer in women. J Nati Cancer Inst $1985 ; 75: 61-5$.

11 Lê MG, Hill C, Kramar A, Flamant R. Alcoholic beverage consumption and breast cancer in a French case-control study. Am I Epidemiol $1984 ; 120: 350-7$. 


\section{Alcohol}

12 lie Moulton LH, Hill C, Kramar A. Consumption of dary produce and alcohol in a case-control study of breast cancer. I Nat 1 Cancex Inst $1986: 77: 633-6$.

13 Talamini R, La Vecchia $C_{\text {, Decarli }}$, et al. Social factors, diet and breast cancer in a northern Italian population. Br J Cancer $1984 ; 49: 723-9$.

14 Harris RE, wynder EL. Breast cancer and alcohol consumption. A study in a weak associations. I Am Med Assoc 1988;259:2867-71.

15 Harvey $\mathbb{E B}$, Schairer $C$, Brinton $\mathbb{L A}$, Hoover RN, Fraumeni. JF. Alcohol consumption and breast cancer. J Natl Cancer Inst $1987 ; 78: 657-61$.

$160^{\prime}$ Connel DL, Hulka BS, Chambless LE, Wilkinson WE, Deubner DC. Cigarette smoking, alcohol consumption, and breast cancer $x$ isk. J Nat1 Cancer Inst $1987 ; 78: 229-34$.

17 Hiatt RA, Bawol RD. Alcoholic beverage consumption and breast cancer incidence. Am J Epidemiol 1984;120:676-83.

18 Willett WC, Stampfer MJ, Colditz GA, Rosnex BA, Hennekens $C H$, Speizer FE. Moderate alcohol consumption and the risk of breast cancer. N Engl I Med 1987;316:1174-80.

19 Schatzkin A, Jones DY, Hoover RN, et al. Alcohol consumption and breast cancer in the epldemiologic follow-up study of the first national health and nutrition examination survey. N Engl J Med $1987 ; 316: 1169-73$.

20 Hiatt RA, Klatsky AL, Armstrong MA. Alcohol consumption and the risk of breast cancer in a prepaid health plan. Cancer Res $1988 ; 48: 2284-7$.

21 Turner ${ }^{\pi} B$, Bennett $V L$, Hernandez $H$. The beneficial side of alcohol use. The John Hopkins Med J 1981;148:53-63.

22 Klatsky AL. The cardiovascular effects of alcohol. Alcohol and Alcoholism 1987; Suppl $1: 117-24$.

23 Lindros $k O$, yikahri $R$, kilanmaa $k$ (eds). Advances in biomedical alcohol research. Oxford. Pergamon Press, 1987.

24 Rothman KJ. Modern Epidemiology. Little, Brown and Company, 1986.

25 BMDP statistical software, University of Californila, 1985.

26 Phidipsen $H$, knibbe RA, Reek J van. Alcohol consumption in The Netherlands as a social phenomenon. In: Hermus RJJ (ed). Alcohol, health and society (Proc). Wageningen, Centre for Agricultural. publishing and Documentation, 1983.

27 Garretsen HFL, knibbe RA. Alcohol consumption and alcohol control policy: the case of the Netherlands. Health Policy 1985;5:151-8. 
COMBINATION OF DIETARY FACTORS IN RELATION TO BREAST CANCER OCCURRENCE :

\begin{abstract}
Pieter van 't Veer. Edith $M$ van Leer, Amnelies Rietdijk, Frans J Kok, Evert $G$ Schouten, Rudolph $J$ J Hermus, Fexd Sturmans.
\end{abstract}

Abstriact

combinations of dietary factors were studied in relation to breast cancer occurrence among 133 breast cancer cases and 289 population controls in the Netherlands.

Dietary factors were classified accoraing to their possible mechanism of action, i.e. either relating to the intestinal microflora (total fat, fiber, fermented milk products), or to the antioxidant hypothesis (beta-carotene, selenium and polyunsaturated fatty acids). From six interactions evaluated, the combination of high fiber and high fermented milk products was the only one suggesting synergistic protection (age and fat adjusted or for interaction $=0.48,95 \%$ confidence interval (CI) $=0.21-1.13$ ). In order to estimate the extent to which the above dietary factors together might be related to breast cancer, subjects with a supposedly favorable dietary pattern (low fat, high fiber, high fermented milk products; high beta-carotene, high selenium, and low polyunsaturated fatty acids) were compared to subjects with an unfavorable dietaxy patterm. This resulted in an age adjusted odds ratio of $0.40(958 \mathrm{CI}=0.14-1.15)$, which was largely attributable to the combination of low fat, high fermented milk products and high fiber (age adjusted $O R=0.33,95 \%$ CI $=0.15-0.73$ ). The othex factors did not appreciably affect the odds ratio.

These analyses show in a quantitative way that a dietary patterri which combines low intake of fat, and high intake of $f$ lber and fermented milk products might provide substantial protection against breast cancer.

\title{
Introduction
}

Results of both case-control and cohort studies have shown that diet may play an important role in the etiology of breast cancer $(1,2)$. In general, individual dietary factors like total fat, polyunsaturated fatty acids (1), fiber, selenium, beta-caroterie (3)

i submitted. 
and fermented milkproducts (4) have been studied in relation to breast cancer.

Based on two biological mechenisms we studied the association between breast cancer and several combinations of dietary factors using data from a case-control study. The combination of total fat, fermented nilk products and fiber was studied because these dietary factors may alter estrogen metabolism by the intestinal microflora $(5-7)$. As lipid peroxidation may be involved in breast cancer etiology, and the antioxidants beta-carotene and selenium may prevent peroxidation of fatty acids, (polyunsaturated fatty acids in particular) these dietary factors were evaluated simultaneously (8-11). First, interactions between pairs of relevant dietary variables were evaluated. Second, the odds ratio of breast cancer was estimated for subjects with a supposed 1 favorable dietary pattern compared to those with the opposite pattern.

\section{Subjects and methods}

\section{Study population}

The study was conducted in 1985-1987. Recruitment of cases and controls was restricted to 25-44 and 55-64 year old women, in order to stratify on menopausal. status. Women with the Dutch nationality, of the caucasian race, and residing in the middle and southern part of the Netherlands, were eligible. A total of 168 newly diagnosed eligible breast cancer cases were enrolled in this study. Controls $(n=548)$, reflecting the age distribution of cases, were sampled randomly Erom municipal population registries in the same area. Complete interview data on the intake of nutrients were obtained from 133 cases (response 808 ) and 289 controls (response 55\%). Further detalis on recruitment of subjects have been published el. sewhere $(12-14)$.

\section{Data collection}

Cases and controls were interviewed on dietary habits by two wel1trained, registered dietitians in a two hour home visit. Most cases (9y) were interviewed within six months after diagnosis. No interviews were conducted during periods of chemo-therapy. Data on average daily food consumption were collected using a structured dietary history method, covering the complete dietary pattern in the twelve-month period preceding diagnosis (for cases) and interview date (for controls). The questionnaire comprised 236 separate food items, covering all the meals (and their preparation), snacks and drinks. The content of most frequently used household utensils was 
measured to obtain a more accurate quantification of the portion sizes. In addition, the questionnare addressed stability of food habits, demographic: and socio-economic characteristics, and potential confounders. The following variables have been considered as potential confounders: age, dietary fat intake, alcohol intake, history of benign breast disease, first and second degree familial history, smoking habits, educational level of the women, use of oral. contraceptives, age at menarche, age at first full-term pregnancy, parity, body mass index and geographical area $(12-14)$.

\section{Data analysis}

Average daily intake of the nutrients of interest was compared between cases and controls. Age adjusted, and age and fat adjusted case-control differences in nutrient intake were estinated by 1 inear regression analysis, including age in four groups (25-39, 40-44, 55-59 and 60-64 years old) using three dumy variables, and fat as a continuous variable (Table $\mathbb{1}$ ). Intake of fermented milk products was expressed as mg calcium contributed by yogurt, buttermilk, curds, kefir and cheese (Gouda, Edammer, Leidse). To remove the association of total fat and polyunsaturated fatty acids $(r=0.71$ in the control group) the latter was expressed as a percentage of total $f_{a t}$ (except for Table 1), which was virtually independent of total. Fat $(r=0.05)$.

odds ratios adjusted for age and fat (if applicable) were calculated by logistic regression analysis (Table 2 ). In these analyses, age was divided $\mathbb{1 n t o}$ two categories $(25-44$ and $55-64$ years old), for fat intake the highest quartile was compared to the other quartiles and the other nutxients were dichotomized at the median.

Analysis of the potentially large number of interations was limited to two categories of nutrients that are supposed to be involved in either one of the two described biological mechanisms, i.e. total fat, fermented milk products and fiber on the one hand (three interaction terms), and selenium, beta-carotene and polyurisaturated fatty acids on the other hand (three interactions terms). For each of these six interactions of interest, age and fat (if applicable) adjusted odds ratios were obtained from a logistic regression modeli. In these models, the four possible combinations of each pair of (dichotomized) nutrients were represented by three dumy variables, one of them indicating the joint exposure category (Table 3 ). Subsequently, statistical interaction was assessed using a logistic model including the main effects for the two nutrients, and their product term. Analyses were repeated for subjects aged $25-44$ years and 55-64 years separately.

Finally, in order to estimate the extent to which the six dietary factors of interest were associated with breast cancer, subjects 
With supposedly favorable dietary habits were compared to subjects With unfavorable habits, using multivariate logistic regression analysis, including the groups of variables of interest. The $95 \%$ confldence intervals were calculated taking into account the covariance of the estimated regression coefficients. In order to Iimit the number of possible models, a total of four age adjusted models were considered based on the formex nutrient combinations (see also Table 4): total fat only (model 1); fat, fermented milk products and fiber (model 2); fat, beta-carotene, selenium and polyunsaturated fatty acids (model 3); dietary factors of model 2 and 3 simultaneously (model 4). The results are presented as odds ratios for favorable vs unfavorable dietary habits, either adjusted for total fat (model 2-4), or including total fat intake as one of the unfavoxable dietary charactexistics (model 5-7). These analyses were conducted with and without the interaction of fexmented milk products and dietary fiber, and they were repieated for younger and older women separatedy.

Results

Average daily intake of total fat, dietary fiber, fermented milk products, beta-carotene, selenium and polyunsaturated fatty acids of cases and controls are presented in Table 1, including adjusted mean exposure differences. Average daily fat intake was

Table 1. Intake of dietary factors in 133 breast cancer cases and 289 population controls.

\begin{tabular}{|c|c|c|c|c|}
\hline $\begin{array}{l}\text { Mean (SD) daily } \\
\text { Hntake of }\end{array}$ & $\begin{array}{l}\text { Cases } \\
(n=133)\end{array}$ & $\begin{array}{l}\text { Controls } \\
(n=289)\end{array}$ & $\begin{array}{l}\text { age and fat } \\
\text { adjusted diffe } \\
\text { mean } 95 \%\end{array}$ & $\begin{array}{l}t^{1} \\
\mathrm{CI}^{2}\end{array}$ \\
\hline total fat (9) & $100.1(36.3)$ & $92.3(30.4)$ & $9.7^{3}<3.0$ & 16.39 \\
\hline $\begin{array}{l}\text { dietary fiber (g) } \\
\text { fermented millk- }\end{array}$ & $25.7 \quad(6.9)$ & $27.3 \quad(8.3)$ & $-1.9(-3.5$ & -0.33 \\
\hline products (mg Ca) & $(269)$ & $(329)$ & $-68(-131$ & $-6)$ \\
\hline beta-carotene (mg) & $2.2(1.5)$ & $2.2(1.2)$ & $0.0(-0.3$ & $0.3)$ \\
\hline $\begin{array}{l}\text { selenium }(\mu g) \\
\text { polyunsaturated }\end{array}$ & $56.0(13.0)$ & $5.6 .1(13.1)$ & $-2.0 \quad-4.0$ & $0.1)$ \\
\hline fatty acids (g) & $(8.1)$ & $(7.0)$ & $-0.1(-1.2$, & $1.0)$ \\
\hline
\end{tabular}

1 Age in four categories, fat intake continuous.

$295 \%$ confidence interval.

i Adjusted for age only. 
significantly highex among cases than controls (difference 9.79 fat, $95 \% C I=3.0-16.3)$. Therefore, exposure differences for the other nutrients were adjusted for both fat intake and age. This analysis showed a significantly lower intake of femented milk products among cases than among controls (difference $=68 \mathrm{mg}$ calcium, 95\% $\mathrm{CI}=6-131$ ) and of Eiber (difference $=1.9 \mathrm{~g}$ fiber, 95: $C I=0.3-3.5)$. No statisticaldy significant case-control differences were observed for the intake of the other nutrients. Age adjusted and age and fat adjusted relative odds for the nutrients are presented in Table 2. The odds ratio of breast cancer for high versus low intake of fat was $1.76(958 \mathrm{CI}=1.11-2.71)$. For the other nutrients, results were in line with gable 1 , but the confidence intervals included unity, because nutrients were dichotomized. Introduction of dietary fat in the analyses as a potential confounder resulted in changes of the relative odds, corresponding to the results in Table 1.

Table 2. The relative odds of breast cancer and their $95 \%$ confidence interval (CI) for different dietary factors.

odds ratio of breast cancer adjusted for: Age ${ }^{2}$

Dietary factor $O R \quad 95 \% \mathrm{CI}$ OR $95 \% \mathrm{CI}$

\begin{tabular}{|c|c|c|c|c|}
\hline total fat & 1.76 & $(1.11-2.71)$ & - & - \\
\hline $\begin{array}{l}\text { dietary fiber } \\
\text { fermented milk }\end{array}$ & 0.82 & $(0.54-1.25)$ & 0.75 & $(0.49-1.15)$ \\
\hline products & 0.83 & $(0.55-1.27)$ & 0.78 & $(0.51-1.19)$ \\
\hline beta-carotene & 0.95 & $(0.63-1.43)$ & 0.91 & $(0.60-1.38)$ \\
\hline $\begin{array}{l}\text { selenium } \\
\text { polyunsaturated }\end{array}$ & 1.08 & $(0.71-1.64)$ & 0.89 & $(0.56-1.25)$ \\
\hline fatty acids & 0.85 & $(0.56-1.29)$ & 0.84 & $(0.55-1.27)$ \\
\hline
\end{tabular}

- Reference categories (see also Data analysis): total fat $\leq 1089$, dietary fiber $\leq 26 \mathrm{~g}$, fermented milkproducts $\leq 464 \mathrm{mg}$ calcium, beta-caroteen $\leq 2.0 \mathrm{mg}$, selenium $\leq 55 \mu \mathrm{g}$, polyunsaturated fatty acids $\leq 16 \%$ of total fat.

2 Age in two categories $(25-44,55-64$ yr).

3 Age and fat intake in two categories each.

Interaction was assessed between the following $\$$ ix pairs of mutrients: fat and fiber, fat and fermented milk products, fiber and fermented milk products, selenium and polyunsaturated fatty acids, 
beta-carotene and polyunsaturated fatty acids, selenium and betacaxotene. As an example table 3 shows the odds ratios of breast cancer for the four combinations of dietary fiber and fermented milk products. For all cells the odds ratios were close to unity, except for the folnt exposure to high fiber and high fermented milk products $\quad(O R=0.58,95 \% \mathrm{CI}=0.32-1.05)$. The reduced odds ratio was most pronounced in the younger age group lor $=0.38,95 \%$ $\mathrm{CI}=0.16-0.89$ ) but also below unity in the older age group $(O R=0.87,95 \% C T=0.39-1.95)$, though this difference may be attributed to chance. The age-adjusted odds ratio of the interaction term fox fermented milk products and dietary fiber (i.e. $0.58 / 1.13 * 1.08=0.48)$ was markedly below unity $(95$ cI $=0.21-$ 1.13). After including selenium, beta-carotene and polyunsaturated fatty acids in the model, these odds ratios remained quite similar. statistical interactions for the other five nutrient combinations were of lesser magnitude and did not reach statistical significance, whether adjusted for age alone or for both age and fat intake. Thus, with the possible exception of interaction between dietary fiber and fermented milk products, the logistic model provided a simple description of the relation between breast cancer and the intake of fat, dietary fiber, fermented milk products, selenium, beta-carotene and polyunsaturated fatty acids, either alone or in combination.

"Iable 4 shows the adjusted odds ratios of breast cancer for subjects with favorable versus unfavorable dietary patterns. All (but one)

Table 3. Relative odds of breast cancer for the combination of dietary fiber intake and consumption of fermented milk products.

Dietary fiber

(g)
Fermented milk products ( $m g$ calcium)

$$
\leq 464.4>464.4
$$

Adjusted for:

Age

$$
\begin{aligned}
& \leq 26.2 \\
& >26.2
\end{aligned}
$$$$
\text { 1. } 00
$$$$
\text { 1. } .17
$$$$
\text { 1. } 18
$$$$
0.69
$$

$(0.39-1.21)^{3}$

Age and fat

intake:

$$
\begin{aligned}
& \leq 26.2 \\
& >26.2
\end{aligned}
$$$$
1.08
$$$$
0.58
$$

$(0.32-1.05)^{3}$

1 Age in two categories.

2 Age and fat intake in two categories.

395 confidence interval. 
odds ratios were below unity. The odds ratio for total fat alone $(0.57,95 \% \mathrm{CI}=0.36-0.90$; model 1$)$. for total fat, fiber and fermented milk products simultaneous $1 y \quad 10.33,95 \% \mathrm{CI}=0.15-0.73$; model 5 ) were statistically significant. Addition of selenium, beta-

Table 4. Adjusted relative odds of breast cancer for subjects with favorable versus unfavorable dietary habits².

\begin{tabular}{|c|c|c|c|c|}
\hline Model: & $\begin{array}{l}\text { Dietary pattern" favorable } \\
\text { with respect to }\end{array}$ & OR & $\begin{aligned} 958 \mathrm{c} & \\
& \mathrm{i}\end{aligned}$ & $\begin{array}{l}\text { onfidence } \\
\text { ntervad. }\end{array}$ \\
\hline $\mathbb{1}$ & Total fat & 0.57 & 10.36 & -0.901 \\
\hline 2 & Fiber, fermented milk & $0.62^{3}$ & 10.35 & $-1.09)$ \\
\hline 3 & Beta-caratene, selenium , pufa & 1. .00 & 10.47 & $-2.13 y$ \\
\hline 4 & $\begin{array}{l}\text { Fiber, fermented milk, } \\
\text { beta-carotene, selenium, pufa }\end{array}$ & $0.76^{3}$ & 10.33 & $-1.74)$ \\
\hline 5 & $\begin{array}{l}\text { Fiber, fermented milk, } \\
\text { total fat }\end{array}$ & 0.333 & 10.15 & $-0.73)$ \\
\hline 6 & $\begin{array}{l}\text { Beta-caratene, selenium, } \\
\text { pufa, total fat }\end{array}$ & 0.54 & $(0.27$ & $-1.09)$ \\
\hline 7 & $\begin{array}{l}\text { Fiber, fermented milk, } \\
\text { beta-carotene, selenium, } \\
\text { pufa, total fat }\end{array}$ & $0.40^{3}$ & 10.14 & -1.151 \\
\hline
\end{tabular}

1 Model 1: adjusted for age; model 2-4 adjusted for age and total fat intake; model $5-7$ total fat intake included as main effect.

2 Reference subject with unfavorable dietary habits: high total fat $(>108 \mathrm{~g})$, Low dietaxy fiber ( $\leq 26 \mathrm{~g})$, low fermented milkproducts ( $\leq 464 \mathrm{mg}$ calcium), Low beta-carotene ( $\leq 2.0 \mathrm{mg})$, Low selenium ( $\leq 55 \mathrm{\mu g})$, high polyunsaturated fatty acids $(>16$ of total fat).

3 Inclusion of product term of fiber and fermented milk resulted in $\mathrm{OR}=0.58,95 \% \mathrm{CI}=0.32-1.05$ (model 2$) ; \mathrm{OR}=0.69,95 \mathrm{CI}=$ $0.29-1.59$ (model 4$) ; O R=0.30,958 C I=0.13-0.69($ model 5$)$; $\mathrm{OR}=0.35,95 \mathrm{CI}=0.12-1.02(\operatorname{model} 7)$.

carotene and polyunsaturated fatty acids to the model (1.e. all nutrients simultaneously) did not lead to a furthex decrease and resulted in wider confidence intervals $(0.40,95 \% \mathrm{CI}=0.14-1.15)$. The results of model 2 where rather different for the younger age group (fat adjusted $\mathrm{OR}=0.39,95 \% \mathrm{CI}=0.17-0.90$ ) as compared to the older age group (fat adjusted $O R=0.94,95$ CI $=0.43-2.04$ ). For the other modelis no relevant differences between the youngex and 
older age group were observed. When the interaction term of fermented milk products was included in these analyses (model $2,4,5$ and 7y, the odds ratios decreased by about ten percent of their initial values.

\section{Discussion}

An inverse association with breast cancer was observed for a dietary pattern characterised by low intake of fat and high intake of fermented milk products and fiber. Total fat and the combination of fermented milk products and fiber were about equally important for this association. Inclusion in the logistic models of seleniumr beta-carotene and polyunsaturated fatty acids did not considerably change the odds ratio. Except for the combination of high fermented milk products and fiber, no clear evidence of interaction was observed between the nutrient combinations of interest.

We considered whether the inverse associations we observed could be explained by recall, selection or confounding bias. First, recall of food habits several years in the past is obviously influenced by recent habits $(15,16)$. This, however, is not necessarily differential for cases and controls. Moreover, in our study the interview referred to food habits covering the past year. Furthermore, if cases had altered food habits after diagnosis, they have usually done so consciously, still well remembering prediagnostic habits. In addition, cases and controls were interwiewed by well-trained dieticians using a highly structured dietary history method, and cases were not interviewed when they were not feeling well because of treatment, e.g. chemotherapy. These precautions minimize the possibility that differences in recall of food habits among cases and controls would lead to systematic errors in the study results.

Second, recruitment of cases and controls could be related to the food habits investigated. Cases were recruited by collaborating surgeons in 17 of 35 hospitals, covering 55 of all hospital admisions for breast cancer in the study area. Coverage of caserecruitment was independent of age and degree of urbanization of residence. One of the case-characteristics that could most obviously trigger case-recruitment by surgeons in the hospital was overweight. When body mass index was compared between cases recruited by their surgeons $(n=84)$ and cases missed by the surgeons but traced afterwards in the local cancer registries ( $n=49$ ), no majox differences were observed. Moreover, both groups of cases showed a similar dietary pattern regarding percentage of energy from macronutrient sources. We also compared dietary and iffe style factors in responders $(n=289)$ and non-responders $(n=89)$ in the 
control group, together representing 71 of of the initial sample from the municipal population registries. No relevant differences were observed with regard to fat and fiber intake as contributed by milk products (skimmed, half-skimmed, full-cream), food items used on bread (e.g. jellies, ham, cheese), and type of bread (whole meal and white bread). Furthermore, daily amount of bread and consumption frequency of eggs and Eish was similar among both groups, and no major differences were observed with regard to age at first fullterm pregnancy, parity, weight and body mass index. Therefore, life style and risk profile of responding and non-responding controls are considered to be similar.

In nutritional epidemiology, the total amount of food eaten, or energy intake has to be taken into account in the analysis (17). In addition to age, all. analyses have been adjusted for fat intake, which was highly correlated with total energy in the control group $(r=0.89)$. The intake of dietary fiber and fermented milk products was positively associated with fat intake (Pearson $r=0.32$ and $r=0.20$, respectively). Despite their higher fat intake, however, cases used on average less fiber and fermented milk products. When fat intake was taken into account in data analysis, these differences became more pronounced for all the nutrients, and the odds ratios for favorable levels of consumption tended to decrease. Moreover, total fat rather than energy may be involved in the biological mechanism as such (18). In our data, energy-adjusted fat intake was positively associated with breast cancer (12), while fatadjusted energy intake was not. Other potential confounders of the diet breast cancer association were not considered in the present analyses, since previous analyses had indicated that their inclusion in the logistic model affected the odds ratios only moderately $(12,13)$.

In order to obtain meaningful and interpretable results, our strategy of data analysis aimed at substantial reduction of the number of comparisons to be made and was guided by biological concepts. Thus, dietary factors were divided in two categories only (high vs low intake). Assessment of interactions and comparison of subjects with favorable and unfavorable dietary habits was restricted to dietary factors that were supposed to be involved in a related biological system. Although other meaningful possibilities could be envisaged, we classified exposures presumably operating at the gastrointestinal level or at the tissue level. At the gastrointestinal level interactions may result from metabolism of (pre)carcinogens and oestrogenic substances (5-7). At the tissue level, antioxidants and polyunsaturated fatty acids may be related to the formation of peroxides or cholesterolepoxides. These latter mutagenic substances have indeed been detected in breast cancer fluid in women at high breast cancer risk (19). Furthermore, the 
reduced odds ratio fox the combination of dietary fiber and fermented mikproducts in Table 3 and 4 , was more pronounced in the younger age group than in the older age group. Although this may be attributable to sampling wariability, ox differences in baseline risk in these age groups, it might also represent biological differences possibly related to hormonal factors. In addition to these biological considerations, the multistage model of cancer generally implies multiplicative relations for joint exposures, unless the factors involved independently affect the same stage of celd-transformation (which may lead to additivity) (20). Because of the reference period of the dietary interview, the nutritional factors included in our study may affect the later stages of carcinogenesis. It cannot be known a priori, however, whether these dietary factors affect the same or different stages of carcinogenesis, or even the growth of a completely transformed population of tumor-cells. Because of this, and to avoid 'fishing' in data analysed before $(12,13)$, we did not conduct furthex analyses.

The results of our study suggest associations between diet and breast cancer only for factors operating at the gastrointestinal level (including fat), but not for factors related to the antioxidant hypothesis. Although this could be interpreted in biological terms, it is also conceivable that the intake of fat, fermented milk products and dietary fiber can be assessed more accurately than the intake of substances like selenium and betacarotene. Moreover, for meaningful evaluation of the antioxidant hypothesis, it may not be appropriate to rely on nutrient intakes because these may be poor indicators of the biologically relevant target tissue concentrations. Thus, although our results may point at the potential importance of the intestinal metabolic capacity, they oanot be taken as evidence against the antioxidant hypothesis for breast cancer.

In conclusion, the results show in a quantitative way that combination of favorable dietary habits may considerably lowex breast cancex risk. In our case-control study this can be attributed to the dietary factors low total fat, high dietary fiber and high fermented milk products.

\section{References}

1. Rohan TE, Bain CJ. Diet in the etiology of breast cancer. Epidemiol. Rev $1987 ; 9: 120-45$.

2 Boyle $P$, Leake $R$. Progress in understanding breast cancer: epidemiological and biological interactions. Breast cancer Res Treatmnt $1988 ; 11: 91-112$. 
3 Rohan TE, MCMichael AJ, Baghurst PA. A population-based casem control study of diet and breast cancer in Austraila. An J Epidemiol $1988 ; 128 ; 478-89$.

4 Lẽ MG, Moulton LH, Hill C, Kramar A. Consumption of dairy produce and alcohol in a case-control study of breast cancer. I Nat1. Cancer Inst $1986 ; 77: 633-6$.

5 Hill MJ, Goddard $P$, Williams REO. Gut bacteria and the aetiology of cancer of the breast. Lancet $1971 ; 2: 472-3$.

6 Goxbach SL. Estrogens, Breast Cancer, and Intestinal Flora. Rev Infect Dis $1984 ; 6: 585-90$.

7 Goldin BR, Gorbach SL. The effect of milk and lactobacillus feeding on human intestinal bacterial enzyme activity. Am J Clin Nutr 1984; 39:756-61.

8 MCBrien DCH, Slater TF. Free radicals, Lipid peroxidation and cancer. London, Academic Press, 1982.

9 Hoekstra, WG. Biochemical function of selenium and its relation to vitamin E. Fed Proc 1975;34:2083-9.

10 Peto $R$, Doll. R, Buckley JD, Sporn MB. Can dietary beta-carotene materially reduce human cancer rates? Nature 1981;290:201-8.

11 Buxton GW, Ingold $\mathrm{KU}$. Beta-carotene: an unusual type of lipid antioxidant. Science $1984 ; 224: 569-73$.

12 Van 't veer P, Kok FJ, Brants HAM, Ockhuizen Th, Sturmans F, Hermus RJJ. Dietary fat and risk of breast cancer. Int J of Epidemiol 1990 (in press).

13 Van 't Veer P, Dekker JM, Lamers JWJ, Kok FJ, Schouten EG, Brants AM, Sturmans F, Hermus RJJ. Consumption of fermented millkproducts and breast cancer: A case-control study in the Netherlands. Cancer Res 1989;49:4020-3.

14 Van 't Veer $P$, Van der Wielen RPJ, Kok FJ, Hermus RJJ, sturmans F. Selenium in diet, blood and toenails in relation to breast cancer: A case-control study. Am J Epidemiol 1990 (in press).

$15 \mathrm{Jain} M$, Howe $G R$, Harrison $L$, Miller AB. A study of repeatibility of dietary data over a seven-year period. Am I Epidemol $1989 ; 129: 422-9$.

16 Rohan TE, Potter JD. Retrospective assessment of dietary intake. Am J Epidemiol $1984 ; 120: 876-87$.

17 Willett WC, Stampfer MJ. Total energy intake: Implications for epidemiologic analysis. Am J Epidemiol 1986;124:17-27.

18 Schatzkin $A$, Greenwald P, Byar DP, Clifford CK. The dietary fatbreast cancer hypothesis is alive. I Am Med Assoc 1989;261:32847.

19 Wrensch MR, Petrakis NL, Gruenke LD, et al. Breast fluid cholesterol $\beta$-epoxide concentrations in women with benign breast disease. Cancer Res $1989 ; 49: 2168-74$. 


\section{Combination of dietary tactors}

20 Ereslow $\mathbb{N E}$, Day HE. Statistical methods in cancer research. Vol

I. Whe design atd analysis of cohort studies. IARC Sci Publ no. 82. IARC, Lyon, 1987. 
As outlined in chapter 1, the primary aim of this study was to determine the relation between dietary fat, selenium and breast cancer. During this first case-control study on dietary habits and breast cancer in the Nethexlands several difficulties were faced with in the conduct of the study, which may interfere with the interpxetation of study results. These problems were mainly related to recruitment of subjects and assessment of exposure, and practical. suggestions for improvement in the conduct of future studies have been provided (chapter 3 ).

In this chapter, the potential biases will be discussed more comprehensively, and the underlying principles emphasized. These general principles provide the basis for the subsequent aljsusion on the methodology and scope of future epidemiological studieg on diet and cancer. Research areas of particular interest for breast cancer are indicated. Finally, the research $\mathbb{f}$ indings $w i l d$ be viewed in the light of current dietary recommendations to the general public.

\section{L Methodological considexations}

The case-control design of our study prompted us to consider selection bias and information bias as potentially important sources of systematic exror in the study results (1). Although the extent to which recruitment of subjects and assessment of exposure may have influenced the study results remains a matter of subjective judgment, it seems not likely that they have introduced major systematic errors. This assumption has been substantiated by describing the methods, standardization, and timing of data collection, and by showing exposure data from cases and controlis entering the study by different modes of recruitment (chapter 3 ). Regarding specific hypotheses, validity aspects have been discussed in Chapters 4 to 9. Despite the arguments presented, however, the directionality of suspected systematio errors remains largely unknown, and their possible presence will leave sceptical readers with 'credibility intervals' considerably larger than the presented confidence intervals.

Therefore, instead of reiterating arguments, potential biases in observational epidemiology on diet and cancer will be discussed in a more general way. Table 1 provides a simple classification of these potential biases, according to their origin and implications for the validity and precision of study results. First, systentatic errors in recruitment of subjects and assessment of exposure will be discussed, with special attention for the common underlying 
Table 1. Potential exrors in observational epidemiology and theix consequences according to their source and type.

\begin{tabular}{lcll} 
Source and type of error & Exror & Consequences \\
\hline $\begin{array}{l}\text { Recruitment } \\
\text { of subjects }\end{array}$ & Systematic & $\begin{array}{l}\text { Exposure-related } \\
\text { subject selection } \\
\text { or follow-up }\end{array}$ & Selection bias \\
& Randon & $\begin{array}{l}\text { Large sampling } \\
\text { variability }\end{array}$ & Low precision \\
$\begin{array}{l}\text { Measurement } \\
\text { of exposures }\end{array}$ & Systematic & $\begin{array}{l}\text { Disease-related } \\
\text { assessment of } \\
\text { exposure }\end{array}$ & Information bias \\
& & Misclassification & $\begin{array}{l}\text { Low precision } \\
\text { Rias to the null }\end{array}$
\end{tabular}

concepts. Second, random errors will affect the study power (Chapter 3 ) and the precision of study results, which is reflected in the confidence intervals of odds ratios, presented throughout this thesis.

In addition, random error in the assessment of exposure leads to misclassification of exposed subjects as unexposed, and vice versa. The resulting incorrect classification will tend to dilute, or attenuate, the association of interest. In contrast to the systematic exrors, the consequence of random misclassification, or 'mismeasurement', is always that they bias the study results 'towards the null-hypothesis)'. Like other biases, this problem becomes increasingly important when the associations observed are weak. Becruse this type of bias has not received much attention in this thesis, and because associations observed in nutritional epidemiology are usually weak, the concepts underlying bias towards the null will be discussed more extensively.

\subsubsection{Selection bias and information bias}

As indicated above, sellection bias and information bias are major validity issues in case-control studies on diet and cancer. Here, the common concepts underlying these types of bias will be addressed. It will appear that these concepts are also related to 
confounding, and are applicable to the prospective cohort design as wel1.

Selection bias occurs when the mode of recruitment of study subjects selectively picks up exposed subjects, this selection being differential for subjects with and without the disease (2). Analogously, information bias occurs when the assessment of exposure is differential among subjects with and without the disease (i.e differential as contrasted with random misclassification, resulting in lack of comparability of information (3). The relation of differential selection and information with the validity of the observed association can easily be seen. Imagine a (stable and dynamic) source population with $E_{2}$ exposed and $\mathbb{E}_{1}$ unexposed subjects, with disease incidence rates $I_{2}$ and $I_{1}$ respectively. "The number of cases occurring will be $C_{2}\left(=E_{2}{ }^{2} I_{2}\right)$ and $C_{1}\left(=E_{1}\right.$ * $\left.I_{1}\right)$. Then, the exposure odds in cases $\left(C_{2} / C_{1}\right)$ divided by the exposure odds in controls $\left(E_{2} / E_{1}\right)$ yields the incidence rate ratio $\left(I_{2} / I_{1}\right)$ as the measure of association. This conclusion is only tenable, however, if the exposure odds differs between cases and controlls solely because of the underlying aetiological association* Differential selection of subjects from the source population and differential assessment of exposure data interfere with this requirement by disproportionately affecting the true (selection bias) or the measured (information bias) distribution of exposure among the study subjects (1). Both result in an odds ratio biased with respect to the association prevailing in the source population of the study subjects.

In addition to selection and information bias, the exposure odds in cases may also be altered due to confounders. Confounding occurs when the cases are selected from the source population not only by the exposure of interest, but also because of other aetiologic factors associated with this exposure (4). The resulting confounding bias can be removed in data analysis, provided that confounders ate adequately assessed. Analogously, confounding will occur when the response of controls is related to an extraneous factor associated with exposure (3). For example, suppose that in our study all subjects were interviewed on dietary habits. Furthermore, suppose that dietary habits are associated with smoking habits, but since smoking habits are not related to breast cancex $(5)$, they are not supposed to be a confounder (4). Now, if response of controls is related to smoking habits, the dietary habits anong the responding controls will not reflect the dietary habits of the source population of cases (i.e. biased sampling) (3). Consequently, the comparison of dietary habits of cases and controls will be biased. due to exposure-related selection of controls. Within strata af smoking habits, however, dietary habits are not affected, and hence adjustment for smoking habits by stratified or multivariate analysis 
wil remove this type of bias in the crude (i.e. unadjusted) disease odds ratio. In conclusion, selection bias acting on the dietary exposures themselves cannot be controlled in the analysis; this problen can be addressed only by collecting (limited) exposure data from cases and controls, including as many non-responders as possible (chapter 3 ). When selection of either cases or controls is related to an extraneous factor related to dietary exposure, not necessarily being a confounder, it can be taken into account in the analysis stage. Like confounders, selection of such extraneous variables should be based on a priori considerations.

In prospective cohort studies, or case-control studies nested in a cohort, exposure-rellated loss to follow-up of subjects will bias the Aisease odds ratio in a similar way as exposure-related response does in a case-control study $(2-4)$. In general, however, the prospective nature of the study makes selection less likely to occur. and gives opportunities to check whether loss to follow-up is indeed related to the exposure(s) of interest. Furthermore, information bias, i.e. differential exposure assessment in cases and controls, is not likely to occur in a prospective setting, because disease status cannot be known at the initial examination. As in casecontrol studies, however, altered food consumption because of subclinical disease may be a source of information bias within a limited period of follow-up. Moreover, this type of bias may be recognized when adds ratios are altered when duration of follow-up increases.

Thus, interpretation of the results from case-control and cohort studies may be hampexed by these potential validity problems. These may be alleviated by taking necessary precautions in study conduct and analysis.

\subsubsection{Bias towards the "nuli"}

As in many other studies on diet and cancer, we observed several weak associations, i.e. odds ratios were between 0.5 and 2.0 (with the exception of dietary fat). These associations may still be relevant to public health (6), but their weakness hampers unequivocal interpretation of the study results.

This paragraph addresses the issue whether the associations are really weak (but relevant), or appear to be weak merely as a result of biases that systematically dilute the associations towards the (statistical) null hypothesis: no association. The answer to this question has a considerable impact on the scope and methodology of future research on diet and cancer (see next section). Weak associations originate from random errors in measurement of disease 
(sensitivity and specificity) and exposure (ratio of measurement error and heterogeneity of the population) (2). In addition to these well-known phenomena, however, conceptual issues related to aetiology of cancer may contribute to a further understanding.

Prentice et al. (7) have argued and quantitatively substantiated, that the association between fat and breast cancer, as derived from ecological studies, can - in fact - haraly be reproduced in either cohort or case-control studies: random errors in the assessment of fat intake lead to misclassification of subjects with regard to exposure. Superimposed on the relative homogeneity of dietary habits within study populations, this misclasification leaves most observational studies with attenuated associations and limited power to detect them. Therefore, these studies are often hampered by difficulties in distinguishing between weak observed associations and selection or information bias oxiginating from the design and/or conduct of the study. This problem may be most obvious in cohort studies, since their large size necessitates assessment of individual exposure data with relatively simple methods of lesser accuracy. The resulting misclassification bias has been referred to as a special case of information bias by some authors $(2)$.

Rothman has drawn attention to the conceptual issues related to the phenomenon of weak associations in aetiological studies (4). In the framework of the sufficient cause-component cause concept, he has pointed to the induction period as a potentially important determinant of weak associations (8). This idea conceptualizes the occurrence of disease as the end result of a number of conditions (component causes) that have to be fulfilled before the actual. disease can become manifest (sufficient cause). In this framework, the induction period can be defined as the period between exposure to the aetiologically relevant agent (a specific component cause) and the completion of all component causes (sufficient cause). The time elapsing between completion of the sufficient cause and clinical disease manifestation is the latent period. In the context of the rullistage model of carcinogenesis, genetic alterations required for full. cell transformation can be considered component causes, and the length of the induction period may vary among subjects, depending on the component causes already present. In addition, the latent period may further increase the time lag between the component cause and clinical disease. Thus, even the most accurate measurement of exposure may only provide a weak indicator of the biologically relevant exposure at the biologically relevant moment. The consequence is misclassification with regard to the true exposure, which, like simple random measurement exror, may obscure relevant associations due to bias towards the null. 
In addition to induction period, the cause concept proposed by Rothman $(8,9)$ may explain weak associations as a result of (partially or completely) distinct sufficient causes (distinct disease aetiologies.. This will be illustrated by two (related) examples, one pointing to the role of background disease risk, the other to diagnostic characteristics of disease.

First, envisage two types of breast cancer, only one of which is related to fat intake. Then, the relative risk for fat will be redatively high if the non-fat-related aetiology is of minor importance in the study population. Conversely, when the non-fatrelated aetiology contributes substantially to the incidence, the background disease risk will be high, and the relative risk for fat will be biased towards the null (despite the same attributable (isk).

Second, most malignancies share the typical age relation, which is attributed to the multistage process, but they differ with respect to other component causes. Thus, when studying smoking and cancer, weak relative risks may be expected because many cancer sites constituting the overall background cancer risk are not related to smoking. However, when the analysis is restricted to lung cancer, for which smoking is one of the component causes, strong relative risks will be apparent. Thus, in epidemiological practice, distinct disease aetiologies will emerge as lack of uniformity of relative risks in different diagnostic categories.

In the preceding section, major biases in obsexvational epidemiology were discussed, including their conceptual and methodological background. Implications for methodological improvements in future epidemiological studies are included in the following section.

\subsection{Directions for research}

In addition to avoidance of selection and information bias, future observational epidemiological research also needs to minimize bias towards the null hypothesis. This requires special attention to measurement error, induction period, and background disease risk. Improvements may be obtained from increased heterogeneity in exposure (as in experiments), distinction of separate stages in carcinogenesis, and selection of the study population.

\subsection{Methodological improvements}

The effect of misclassification of exposure may be reduced by taking adwantage of the natural heterogeneity existing within populations or by extending the study to other countries with different food 
habits. Furthermore, assessment of exposure may be improved asing long-term biomarkers of nutrient intake or nutrient status, both in case-control and cohort studies (bio-banking). Finally, diet-related 'intermediate vaxiables" could be identified which are more closely related to the pathophysiology of the disease (like blood cholesteral in cardiovascular disease). For cancer, however, these intermediate variables may need to be assessed at the level of the target organ, rather than in the blood.

The concept of induction time and blologically relevant exposure opens several interesting opportunities for strengthening weak associations. First, distinguishing separate steps in (breast) cancer aetiology may imply that $x$ isk factors are studied in different periods of life, e.g., susceptible periods in puberty and pregnancy in relation to breast cell proliferation and differentiation. Furthermore, precursor lesions and their aetiology and prognosis may be studied, each in relation to dietary and other risk factors $(\mathrm{e} . \mathrm{g} \cdot 10,11)$. Finally, progression of latent tumours to clinically detectable tumours may be the abject of studies on growth factors, immunological factors and (breast) cancer.

The sufficient cause concept triggers the idea that what is considered as a disease entity nowadays, may ultimately be perceived as distinct diseases. A generally applicable way of detecting distinct disease aetiologies may be further differentiation of cancer diagnosis, e.g., according to growth factor (receptors) or expressed (onco)genes (e.g. 12). This approach may point to differences in relative $x i s k$ between different categories of disease, with specific subcategories showing strong associations with exposure, possibly pointing to different aetiologies (e.g. 13). selection of study subjects with low background disease risk may be useful when studying risk factors, while high risk categories are indicated when preventive factors are the object of the study $(8)$. Finally, populations at high disease risk, e.g. (breast) cancer families or women with atypical hyperplasia, may yield important clues at the genetic level.

\section{2 .2 scope of case-control and cohort studies}

The above methodological issues have some important consequences for the scope of future epidemiological studies. Our study was primarily focused on food habits and the resulting intake of fat, selenim and other food constituents. Although the dietary method was extensive and selenium status was assessed by several biomarkers, the methodological problem of weak associations leaves subjective arguments essential to the interpretation of the results. Becase 
the uncertainties regarding selection and information bias have different weights in case-control and cohort studies, the implications of the suggested methodological improvements also differ acoording to study design.

For case-control studies, improved methodology, resulting in reduced attenution and strengthened associations, seems more promising than increased study size as such. Substantial improvement may be achieved by assessing biologically relevant exposure and/or distinguishing subcategories of disease, both having implications for the study design.

First, in addition to dietary assessment, long-term biomarkers (e.g. fatty acids and fat-soluble antioxidants in fat biopsy or erythrocyte membranes) may lead to reduced misclassification of exposure. Although these biomarkers can be obtained from population. controls, feasibility may be better when hospital controls are selected. Furthermore, if tumour oncogeries are persistent and reflect aetiologically relevant exposure in the past $(14,15)$, identification of the environmental factors related to these oncogenes may point to the main routes of exposure to carcinogenic agents (e.g. diet) or to dietary factors affecting the metabolism of (pre-) carcinogens. Here, hospital-based case-control studies and case-case comparisons (see below) may be of particular relevance. second, pathophysiological insights may suggest that dietary habits may have different consequences for different disease pathways, possibly reflected in distinct diagnostic disease categories (e.g. degree of differentiation of glandular tissue, oestrogen receptor status, oncogenes and/or their encoded proteins). Although the relation of dietary habits to more specifically defined disease categories can be studied in the (usual) case-control design with population controls, it may be attractive to consider hospital-based case-control studies and case-case comparisons. Hospital-based casecontroll studies prowide opportunities to obtain target tissue (e.g. breast tissue) from subjects with other diseases (e.g. benign breast diseases unrelated to breast cancer), facilitating the assessment of both exposure and (eacly) endpoint(s). Case-case comparisons may be helptul when different disease characteristics have (partially) distinct causes. These distinct causes can be detected by comparing dietary habits among women in these disease categories, but could easily remain undetected in a 'usual' case-control study of similar size.

whe above variants of the case-control design may lead to the identification of stronger associations for specific (diet-related) exposures and more narrowly defined disease categories. These associations will appear as interactions between dietary factors and 
known risk factors on the one hand, and characteristics of the disease and the genes (either inherited or acquired) on the other.

For cohort studies, improvement of methodology may imply the conduct of large-scale praspective cohort studies with improved dietary questionnaires, coupled to follow-up of a sample rather than of the total cohort. Because of misclassification of exposure, however, these studies are not likely to report strong associations between diet and cancer, but may identify dietary patterns and life styles associated with lowered risk (e.g. 16). In order to increase the study power, pooling of data from observational studies (world-wide) is indicated, if possible weighted for differences in study design and adjusted for misclassification rates.

In addition, these studies may generate new hypotheses, especially for less frequent cancer sites to which no diet-oriented casecontrol studies have been devoted. At the expense of study size, incorporation of biological specimen (biobanking) in prospective cohort studies will generally lead to improved exposure data and increased biological significance of results, and may also include markers of cancer susceptibility $(14,17)$.

\section{2 .3 subject matter areas}

After the above discussion on areas for methodological improvement and the general scope of epidemiological studies on diet and cancer, areas for future research on dietary factors and cancer can be identified. Several general outlooks have been mentioned in the preceding section. Here, we will restrict ourselves to those areas that are related to our study results and hypotheses.

First, the data collected in our study on diet and breast cancer provide opportunities for further analysis, e.g., analysis of diet according to dietary patterns (rather than nutrients) or dietary recommendations and breast cancer. Furthermore, new hypotheses on food constituents and breast cancex can be evaluated using the data collected, provided that the dietary questionnaire and food tables are judged reliable for the constituent considered.

second, the role of diet can be studied in different periods of life of particular relevance to breast cancer pathogenesis. In our data, the potential role of marginal nutrition during puberty in the $1930 \mathrm{~s}$ and 1940 s can be studied in the 1920-1930 birth cohort. There is circumstantial evidence supporting the role of marginal nutxition during this critical period in life (18), but epidemiological data directly addressing this issue are limited (19-21). Furthermore, animal experiments could indicate which nutritional factors (fat, 
ibre, alcohol, retinoids affect the sensitivity of proliferating and subsequenty differentiating breast tissue (e.g. in ratsh, and the identity of genetic darage caused by the carcinogens applied. In addition, possible precursor lesions of breast cancer (atypical hyperplasia) could be studied using the case-control design. Both of these approaches address aetiologically relevant periods of life that are usually not included in case-control studies.

Third, our study results suggest that factors possibly affecting immunological status and gastrointestinal metabolism of hormones or (pre)carcinogens may be of importance in breast cancer aetiology. Therefore, it needs to be investigated whether the findings regarding dietary fat, fibre and fermented milk products can be confixmed, and whether they may be generalized to other hormonerelated malignancies or cancer of the colon, which possibly also shares several other aetiological factors with breast cancer (fibre, fat, reproductive history) (22). These issues are part of the Dutch prospective cohort study, conducted by the TNo-CIVo Institutes and the University of Limburg (16).

In addition, a further biological explanation could be obtained by physiological experiments with female volunteers. For example, the effect of high and low consumption of fermented milk products at high and low fibre intake could be studied in relation to immunological and hormonal factors (either in blood or in faeces). Case-control studies and laboratory research could address the relation of these biological intermediates to breast cancer.

A related, intriguing question is whether fermented foods when ingested simultaneously with nitrate-rich foods might actually adversely affect cancer risk. Indeed, it has been shown that this combined exposure may produce large amounts of alkylating agents under quasi-gastric in vitro conditions (23). This might be of relevanoe to a dixectly exposed target site like the stomach, but indirect exposure of other sites (e.g. colon, breast) cannot be excluded either.

Finally, our study did not provide evidence supporting the inverse association between breast cancer on the one hand, and polyunsaturated fatty acids and the antioxidants beta-carotene and selenium on the other hand. In order to substantiate this biochemical hypothesis, other antioxidants (e.g. tocopherols) and related nutritional factors (e.g. retinol) may need to be incorporated. Because the dietary intake of such minor dietary constituents is difficult to assess, it may be more appropriate to study this hypothesis using long-term biomarkers fe.g. fat biopsy and toe-nail clippings) in a case-control study. 
In order to address the biologically relevant target tissue exposure more directly, hospital-based case-control (and case-case) studies could investigate antioxidant status and indicators of oxidative stress in breast tissue from breast cancer cases and from women with benign breast diseases (e.g. 10). Further refinement nay be obtained by incorporating more detailed disease characteristics in such studies, e.g. oncogenes. It is not clear as yet, however, which oncogenes are most relevant in breast cancer aetiology. For instance, ras-oncogenes have been detected in chemically induced breast tumours in rats (24), but not frequently in human breast cancer (15). In addition, it should be realized that the expression of oncogene products (proteins) is the criticall factor, rather than the presence of the oncogene as such.

\subsection{Dietary recommendations}

At the end of this epidemiological study it may be asked whether our results have implications for dietary recommendations. This question probably originates from the idea that nutritional epidemiology directly addresses everyday 1 ife and life style of the population and, hence, that the results should be of direct relevance to the study population. The development of dietary recommendations, however, aims at including all relevant aspects of diet and all investigative approaches. Dietary recommendations are not, and should not be modified by results of one single study on one specific cancer site and selected dietary factors. For instance, it has been noted that the findings of lowered (colon) cancer risk related to fruit and vegetables have led to the promotion of consumption of cereal products (25). General dietary recommendations should simultaneously take into account many different health aspects, e.g., the incidence of the disease relative to other diseases, biological mechanisms, quality of life, and non-medical values attributed to diet and 1 ife style. Given these restrictions " we shall indicate how our observations are related to dietary recommendations.

General dietary guidelines include reduced fat consumption, increased consumption of vegetables and fibre-rich foods, and moderate alcohol use, all incorporated in a varied diet (26). "These recommendations are also supported by the "Europe Against Cancer Programme' and the Netherlands Cancer Foundation (campaign 'Eetwijzer'). It should be mentioned here that campaigns against cancer tend to refer to the weaker, but suggestive, types of epidemiological research like time trends in incidence, ecological 
studies and comparisons of diets of high-risk and low-risk populations.

In this case-control study we observed a positive association between fat intake and breast cancer, and our results suggested an inverse association with a diet rich in fermented milk products and cereal products. Potential health benefits are suggested for reduced fat consumption and increased daily consumption of fermented milk products and dietary fibre, especially when combined. None of these research findings conflict with the recommendations. Moreover, this dietary pattern may actually offer a possibility to compose a "recommended' diet. Furthermore, a high consumption of alcohol was found to be positively associated with breast cancer in young women, and also in older women who had started drinking alcohol at young age. Finally, our results did not support the idea that selenium and beta-carotene, which are advocated in the lay press as useful dietary supplements possibly reducing the risk of chronic diseases " may be inversely related to breast cancer.

The scope of this study was to obtain additional knowledge on nutritional factors in breast cancer aetiology. The results are in line with current dietary recommendations, and do not suggest that they need to be modified. As indicated in this chapter, however, future research may identify specific nutritional factors with relevance to more narrowly defined disease categories. When combined with laboratory research and pathophysiological insight, the resulting understanding of mechanisms may open opportunities for chemoprevention, or dietary and life style recommendations directed at specific subgroups of the general population (27-29).

\section{References}

1 Schllesselman JJ. Case-control studies. Desỉgn, conduct, analysis. oxford uniw press, oxford, 1982.

2 KLleinbaum DG. Kupper LL, Morgenstern H. Epidemiologic Research. Principles and quantitative methods. Lifetime Learning Public, Belmont, CA, 1982 .

3 Miettinen Os. Theoretical epidemiology. Principles of occurrence research in medicine. John Wiley \& Sons, New York, 1985.

4 Rothman $\mathrm{KJ}$. Modern epidemiology. Little, Brown and Co, Boston, 1986.

5 London SJ, Colditz GA, Stampfer MJ, Willett WC, Rosner BA, Speizer FE. Prospective study of smoking and the risk of breast cancer. I Nat 1 Cancer Inst 1989;81:1625-31. 
6 Wahrendorf $\mathrm{J}$. An estimate of the proportion of colo-rectal and stomach cancers which might be prevented by certain changes in dietary habits. Int J Cancer 1987;40:625-8.

7 Prentice RL, pepe $M$, self $S G$. Dietaxy fat and breast cancex: $A$ quantitative assessment of the epidemiological literature and a discussion of methodologiccal issues. Cancer Res 1989;49:3147-56.

8 Rothman $\mathrm{KJ}$, Poole $\mathrm{C}$. A strengthening program for weak associations. Meeting of the Netherlands Epidemiological society, Wageningen, April 28-29, 1988. Int J Epidemiol $1988 ; 17:$ ( supp 1) 955-9.

9 Kok FJ, Van 't veer $\mathrm{P}$. The strength of relationships which can be detected between diet and disease. In: Kohlmeijer $L_{\text {, Helsing } \mathbb{E}}$ (eds). Epidemiology, nutrition and health. proc of the first Berlin meeting on nutritional epidemiology. Smith-Gordon, Berlin, 1988, 19-29.

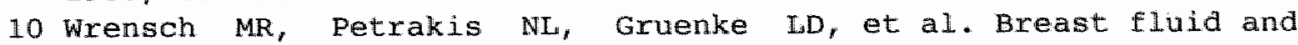
cholestexol $\beta$-epoxide concentrations in women with benign breast disease. Cancer Res 1989;49:2168-74.

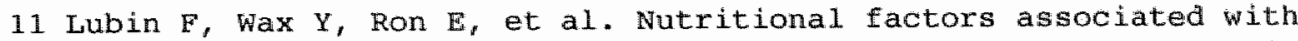
benign breast disease etiology: a case-control study. Am ij clin Nutr $1989 ; 50: 551-6$.

12 Verreault $R$, Brisson $J$, Deschenes $L$, Naud $F$. Body weight and prognostic indicators in breast cancer. Am $J$ Epidemiol $1989 ; 129: 260-8$.

13 Verreault $R$, Brisson $J$, Deschênes $I$, Naud F, Meyer F, Bélanger $L$. Dietary fat in relation to prognostic indicators in breast cancer. J Nat1 Cancer Inst 1988;80:819-25.

14 Taylor JA. Oncogenes and their applications in epidemiologic studies. Am J Epidemiol 1989;130:6-13.

15 Bos $\pi L$. ras-oncogenes in human cancer: A review. Cancer Res $1989 ; 49: 4682-9$.

16 Van den Bxandt $\mathbb{P A}_{\text {, Goldbohm } R A}$, Van 't Veer $P$, Volovicz $A$, Hermus RJJ, sturmans $F$. A large-scale prospective cohort study on diet and cancer in the Netherlands. J clin Epidemiol 1990;43:285-95.

17 International Agency for Research on Cancer, wHo. Europe against cancer programme, Commission of the European Communities. prospective studies on diet and cancer (No. 2). IARC, Lyon, sept 1989.

18 De Waard $F$, Trichopoulos D. A unifying concept of the aetiology of breast cancer. Int J Cancer $1988 ; 41: 666-9$.

19 Willett WC. Implications of total energy intake for epideniologic studies of breast and large-bowel cancer. Am J clin Nutr $1987 ; 45: 354-60$.

20 Pryor $M$, slattery ML, Robison LM, Egger M. Adolescent diet and breast cancer in Utah. Cancer Res 1989;49:2161-7. 
21 Hislop TG, Coldman AJ, Elwood JM, Braver G, Kan L. Chilhood and recent eating patterns and risk of breast cancer. Cancer Detect prev $1986 ; 9: 47-58$.

22 McMichael AJ, Potter JD. Reproduction, endogenous and exogenous sex hormones, and colon cancer: A review and hypothesis. I NatI Cancer Inst $1980 ; 65: 1201-7$.

23 Gronen PJ, Busink $\mathbb{E}$. Alkylating activity in food products espedilly sauerkrat and sour fermented dairy products- aftex incubation with nitrate under quasi-gastric conditions. Fa chem Toxic $1988 ; 26: 215-25$.

24 Barbacid M. ras-Genes. Ann Rev Biochem 1987;56:779-827.

25 Willett WC. The search for the causes of breast and colon cancer. Nature $1989 ; 338: 389-94$.

26 Voedingsraad. Richtiljnen goede voeding. Voeding 1986;47:159-81.

27 Greenwald P, Sondik E. Diet and chemoprevention in NCI's research strategy to achieve national cancer control objectives. Ann Rev Publ Health $1986 ; 7: 267-91$.

28 Meyskens FL. Thinking about cancer causality and chemoprevention. $J$ Nat 1 Cancer Inst $1988 ; 80: 1278-8 \mathrm{I}$.

29 Simopoulos AP. Genetics and nutrition: introduction to the symposium on human genetic variation and nutrition. Am J Clin Nuter $1988 ; 48: 1497-9$. 


\section{SUMMARY}

This thesis addresses the role of diet in breast cancer aetiology from an epidemiological point of view. International variation in breast cancer rates has suggested that high fat and low selenium intake may partially account for the high breast cancer incidence in the Netherlands. These two topics, and several other hypotheses put forward in the literature, i.e. on fermented milk products, fibre, beta-carotene and alcohol were investigated in a case-control study in the Netherlands' (Chapter 1 ).

Biological evidence and descriptive epidemiology have provided a basis for the multistage theory of carcinogenesis, which functions as a useful framework for ordering known risk factors of breast cancer and determining the role of dietary factors. Diet may influence breast cancer risk both at young age, during reproductive years and after menopause. In practice, most epidemiological studies, including ours, take into account the diet in a relatively short period of time before the disease is diagnosed (sections 2.1 and 2.2).

For high fat and low selenium intake increased breast cancer rusk has been reported from animal experiments, but biological mechanisms remain largely unknown. Dietary fat might affect breast cancer risk through its contribution to energy intake, energy balance, growth and development on the one hand, and to physiological and oxidative properties of fatty acids on the other hand, the latter possibly counteracted by antioxidative food constituents such as selenium and beta-carotene. In addition, dietary fibre and fermented milk products may affect the metabolic activity of intestinal bacteria. This may alter the conversion of diet-related and endogenous oestrogenic compounds and of (pre)carcinogens, as well as the immunological status of the host (Section 2.3.1).

A first generation of case-control and prospective cohort studies initially pointed at an unfavourable role of a diet frequently comprising fat-rich food products. This was not uniformly confirmed in a second generation of studies, in which total daily fat intake has been assessed in more detail. The epidemiological evidence for a protective effect of selenium is mainly based on serum selenium assessed in nested case-cohort studies on total cancer risk, including only few breast cancer cases. Although encouraging results were initially reported from two case-control studies, these have not been confirmed by more recent studies. Evidence for a protective

1 This study was financially supported by the Netherlands Cancer Foundation (grant no. CIVO $84-4$ ). 
effect of beta-carotene, fibre and fermented milk products derives from generalization of hypotheses on the aetiology of other cancer wites or total cancer, and epidemiological studies have provided sone additional stpport for breast cancer. In contrast, the potential hazardous role of moderate alcohol consumption in breast cancer has been reported by several epidemiological studies, but evidence from laboratory research is limited (Section 2.3.2).

In 1985-1987, a case-control study on dietary fat, selenium and other dietary factors was conducted among Dutch caucasian women aged 25-44 or 55-64 Yr, living in the middle and southern parts of the Netherlands. Considerations on the design, conduct and analysis of this study are presented in chapter 3 .

Experienced dietitians conducted interviews on life style factors, potential confounders, and dietary habits, using a structured anamesis on the complete food pattern, which included questions on consumption frequency and amount, followed by measurement of portion sizes. In addition to dietary selenium intake, biomarkers of selenium status were included in the study (Section 3.1.2).

Participation of surgeons in hospitals and of community controls was a major issue in the conduct of the study. About $45 \%$ of the cases in participating hospitals entered into the study. 80\% $(n=134)$ of these cases and $55 \%(n=289)$ of the controlls were interviewed. (Preoperative) blood and/or toe-nail clippings were obtained from $77 \%$ and $88 \%$ of the interviewed cases and controls, respectively. Food habits and risk factors were compared between cases recruited by surgeons and those from cancer registries; these groups did not show relevant differences. Similarly, no important differences were observed between full responders and partial responders among the controls. Serious bias resulting from differential selection of subjects is therefore considered unlikely (section 3.2).

Data analysis included compaxison of mean food and nutrient intakes, and selenium values in biomarkers of cases and controls, with and without adjustment for age, energy or fat intake. Subsequently, simple and stratified analysis of categorical data was conducted, followed by logistic regression analysis (with and without adjustment for potential confounders, to obtain odds ratios, their standard errors, and/or tests for trend. Specific attention is given to the conceptual issues relating to energy adjustment and to the assessment of effect modification in this study (Section 3.3 ).

In Chapters 4 to 9 the objectives, analyses and results pertaining to the research questions are presented. Main results were:

1) Daily fat intake among cases (100 g) was considerably higher than among controls $(92 \mathrm{~g})$. The adjusted odds ratio for high (> $113 \mathrm{~g})$ vs low $(<65 \mathrm{~g}$ ) fat intake was 3.54 (95\% confidence interval 
$\mathrm{CI}=1.64-7.64 \%$. This association remained similar after adjustment for energy intake and could not be attributed to a specific type or source of fat (Chapter 4 ).

2) Energy-adjusted selemium intake and plasma selenium concentration was slightly lower in cases. No assoclation was observed with total daily selenium intake, or selenium concentration in longterm biomarkers, i.e. exythrocytes and toe-nails (chapter 5 ).

3) Daily consumption of fermented milk products (mainly buttermilk and yogurt) was low among cases (116 g) as compared to controls $(157 \mathrm{~g})$. For high (>225 g) vs no intake of these products the odds ratio was 0.55 (958 $C I=0.24-1.27)$ and a significantly decreasing trend was observed. Similar results were observed for the consumption of Gouda cheese, after adjustment for total fat intake (Chapter 6).

4) Vegetable products (cereal products, fruit and vegetables including potatoes) were consumed in a lesser amount by cases (649 $\mathrm{g} /$ day) than by controls $(695 \mathrm{~g} /$ day $)$. This difference was mainly accounted for by cereal products and fruit. On the nutrient level this was reflected in lowered intake of dietary fibre rather than beta-carotene. For these indicators of diet, the adds ratio among women in the highest quartile of consumption was less than unity, and the test for trend was statistically significant for cereal products (Chapter 7 ).

5) Habitual alcohol consumption in the younger age group (25-44 yr) was higher than in the older age group (55-64 yr), both in cases and controls. In the younger women, the odds ratio for high alcohol consumption $(>30 \mathrm{~g} /$ day, i.e. $>3$ glasses) was 2.3 as compared to non-drinkers, and $8.5(95 \% \mathrm{CI}=1.1-65.1)$ as compared to women drinking moderately ( $1-4 \mathrm{~g}$ alcohol/day). Dose of alcohol, rather than frequency of consumption, appeared to be responsible for these results. In the older age group (55-64 yrs old) no association between habitual alcohol consumption and breast cancer was observed. Among these women, however, the adjusted odds ratio for drinking alcohol before the age of 25 was $2.4(95 \%) C I=1.0-5.6)$ (Chapter 8).

6) In a final analysis (Chapter 9), several of the above dietary factors were classified according to the hypothesized biological mechanism relevant to breast cancer, i.e. either relating to the intestinal microflora (fat, fibre, fermented milk products) or to the antioxidant hypothesis (polyunsaturated fatty acids, selenium, beta-carotene). Subjects with favourable dietary habits (i.e. low fat, high fibre and high fermented milk products; low polyunsaturated fatty acids, high selenium and high betacarotene) were compared with subjects having unfavourable dietary habits. Fis resulted in an odds ratio of 0.40 (95\% CI $=0.14-$ 1.15), which was mainly accounted for by low fat, high fibre and 
nigh fermented milk products lodds ratio 0.33 , 95 cI $=0.15-$ $0.73 \%$

In sumary, the results support the alleged positive association between dietary fat and breast cancer, but the inverse association between selenium and breast cancer was not confirmed. With regard to biological mechanisms, these results tend to favour hypotheses regarding a xole for bacterial and immunological factors in the intestines (fibre, fermented milk), rather than protection by antioxidants (selenium, beta-carotene). This fits into a role of diet in the late promotion stage of carcinogenesis, but the type of data collected do not permit a conclusion as to the role of antioxidants. Especially with regard to alcohol intake it is not clear, whether the results may be interpreted causally or merely reflect other life style characteristics.

The general discussion (Chapter 10) focuses on the principles underlying the problems of selection and information bias, with speciall emphasis on 'bias towards the null', resulting from random exror in the assessment of exposure and disease, lack of knowledge on the induction and latent pexiod, and background risk of breast cancer. Starting from this case-control study, directions for future epidemiological research are suggested, indicating possible ways for methodological and practical improvement. Finally, the study results are compared to dietary guidelines for cancer prevention and appear to be generally supportive. Future research may help to develop more specific guidelines based on an improved understanding of breast cancer pathogenesis. 
In dit onderzoek is de rol van voeding bij het ontstaan van borstkanker bestudeerd vanuit epidemiologisch perspectief. op grond van verschilien tussen danden in het wórkomen van borstkanker zou men kunnen veronderstellen dat de hoge frequentie van deze ziekte in Nederland ten dele kan worden toegeschreven aan een hoge vetinneming en een lage seleniuminneming. Deze twee aandachtspunten, alsmede de mogelijke rol van andere voedingsfactoren (gefermenteerde melkprodukten, vezel, beta-caroteen en alcohol), zijn nader onderzocht in een epidemiologische studie van het type patient-contrôle onderzoek ${ }^{2}$ (hoofdstuk 1 ).

Op grond van algemene biologische principes en diexexperimentele en epidemiologische aanwijzingen is de zogenaamde 'multistage'-theorie voor het ontstaan van kanker geformuleerd. Deze theorie doet dienst als een denkkader waarin reeds langer bekende risicofactoren voor borstkanker alsmede voedingsfactoren een duidelijke plats hebben (paragrafen 2.1 en 2.2). Voeding kan het risico op borstkanker beinvloeden op jonge leeftijd, tijdens de reproductieve jaren, en ook na de menopauze. De meeste epidemiologische studies, ook het in dit proefschrift beschreven onderzoek, bestuderen de rol van vaeding in de relatief korte periode van hooguit enkele jaren voor het optreden van de ziekte (paragraaf 2.1 en 2.2 ).

Een verhoogd borstkankerrisico bij hoge vet- en lage seleniuminneming is beschreven in dierexperimenten, maar het biologisch werkingsmechanisme is nog onduidelijk. Vet zou enexzijds invloed kunnen uitoefenen door zijn bijarage aan de energieinneming, energiebalans, groei en ontwikkeling, en anderzijds door fysiologische en oxidatieve eigenschappen van verschillende soorten vetzuren. Wat dit laatste betreft spelen antiokidanten, zoals selenium en beta-caroteen, mogelijk een beschermende rol. Daarnaast zouden vezel en gefermenteerde melkprodukten de activiteit van darmbacteriën gunstig kunnen beinvloeden, resulterend in een verminderde blootstelling van borstweefsel an oestrogenen of een stimulexend effect op het immunologisch systeem (paragraaf 2.3 .1 ).

Een eerste generatie patiènt-contrôle en cohort onderzoeken wees aanvankelijk op een ongunstige rol van een voedingspatroon gekenmerkt door frequent gebruik van vetrijke produkten. Dit is echter niet zonder meer bevestigd in daropvolgend onderzoek, warin de vetinneming zorguldiger is vastgesteld. De epidemiologische anwijzingen voor een beschermend effect van selenium zijn voornamelijk

1 Dit onderzoek is gesubsidieerd door de Nederlandse Kankerbestrijding, Het Koningin Wilhelmina Fonds (subsidie nx CIVO 84-4). 
gebaseerd op lagere serum-meleniumgehalten bij kankerpatienten (alle tumorlokalisaties) dan bij contrôlepersonen, zoals waargenomen in vexschillende zogenaamide "nested" patiënt-contrôle onderzoeken. De geringe aantalien personen en gebruik van serum-seleniumwarden ataan een eendulíge interpretatie echter in de weg. Aarwijzingen voor een beschermend effect van beta-caroteen, vezel en gefermenteerde melkprodukten $z$ ijn vooxal gebaseerd op generalisatie van hypothesen betreffende de carcinogenese van andere lokalisaties dan de borst, of van alle vormen van kanker samen. Het mogelijk positieve verband tussen alcoholconsumptie en borstkanker is voornamelijk gebaseerd op epidemiologisch onderzoek, terwijl de biologlsche verklaring hiervoox nog ontbreekt (paragraaf 2.3.2).

Van 1985 tot 1987 is in Nederland een patiènt-contrôle onderzoek uitgevoerd naar vet, sellenium en andere voedingsfactoren in relatie tot borstkanker. Overwegingen ten aanzien van de opzet, de uitvoexing en de analyse van dit onderzoek zijn beschreven in hoofdstuk 3. Aan dit onderzoek is deelgenomen door in total 422 wrouwen van 25 tot 44 jaar en van 55 tot 64 jaar, woonachtig in Utrecht, Gelderland of Limburg. Voedingsgewoonten van patiënten en contrôlepersonen zijn nagegaan door een gestandaardiseerde voedingsanamnese, gevolgd door vragen betreffende andere relevante levensstijlfactoren. Bij de voedingsanamnese is gebruik gemakt van een gestructureerde vragenlijst warbij, naast vragen naar gebruiksfrequentie en hoeveelheid, tevens gebruikelijke portiegrootten zijn nagegaan door huishoudelijke maten te wegen en meten. Voor de bepaling van de seleniumporziening is bovendien gebruik gemaakt van biologische monsters (bloed en nagelknipsels) (paragraaf 3.1).

De medewerking van chirurgen uit de verschillende ziekenhuizen en van de contrôlepersonen uit de algemene bevolking vormde een bellangrijk knelpunt tijdens de uitvoering van het onderzoek. circa 458 van de patiénten in meewerkende chirurgische matschappen hebben aan het onderzoek deelgenomen. Tachtig procent $(n=133)$ van deze patienten en 556 $(n=289)$ var de contrólepersonen $z i j n$ door een dietiste onderwraga over hun levensstijl en voedingsgewoonten. (Preoperatief) bloed en/of knipseis van teennagels $2 \mathrm{ijn}$ verkregen van 776 van de deelnemende patiënten en van $88 \%$ van de contrôlepersonen (paragraaf 3.2 .1 tot 3.2 .3 ). De voedingsgewoonten en enkele risicofactoren voor borstkanker bij patiënten die via de behandelende chirurg voor onderzoek waren aangemeld en voor patiënten die achteraf via de kankerregistratie waren opgespoord, bleken vergelijkbaar. Hetzelfde kan worden gezegd voor de vergelijking van deze factoren tussen respondenten (55\%) en een deel van de nonrespondenten $(17 \%)$ in de contrôlegroep. Op grond van deze resultaten is ex geen sprake van duidelijke selectie van patiënten en contrólepersonen ten aanzien van relevante factoren (zie 3.2.4). 
In de gegevensanalyse zijn de gemiddelde waarden voor inneming van voedingsstoffen en/of voedingsmiddelen, en voor seleniumconcentraties in biologisch materiaal van patiènten en contrôles vergeleken. Hierbij is rekening gehouden met verschillen in leettijdsopbouw, energie- of vetinneming. Discrete gegevens analyse en logistische regressie zijn gebruikt on relevante covariabelen te selecteren en er vervolgens voor te corrigeren. Hieruit ziju schattingen verkregen van 'odds ratios', hun standaardfouten, en eventueel tests voor trend. Verder is aandacht besteed an de inhoudelijke achtergronden van correctie voor energieinneming en het bestuderen van effectmodificatie in de verzamelde gegevens (zie 3.3).

In de hoofdstukken 4 tot en met 9 wordt voor elk van de vraagstellingen van het onderzoek de aanleiding, de analyse en de resultaten beschreven. De belangrijkste resultaten zijn in het onderstaande samengevat:

1) De gemiddelde dagelijkse vetinneming door patiënten $(100 \mathrm{~g})$ is aanmerkelijk hoger dan die door contrôles (92 g). De gecorrigeerde odds ratio (OR) voar hoge $(>113$ g) versus lage $(<65$ g) vetinneming is $\mathrm{OR}=3,54$ (95\% betrouwbaarheidsinterval $\mathrm{BI}=1,64$ $-7,64)$. Dit verband blijft bestaan wanneer rekening wordt gehouden met energieinneming, en kan niet duidelijk worden toegeschreven aan een bepaald type vetzuren, noch aan een bepaalde groep voedingsmiddelen (Hoofdstuk 4 ).

2) De voor energie gecorrigeerde inneming van selenium en de plasmaseleniumconcentratie is enigszins lager in de patiëntengroep dan in de contrôles. Geen verband is wargenomen met de absolute dagelijkse seleniuminneming, noch voor de seleniumconcentratie in de langere termijn indicatoren van selenium, nagels en rode bloedcellen (Hoofdstuk 5 ).

3) De dagelijkse consumptie van gefermenteerde melkprodukten (voornamelijk karnemelk en yoghurt) is lager onder patiènten $(116 \mathrm{~g})$ dan onder contrôles $(157 \mathrm{~g})$. Voor een hoog gebruik $(>225 \mathrm{~g})$ versus geen gebruik van deze produkten $\mathrm{is} \mathrm{OR}=0,55$ $(95 \% \mathrm{BI}=0,24-1,27)$ en er blijkt een statistisch significant dalende trend te bestaan. Rekening houdend met de totale vetinneming wordt een vergelijkbaar resultaat waargenomen voor gebruik van Goudse kaas (Hoofdstuk 6).

4) Plantaardige produkten (graanprodukten, groenten inclusief aardappelen, fruit) worden in mindere mate geconsumeerd door
patiënten ( $649 \mathrm{~g} / \mathrm{dag})$ dan door contróles $(695 \mathrm{~g} / \mathrm{dag})$. Ditt verschil is vooral toe te schrijven aan graanprodukten en fruit, hetgeen mede tot uiting komt in de lagere vezelinneming door patiënten, terwijl de beta-caroteeninneming in beide groepen vergelijkbaar is. Voor elk van deze factoren is de odds ratio in het hoogste kwartiel van inneming (ten opzichte van het laagste) 
Kelner dan 1,0, terwijl voor graanprodukten een statistisch significant invers verband wordt wargenomen (Hoofdstuk 7 ).

5) De gebruikelijke alcoholconsumptie in de jongste leeftijascategowie (25-44 jaar) is hoger bij patiénten dan bij contrôles, met betrekking tot zowel de gemiddelde dagelijkse inneming als de hoeveelheid alcohol per gebruiksmoment. Voor een hoog alcoholgebruik ( $>30 \mathrm{~g} / \mathrm{dag}$, meer dan drie glazen) bedraagt de $\mathrm{OR}=2,3$ ten opzichte var niet-arinkers, en $\mathrm{OR}=8,5,(95 \mathrm{~s} \mathrm{BI}=1,1-65,1)$ ten opzichte var matige arinkers $(1-4 \mathrm{~g} / \mathrm{dag})$. Deze resultaten zijn eerder toe te schrijuen aan het aantal glazen per keer dan aan de gebruiksfrequentie. In de oudere leeftijdsklasse (55-64 jaar) wordt geen verband wargenomen tussen alcoholgebruik en borstkanker, maar in deze groep blijkt de gecorrigeerde odds ratio voor vrouwen die reeds voor hun $25 \mathrm{e}$ levensjaar alcohol gebruikten $2,4(95 \% \mathrm{BI}=1,0-5,6)$ ten opzichte van vrouwen die pas later of nooit zijn gaan arinken (Hoofdstuk 8).

6) Om het gezamenlijke effect van een aantal van de bovengenoemde voedingsfactoren na te gaan zijn ze ingedeeld op grond van veronderstelde werkingsmechanismen ten aanzien van borstkankex. Hierbij is onderscheid gemaakt tussen factoren die de darmflora kunnen beinvloeden (vet, vezel, gefermenteerde melkprodukten) en factoren die in verband staan met de antioxidant-hypothese (meervoudig onverzadigde vetzuren, selenium, beta-caroteen). De odds ratio voor borstkanker is bepald voor vrouwen met gunstige versus ongunstige voedingsgewoonten betreffende de factoren die bij deze mechanismen een rol spelen (gunstig: Laag vet, hoog vezel, hoog gefermenteerde melkprodukten; laag meervoudig onverzadigd vet, hoog selenium, hoog beta-caroteen). Dit resulteert in een odds ratio $\operatorname{wan} 0,40(95 \% \mathrm{BI}=0,14-1,15)$, hetgeen voornamelijk is toe te schrijven aam een voeding met weinid vet. veel vezel en veel gefermenteerde melkprodukten $(\mathrm{OR}=0,33,95 \% \mathrm{BI}=$ $0,15-0,73)$ (Hoofdstuk 9).

Samenvattend ondersteunen de resultaten de veronderstelde positieve relatie tussen vetinheming en borstkanker, doch een mogelijk beschermende werking van selenium kon niet worden bevestigd. In het algemeen lijken de resultaten eexder in overeensteming met een werkingsmechanisme via bacteriele en immunologische factoren (vezel, gefermenteerde melkprodukten), dan via bescherming door antioxidanten (selenium, beta-caroteen). Dit zou kunnen passen binnen een rol van voeding in de late promotiefase van borstkanker; de aard van de verzamelde gegevens laat een duidelijke conclusie ten aanzien van antioxidanten echter niet toe. voor de resultaten betreffende alcohol is het nog onvoldoende duidelijk of hier een biologische interpretatie mogelijk is, of dat de resultaten andere levensstijlfactoren weerspiegelen. 
In elk van de hoofdstukken $4 \mathrm{t} / \mathrm{m} 9 \mathrm{zijn}$, na bespreking van validiteitsaspecten, de resultaten besproken in het licht van de literatuur over de epidemiologie en werkingsmechanismen betreffende voeding en borstkanker. In de algemene discussie (Hoofdstuk 10) wordt derhalve ingegaan op de algemene principes die ten grondslag liggen aan de mogelijke vertekening van onderzoeksresultaten door selectie van personen en verzameling van gegevens. speciale aandacht is besteed aan vextekening in de richting van de nul-hypothese, welke voortvloeit uit toevallige meetfouten, gebrekkig inzicht in de inductie- en latentieperiode, en het 'achtergrondsrisico' voor borstkanker.

Uitgaande van het beschreven patiènt-contrôle onderzoek worden mogelijke richtingen voor verder onderzoek aangegeven, met aandacht voor methodologische verbeteringen. Vervolgens blijken de resultaten, gelegd naast de aanbevelingen ter preventie van kanker, deze te ondersteunen. Toekomstig onderzoek zal mogelijk kunmen leiden tot meer gerichte aanbevelingen aan specifieke risicogroepen, met een betere aansluiting bij de pathofysiologie van (borst) kanker. 



\section{CURRICULUM VITAE}

Pieter van 't Veer was born 21 December 1957 at Dokkum, Netherlands. He graduated from Grammar School (Gymnasium- $\beta$ ) in Gouda in 1976, and obtained his MSc degree in fuman Nutrition in 1982 at the Agricultural University, Wageningen. His doctoral training focused on methodological and epidemiological aspects of nutrition research, and was completed at the Department of Human Nutrition of the TNo Crvo-Toxicology and Nutrition Institute, zeist.

He obtained his MSc Degree in Epidemiology at the Department of Epidemiology of the Harvard School of Public Health (Boston, USA) in 1983. In that period he concentrated on nutritional epidemiology and cancer biology. Subsequently, two grant proposals were accepted by the Netherlands Cancer Foundation, i.e. the case-control study described in this thesis, and the Dutch prospective cohort study on diet and cancer (in collaboration with the university of Limburg). These activities have been the major elements of a two-year fellowship from the Netherlands Cancer Foundation (1982-1984).

Since 1984 he is staff member of the Epidemiology section of the TNO-CIVO Toxicology and Nutrition Institute. Here, he has conducted the case-control study on dietary habits and breast cancer. His current activities include design and conduct of epidemiological studies on diet-related malignancies. 